\title{
CARBON DIOXIDE CAPTURE FROM FLUE GAS USING DRY REGENERABLE SORBENTS
}

\author{
QUARTERLY TECHNICAL PROGRESS REPORT
}

Reporting Period: April 1, 2002 to June 30, 2002

by

David A. Green

Brian S. Turk

Jeffrey W. Portzer

Raghubir P. Gupta

William J. McMichael

Ya Liang*

Douglas P. Harrison*

DOE Cooperative Agreement No. DE-FC26-00NT40923

Submitted by:

Research Triangle Institute

Post Office Box 12194

Research Triangle Park, NC 27709-2194

*Louisiana State University

Department of Chemical Engineering

Baton Rouge, LA 70803

July 2002 


\section{DISCLAIMER}

This report was prepared as an account of work sponsored by an agency of the United States Government. Neither the United States Government nor any agency thereof, nor any of their employees, makes any warranty, express or implied, or assumes any legal liability or responsibility for the accuracy, completeness, or usefulness of any information, apparatus, product, or process disclosed, or represents that its use would not infringe privately owned rights. Reference herein to any specific commercial product, process, or service by trade name, trademark, manufacturer, or otherwise does not necessarily constitute or imply its endorsement, recommendation, or favoring by the United State Government or any agency thereof. The views and opinions of authors expressed therein do not necessarily state or reflect those of the United States Government or any agency thereof. 


\section{TABLE OF CONTENTS}

Page



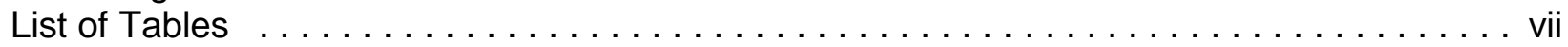

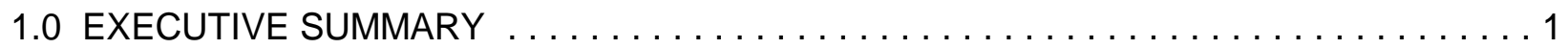

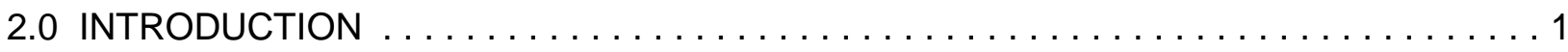

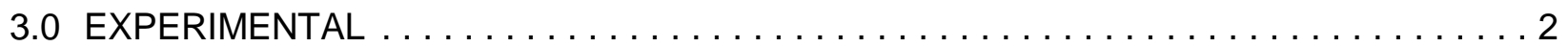

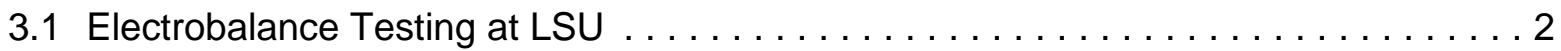

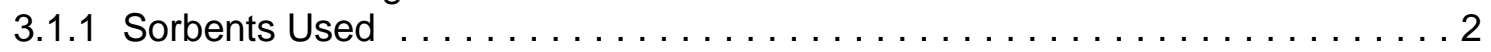

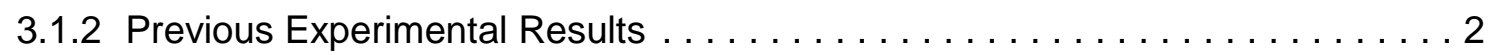

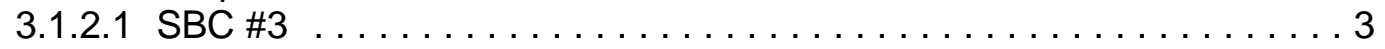

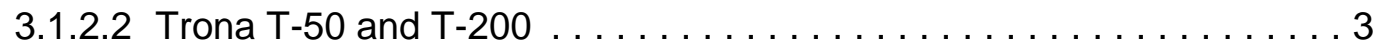

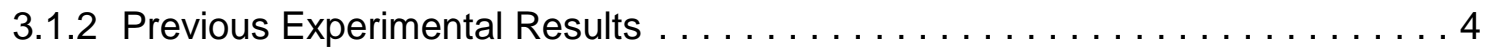



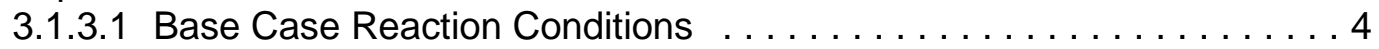

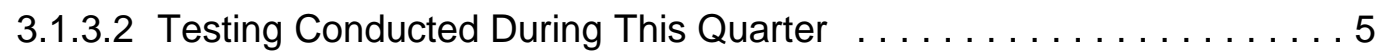



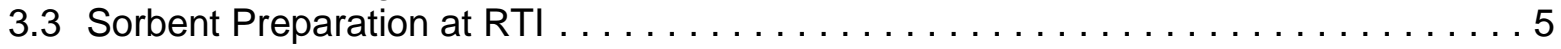

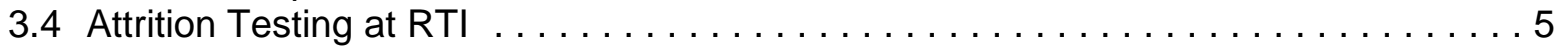

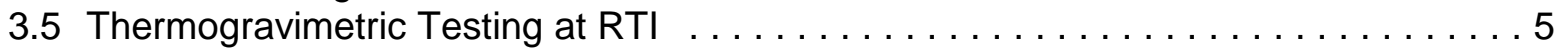



3.7 Material Characterization Studies at Church \& Dwight $\ldots \ldots \ldots \ldots \ldots \ldots \ldots \ldots$

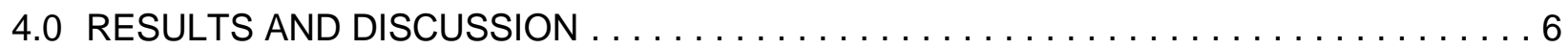

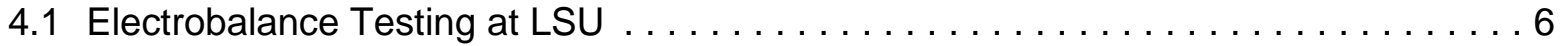

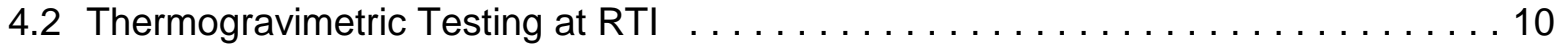

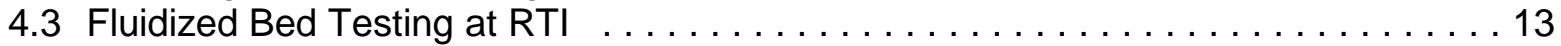

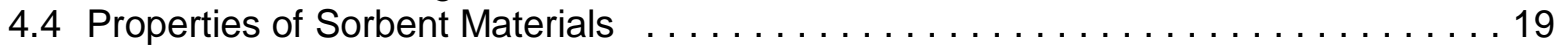

4.4.1 Attrition Characteristics of $40 \%$ Supported Sorbent Materials . . . . . . . . . 19

4.4.2 Surface Area and Porosity Characteristics of $40 \%$ Supported Sorbent

Material . . . . . . . . . . . . . . . . . . . . . . . . . . . . . . 19

4.4.3 Physical Properties of $10 \%$ Supported Potassium Carbonate . . . . . . . . 26

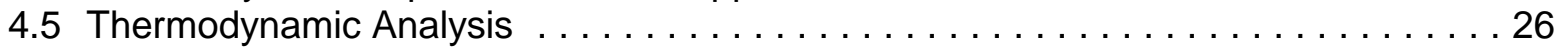

4.6 Thermodynamic Considerations for $\mathrm{CO}_{2}$ Removal Process Design . . . . . . . . 30

4.7 Properties of Sorbent Materials Removed from Fixed Bed Reactor . . . . . . . . 42

5.0 CONCLUSIONS AND FUTURE WORK $\ldots \ldots \ldots \ldots \ldots \ldots \ldots \ldots \ldots \ldots \ldots \ldots \ldots$






\section{LIST OF FIGURES}

Figure

Page

1 Dimensionless weight-time results for five carbonation cycles using trona T-200 and

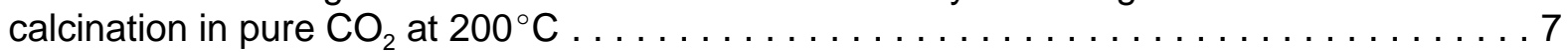

2 Comparison of $f(25)$ and $f(150)$ from duplicate tests using trona T-200. Calcination

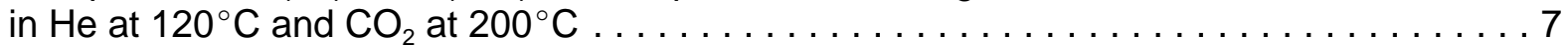

3 Comparison of $f(25)$ and $f(150)$ using trona T-50 with calcination in $\mathrm{He}$ at $120^{\circ} \mathrm{C}$ and

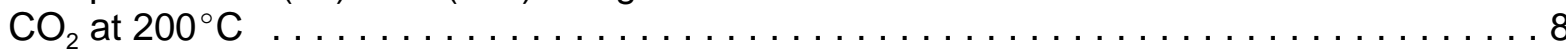

4 Comparison of $f(25)$ values for trona T-200 as a function of calcination temperature

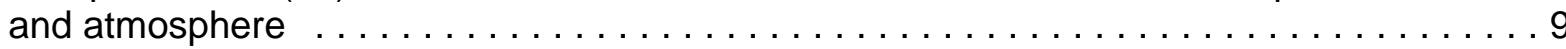

5 Comparison of $f(150)$ values for trona T-200 as a function of calcination temperature

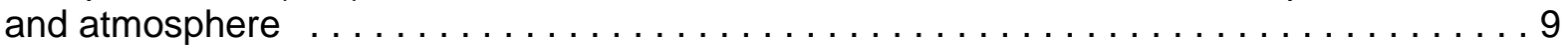

6 Carbonation of dried commercial grade and extra fine potassium carbonate samples

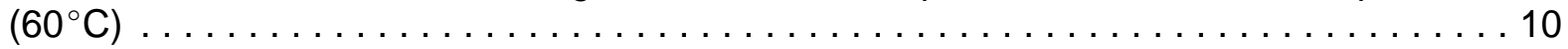

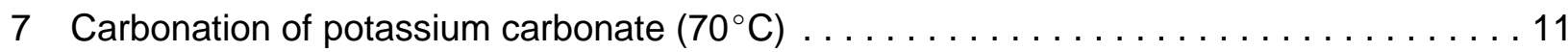

8 Duplicate carbonation tests of $40 \%$ supported potassium carbonate $\ldots \ldots \ldots \ldots$

9 Carbonation of $40 \%$ supported potassium carbonate at $70^{\circ} \mathrm{C}$ followed by calcination

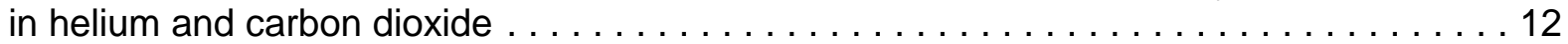

10 Cyclic carbonation/calcination of supported (40\%) potassium carbonate -- isothermal

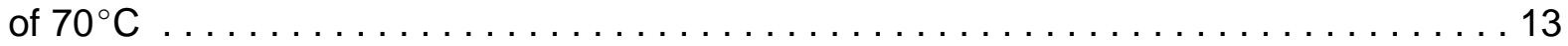

11 Carbon dioxide removal with trona Cycle $1--5 / 13 / 2002 \ldots \ldots \ldots \ldots \ldots \ldots \ldots$

12 Temperature profile--carbonation Cycle 1 -- 5/13/2002 . . . . . . . . . . . . . . 14

13 Carbon dioxide removal with trona- Cycle $2-5 / 14 / 2002 \ldots \ldots \ldots \ldots \ldots \ldots$

14 Temperature profile-carbonation Cycle $2-5 / 14 / 2002 \ldots \ldots \ldots \ldots \ldots \ldots$

15 Carbon dioxide removal with trona- Cycle $3-5 / 15 / 2002 \ldots \ldots \ldots \ldots \ldots \ldots$

16 Temperature profile-carbonation Cycle $3-5 / 15 / 2002 \ldots \ldots \ldots \ldots \ldots \ldots$

17 Carbon dioxide removal with trona- Cycle $4-5 / 16 / 2002 \ldots \ldots \ldots \ldots \ldots \ldots \ldots$ 


\section{LIST OF FIGURES (cont'd)}

\section{Figure}

Page

18 Temperature profile-carbonation Cycle $4-5 / 16 / 2002 \ldots \ldots \ldots \ldots \ldots \ldots \ldots$

19 Carbon dioxide removal with trona- Cycle $5-5 / 20 / 2002 \ldots \ldots \ldots \ldots \ldots$

20 Temperature profile-carbonation Cycle $5-5 / 20 / 2002 \ldots \ldots \ldots \ldots \ldots$

21 Fluidized bed carbonation of $40 \%$ supported potassium carbonate--Cycle $1 \ldots \ldots 20$

22 Temperature profile $--40 \%$ supported potassium carbonate--Cycle $1 \ldots \ldots$. . . . . 20

23 Fluidized bed carbonation of $40 \%$ supported potassium carbonate--Cycle $2 \ldots \ldots 21$

24 Temperature profile-40\% supported potassium carbonate-Cycle $2 \ldots \ldots \ldots \ldots$

25 Fluidized bed carbonation of $40 \%$ supported potassium carbonate-Cycle $3 \ldots \ldots 22$

26 Temperature profile-40\% supported potassium carbonate-Cycle $3 \ldots \ldots \ldots 22$

27 Fluidized bed carbonation of $40 \%$ supported potassium carbonate-Cycle $4 \ldots \ldots 23$

28 Temperature profile-40\% supported potassium carbonate-Cycle $4 \ldots \ldots \ldots 23$

29 Fluidized bed carbonation of $40 \%$ supported potassium carbonate-Cycle $5 \ldots \ldots \ldots$

30 Temperature profile-40\% supported potassium carbonate-Cycle $5 \ldots \ldots \ldots 24$

31 Equilibrium temperatures for the carbonizer at various levels of $\mathrm{CO}_{2}$ adsorption $\ldots \ldots 33$

32 Graphical determination of outlet temperature and $\mathrm{CO}_{2}$ removed in the carbonizer . . . . 34

33 Dry sorbent $\mathrm{CO}_{2}$ removal process utilizing sorbent as heat carrier $\ldots \ldots \ldots \ldots$

34 Equilibrium curves for the moles $\mathrm{CO}_{2}$ transferred to the sweep gas per 100 moles

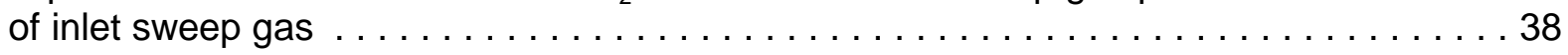

35 Equilibrium curves for regeneration of sodium carbonate based sorbent $\ldots \ldots \ldots 4$

36 Equilibrium curves for regeneration of potassium carbonate based sorbent $\ldots \ldots \ldots 4$

37 Sample $\# 6$ at $50 \times$ magnification $\ldots \ldots \ldots \ldots \ldots \ldots \ldots \ldots \ldots \ldots \ldots \ldots \ldots \ldots \ldots \ldots \ldots$

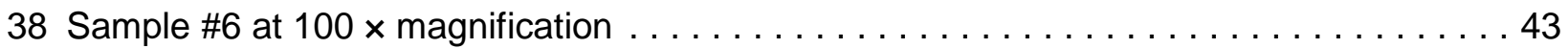




\section{LIST OF FIGURES (cont'd)}

Figure

Page

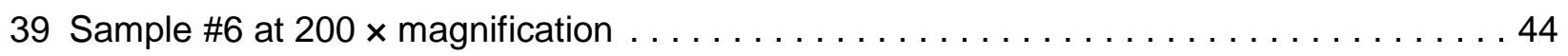

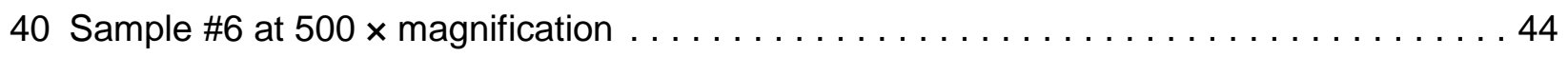

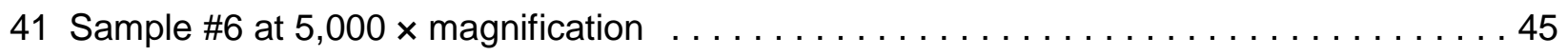

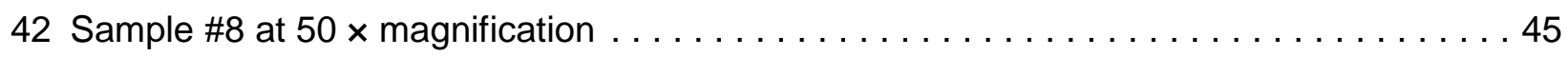

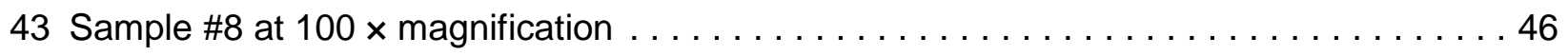

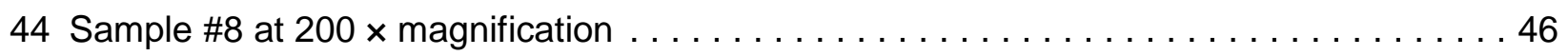

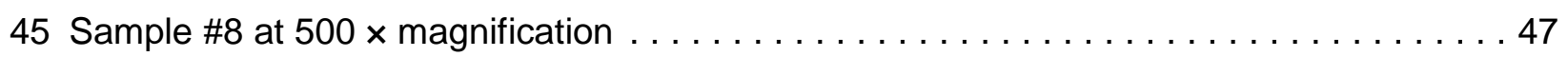

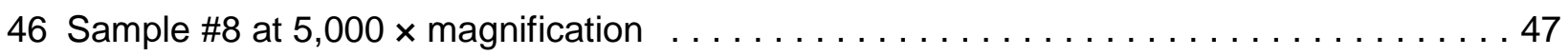




\section{LIST OF TABLES}

Table

Page

1 Base Case Reaction Conditions For LSU TG Experiments $\ldots \ldots \ldots \ldots \ldots \ldots \ldots \ldots$

2 Carbon Dioxide Removal in 5-cycle Fluidized Bed Test Using Trona T-50 as Sorbent

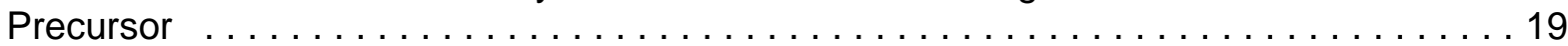

3 Carbon Dioxide Removal in 5-cycle Fluidized Bed Test Using Spray Dried Supported

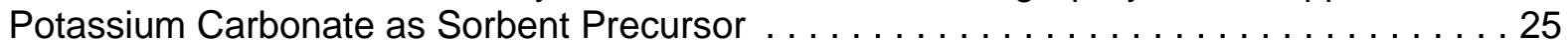

4 Properties of $40 \%$ Supported Potassium Carbonate $\ldots \ldots \ldots \ldots \ldots \ldots$

5 BET Surface Areas of Fines for $40 \%$ Supported Material $\ldots \ldots \ldots \ldots \ldots \ldots \ldots$

6 Properties of $10 \%$ Supported Potassium Carbonate $\ldots \ldots \ldots \ldots \ldots \ldots \ldots$

7 Equilibrium constants and temperatures determined from TGA experiments for

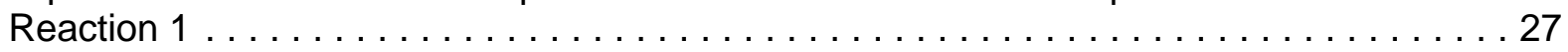

8 Comparison of equilibrium temperature calculated based on inlet gas composition and maximum observed fluidized bed temperature $\ldots \ldots \ldots \ldots \ldots \ldots \ldots \ldots \ldots \ldots$

9 Calculation of the equilibrium constant for the carbonizer after the absorption of $x$

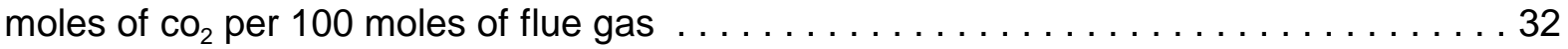

10 Development of equilibrium curves for the regenerator $\ldots \ldots \ldots \ldots \ldots \ldots \ldots \ldots$

11 Possible $\mathrm{CO}_{2}$ Removals using the sorbent as a heat absorber in the carbonizer

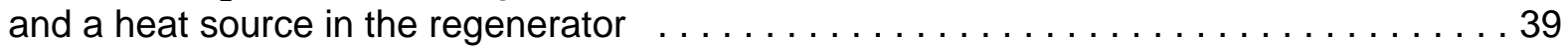

12 Surface Areas and X-ray Diffraction Analyses of Samples from Fixed Bed

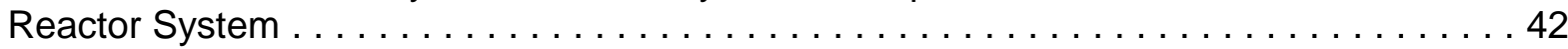




\subsection{EXECUTIVE SUMMARY}

The objective of this project is to develop a simple, inexpensive process to separate $\mathrm{CO}_{2}$ as an essentially pure stream from a fossil fuel combustion system using a regenerable sorbent. The sorbents being investigated in this project are primarily alkali carbonates, and particularly sodium carbonate and potassium carbonate, which are converted to bicarbonates through reaction with carbon dioxide and water vapor. Bicarbonates are regenerated to carbonates when heated, producing a nearly pure $\mathrm{CO}_{2}$ stream after condensation of water vapor.

This quarter, electrobalance tests conducted at LSU suggested that the severity of calcination conditions had a noticeable effect on the carbonation activity of trona during subsequent cycles, while the effect of calcination severity on sodium bicarbonate was much less significant. Severe calcination conditions were represented by a carbon dioxide atmosphere at $200^{\circ} \mathrm{C}$, while mild conditions were represented by a helium atmosphere at $120^{\circ} \mathrm{C}$.

High initial carbonation rates were observed in fluidized bed reactor testing at RTI using trona as a sorbent precursor. Rates declined rapidly over the course of the experiments with capacity utilization (based on sodium carbonate) ranging from 11 to $16 \%$ over 5 cycles. No decline in activity from cycle to cycle was noted with calcination in nitrogen at $150^{\circ} \mathrm{C}$. Fluidized bed testing was also conducted using a $40 \%$ potassium carbonate material on an inert support. Potassium carbonate has a higher useful temperature range for carbonation and a spray dried supported material was used to obtain greater attrition resistence. Carbonation rates and the extent of capacity utilization were higher with this material than with trona. Some decline in activity over the course of the test, particularly between the first and second cycles was observed. Carbon dioxide removals varied between 18 and 24\%.

X-ray diffraction studies conducted on samples withdrawn from the LSU fixed bed reactor system confirmed that the product of the reaction between sodium carbonate and simulated flue gas was approximately $85 \%$ Wegscheider's salt.

\subsection{INTRODUCTION}

Fossil fuels used for power generation, transportation, and by industry are the primary source of anthropogenic $\mathrm{CO}_{2}$ emissions to the atmosphere. Much of the $\mathrm{CO}_{2}$ emission reduction effort will focus on large point sources, with fossil fuel fired power plants being a prime target. The $\mathrm{CO}_{2}$ content of power plant flue gas varies from $4 \%$ to $9 \%$ (vol), depending on the type of fossil fuel used and on operating conditions. Although new power generation concepts that may result in $\mathrm{CO}_{2}$ control with minimal economic penalty are under development, these concepts are not generally applicable to the large number of existing power plants.

This study is based on the use of a dry, regenerable sorbent to remove $\mathrm{CO}_{2}$ from flue gases. Sorbent regeneration produces a gas stream containing only $\mathrm{CO}_{2}$ and $\mathrm{H}_{2} \mathrm{O}$. The $\mathrm{H}_{2} \mathrm{O}$ may be separated by condensation to produce a pure $\mathrm{CO}_{2}$ stream for subsequent use or sequestration. The primary reactions, based upon the use of sodium bicarbonate as the sorbent precursor and sodium carbonate as the reaction product are: 


$$
\begin{gathered}
2 \mathrm{NaHCO}_{3}(\mathrm{~s}) \rightarrow \mathrm{Na}_{2} \mathrm{CO}_{3}(\mathrm{~s})+\mathrm{CO}_{2}(\mathrm{~g})+\mathrm{H}_{2} \mathrm{O}(\mathrm{g}) \\
\text { and } \\
\mathrm{Na}_{2} \mathrm{CO}_{3}(\mathrm{~s})+\mathrm{CO}_{2}(\mathrm{~g})+\mathrm{H}_{2} \mathrm{O}(\mathrm{g}) \rightarrow 2 \mathrm{NaHCO}_{3}(\mathrm{~s})
\end{gathered}
$$

Reaction (1) releases $\mathrm{CO}_{2}$ and regenerates the sorbent, while Reaction (2) is used to capture $\mathrm{CO}_{2}$. Several other solid products, intermediate between sodium carbonate and sodium bicarbonate, may also be produced under the anticipated reaction conditions. An intermediate compound, $\mathrm{Na}_{2} \mathrm{CO}_{3} \cdot 3 \mathrm{NaHCO}_{3}$, forms at the reaction conditions of interest.

Analogous reactions (Reactions 3 and 4) take place within the potassium carbonate system:

$$
\begin{gathered}
2 \mathrm{KHCO}_{3}(\mathrm{~s}) \rightarrow \mathrm{K}_{2} \mathrm{CO}_{3}(\mathrm{~s})+\mathrm{CO}_{2}(\mathrm{~g})+\mathrm{H}_{2} \mathrm{O}(\mathrm{g}) \\
\text { and } \\
\mathrm{K}_{2} \mathrm{CO}_{3}(\mathrm{~s})+\mathrm{CO}_{2}(\mathrm{~g})+\mathrm{H}_{2} \mathrm{O}(\mathrm{g}) \rightarrow 2 \mathrm{KHCO}_{3}(\mathrm{~s}) .
\end{gathered}
$$

A compound salt of potassium carbonate and potassium bicarbonate is also thought to be of importance at the conditions of interest.

This report describes activities conducted between April 1, 2002 and June 30, 2002 by RTI and its subcontractors Louisiana State University (LSU) and Church and Dwight (C\&D). Activities conducted this quarter include electrobalance (thermogravimetric analysis [TGA]) studies at LSU, and TGA, fluidized-bed reactor testing, attrition index determinations and thermodynamic and kinetic analyses at RTI. Church and Dwight conducted material characterization and surface area determinations on samples produced in the LSU fixed bed reactor system.

\subsection{EXPERIMENTAL}

\subsection{Electrobalance Testing at LSU}

\subsubsection{Sorbents Used}

Thermogravimetric analysis (TGA) testing was conducted at LSU with trona Grade T-50 and trona Grade T-200. Selected properties of these materials, and other sorbents used (both asreceived and following calcination), were reported in previous quarterly reports (Green et al., 2001a; b).

\subsubsection{Previous Experimental Results}

A summary of experimental results reported in the previous quarterly reports is presented below to provide background for the new results reported in this report. Although all samples were screened initially for reactivity, most of the early detailed testing used SBC \#3. More recently 
the study has been expanded to include Trona T-50 and Trona T-200. Because of somewhat different results, separate summaries are presented for SBC \# 3 and the trona samples.

\subsubsection{1 $\underline{\mathrm{SBC} \# 3}$}

1. Both the initial reaction rate and achievable $\mathrm{CO}_{2}$ capacity decrease with increasing carbonation temperature.

2. The possible formation of by-products including $\mathrm{Na}_{2} \mathrm{CO}_{3} \cdot \mathrm{H}_{2} \mathrm{O}, \mathrm{Na}_{2} \mathrm{CO}_{3} \cdot \mathrm{NaHCO}_{3} \cdot 2 \mathrm{H}_{2} \mathrm{O}$, and $\mathrm{Na}_{2} \mathrm{CO}_{3} \cdot 3 \mathrm{NaHCO}_{3}$ at carbonation conditions of potential interest was proven by thermodynamic analysis.

3. At constant temperature the global reaction rate increases with an increase in both $\mathrm{CO}_{2}$ and $\mathrm{H}_{2} \mathrm{O}$ concentrations.

4. Calcination in $100 \% \mathrm{CO}_{2}$ and $80 \% \mathrm{CO}_{2} / 20 \% \mathrm{H}_{2} \mathrm{O}$ at temperatures as high as $200^{\circ} \mathrm{C}$ did not cause a significant reduction in the sorbent activity in the subsequent carbonation cycle.

5. Five-cycle tests using SBC Grade \#3 at standard carbonation and calcination conditions show a gradual loss in both reaction rate and final fractional carbonation with increasing cycle number.

6. Five-cycle test results using SBC Grade \#3 at more severe calcination conditions of $200^{\circ} \mathrm{C}$ in atmospheres of pure $\mathrm{CO}_{2}$ and $80 \% \mathrm{CO}_{2} / 20 \% \mathrm{H}_{2} \mathrm{O}$ were not significantly different than results at less severe standard calcination conditions.

7. The narrow operating temperature window and the difficulty in achieving $\mathrm{H}_{2} \mathrm{O}$ vaporization at the $70^{\circ} \mathrm{C}$ carbonation temperature have troubled fixed-bed reactor tests. If the preheat temperature is too low, the $\mathrm{H}_{2} \mathrm{O}$ does not vaporize and no carbonation occurs. If the preheat temperature is too high, the gases entering the reactor exceed the maximum carbonation temperature.

8. Reasonable success has been achieved in two fixed-bed runs. Material balance closure was good and prebreakthrough concentrations corresponded to approximately $50 \%$ to $60 \%$ $\mathrm{CO}_{2}$ removal.

\subsubsection{Trona $\mathrm{T}-50$ and $\mathrm{T}-200$}

1. All trona tests that examined the effect of reaction parameters using different samples for each run have been plagued with lack of reproducibility.

2. An initial multicycle test using the same sample of T-200 at standard calcination and carbonation conditions showed no loss of either reactivity or capacity over five cycles. 
3. More severe calcination conditions (higher temperature and $\mathrm{CO}_{2}$ atmosphere) caused greater losses in reactivity and capacity for both T-50 and T-200 than for SBC \#3.

\subsubsection{Experimental Procedure}

\subsubsection{Base Case Reaction Conditions}

Base case reaction conditions are shown in Table 1. Results from experimental tests to examine the effect of carbonation and calcination temperature and gas composition are compared to results from these base case conditions. Base case carbonation gas composition approximates the flue gas composition resulting from the combustion of natural gas using $10 \%$ excess air. Base case calcination conditions, while not practical in commercial operation, were chosen to provide minimum severity of sorbent exposure during regeneration.

Table 1. Base Case Reaction Conditions For LSU TG Experiments.

\begin{tabular}{l|l|l}
\hline \hline Calcination & Temperature & $120^{\circ} \mathrm{C}$ \\
& Pressure & $1 \mathrm{~atm}$ \\
& Gas Composition & $100 \% \mathrm{He}$ \\
& & \\
Carbonation & Temperature & $70^{\circ} \mathrm{C}$ \\
& Pressure & $1 \mathrm{~atm}$ \\
& Gas Composition & $8 \mathrm{~mol} \% \mathrm{CO}_{2}$ \\
& & $16 \mathrm{~mol} \% \mathrm{H}_{2} \mathrm{O}$ \\
& & $76 \mathrm{~mol} \% \mathrm{He}$ \\
& Gas Flow Rate & $600 \mathrm{scc} / \mathrm{min}$ \\
\hline \hline
\end{tabular}

The following experimental procedure is used in base case tests. An initial charge of approximately $70 \mathrm{mg}$ of sorbent precursor is heated from room temperature to $100^{\circ} \mathrm{C}$ at a rate of $5^{\circ} \mathrm{C} / \mathrm{min}$ and from $100^{\circ} \mathrm{C}$ to the final calcination temperature of $120^{\circ} \mathrm{C}$ at a rate of $1^{\circ} \mathrm{C} / \mathrm{min}$ under flowing $\mathrm{He}$. After calcination is complete (as indicated by constant weight), the temperature is decreased at a rate of $2^{\circ} \mathrm{C} / \mathrm{min}$ still under He to the $70^{\circ} \mathrm{C}$ carbonation temperature. The gas composition is then changed to $8 \mathrm{~mol}_{\mathrm{C}} \mathrm{CO}_{2}, 16 \mathrm{~mol} \% \mathrm{H}_{2} \mathrm{O}$, balance $\mathrm{He}$ flowing at $600 \mathrm{scc} / \mathrm{min}$ and carbonation is continued until the reaction rate approaches zero. Appropriate changes in procedure are made when carbonation and calcination temperatures and gas compositions are altered from the base case. 


\subsubsection{Testing Conducted During This Quarter}

Five multicycle electrobalance runs were carried out during the quarter. Five cycles were completed in four of the tests while one was terminated after three cycles due to reactor problems. Trona T-200 was used in four tests while Trona T-50 was used in the fifth. These tests examined the effects of calcination temperature and atmosphere on subsequent carbonation performance.

\subsection{Fixed Bed Testing at LSU}

Two unsuccessful fixed-bed reactor tests were made early in the quarter. The results were similar to those shown in Figure 9 in the previous quarterly report (Green, et al. 2002b). The failure to achieve significant $\mathrm{CO}_{2}$ removal is assumed to be associated with the difficulty in forming $\mathrm{H}_{2} \mathrm{O}$ vapor.

In all fixed-bed tests to date, $\mathrm{H}_{2} \mathrm{O}$ was fed as a liquid using a syringe pump and vaporization was accomplished by heat tracing reactor feed lines. The narrow temperature window and the difficulty in achieving complete vaporization without overheating the feed gas have been described previously. Additional tests are planned during the next quarter in which the addition of steam using gas bubblers at controlled temperature will be evaluated.

\subsection{Sorbent Preparation at RTI}

Because of the less than optimal attrition resistence of the sodium and potassium carbonate materials considered in the project to date, effort was directed towards preparation of more durable sorbents composed of potassium carbonate supported on an matrix similar to that used in commercial fluidized bed catalytic cracking catalysts.

Two materials were produced in 1 to $2 \mathrm{~kg}$ batches by spray drying a slurry of potassium carbonate and proprietary support materials. The spray dried product was then calcined in a laboratory furnace. A $40 \%$ potassium carbonate material was produced and tested this quarter in both TG and bench scale fluidized bed reactor equipment. A similar $10 \%$ potassium carbonate material was prepared and will be tested in the next quarter.

\subsection{Attrition Testing at RTI}

Samples of supported potassium carbonate ( $10 \%$ and $40 \%)$ were subjected to testing by ASTM Method D 5757-95, Determination of Attrition and Abrasion of Powdered Catalysts by Air Jets. One sample of supported potassium carbonate was subjected to attrition testing after a 5cycle fluidized bed test.

\subsection{Thermogravimetric (TG) Testing at RTI}

This quarter carbonation/calcination tests were conducted on potassium carbonate as well as the $40 \%$ potassium carbonate supported material. The supported material was also subjected to multicycle testing. The steam delivery system was changed during the quarter to minimize uncertainty associated with delay in water vapor addition to the carbonation gas and inconsistency in discharge rate from the syringe pump. The current system involves 
saturating a portion of the carbonation gas by passing it through a heated impinger.

Carbonation gases of the desired humidity were produced by controlling the impinger solution

temperature and heat tracing the line from the impinger to the thermogravimetric analyzer inlet.

\subsection{Fluidized Bed Reactor Testing at RTI}

Two 5-cycle fluidized bed reactor tests were conducted this quarter. Trona (T-50) was used as the sorbent precursor in the first test. The supported $40 \%$ potassium carbonate was used in the second test.

\subsection{Material Characterization Studies at Church and Dwight (C \& D)}

Two samples produced in the LSU fixed bed reactor system were analyzed by C \& D this quarter. BET surface areas were measured on a samples produced from SBC\#3. One sample was calcined and then carbonated in the fixed bed reactor. A second sample was calcined, carbonated and then calcined a second time. The same samples were subjected to X-ray diffraction to determine the chemical phases present, and photographed at 5 different magnifications from $50 \mathrm{X}$ to $5000 \mathrm{X}$.

\subsection{RESULTS AND DISCUSSION}

\subsection{Electrobalance Testing at LSU}

Five multicycle electrobalance runs were carried out during the quarter. Five cycles were completed in four of the tests; one test was terminated after three cycles due to reactor problems. Trona T-200 was used in four tests while the fifth used Trona T-50. These tests examined the effects of calcination temperature and atmosphere on subsequent carbonation performance.

Problems in obtaining satisfactory reproducibility when using different trona samples have been described previously. Because of this, the first two five-cycle electrobalance tests were duplicates of five-cycle tests described in the previous quarterly report (Green, et al. 2002b). Both tests used Trona T-200 and standard carbonation conditions; the first also used standard calcination conditions of $120^{\circ} \mathrm{C}$ in He while the second used severe calcination conditions of $200^{\circ} \mathrm{C}$ in $\mathrm{CO}_{2}$. Dimensionless weight-time results for the repeat five-cycle test using calcination at $200^{\circ} \mathrm{C}$ in $\mathrm{CO}_{2}$ are shown in Figure 1.

The results were somewhat more scattered than obtained in the earlier test, but were reasonably comparable. Both the reactivity and capacity were highest in cycle 1 . There was a small decrease in reactivity during the first four cycles but the fifth cycle reactivity increased and was almost as large as was obtained in the first cycle. Capacity dropped significantly between cycles 1, 2, and 3, then increased somewhat in cycles 4 and 5.

Figure 2 compares the performance of the duplicate tests in terms of $f(25)$ and $f(150)$ as a function of cycle number. The duplicate tests using both the standard $\left(120^{\circ} \mathrm{C}\right.$ in $\left.\mathrm{He}\right)$ and the more severe $\left(200^{\circ} \mathrm{C}\right.$ in $\left.\mathrm{CO}_{2}\right)$ calcination conditions are included. While the results were not totally reproducible, there are clearly four distinct sets of data, and the adverse effect of the 


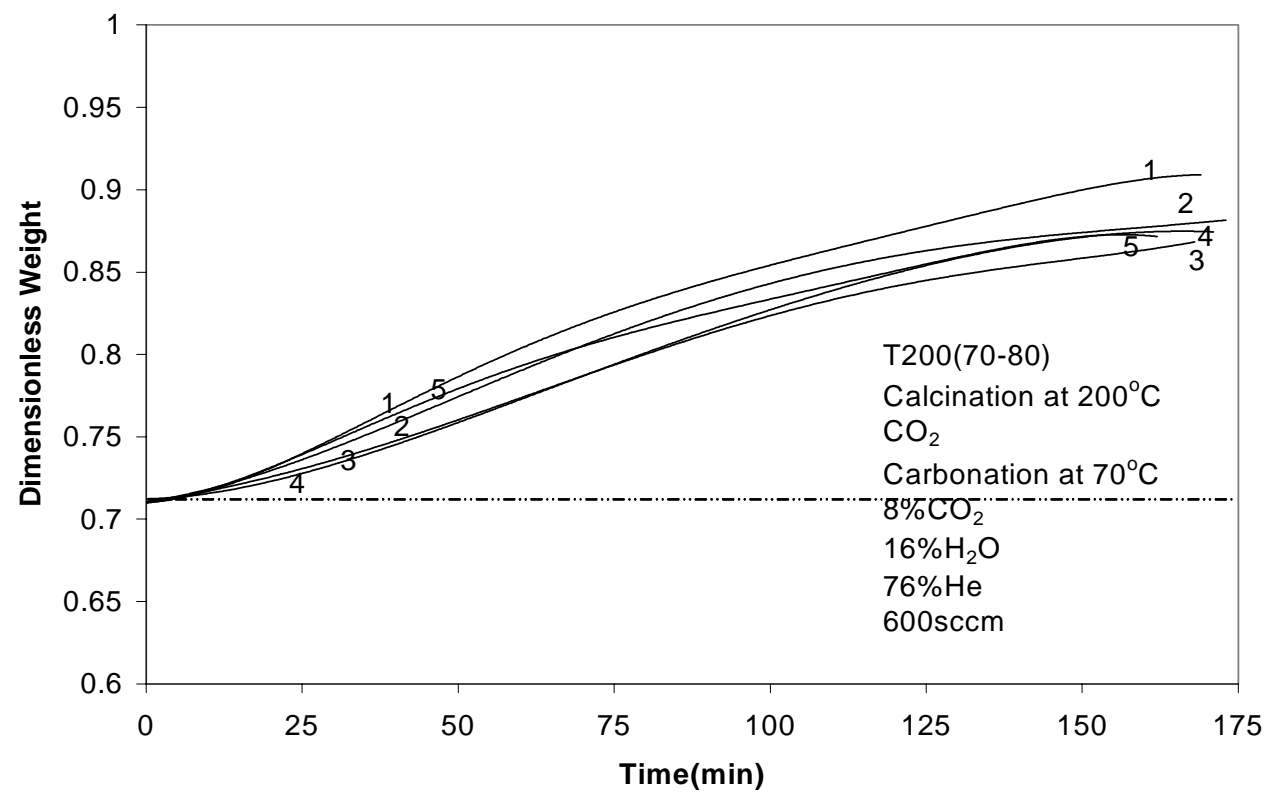

Figure 1. Dimensionless weight-time results for five carbonation cycles using trona $\mathrm{T}-200$ and calcination in pure $\mathrm{CO}_{2}$ at $200^{\circ} \mathrm{C}$.

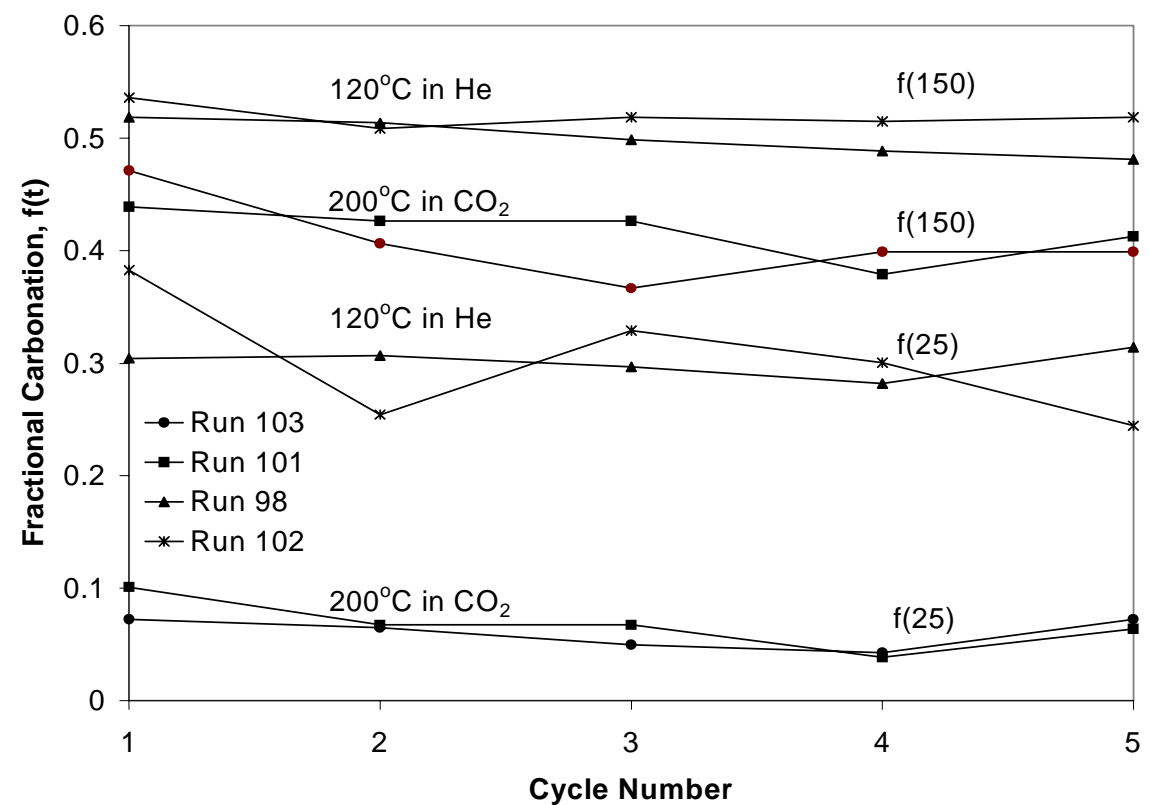

Figure 2. Comparison of $f(25)$ and $f(150)$ from duplicate tests using trona T-200. Calcination in $\mathrm{He}$ at $120^{\circ} \mathrm{C}$ and $\mathrm{CO}_{2}$ at $200^{\circ} \mathrm{C}$. 
more severe calcination conditions on T-200 performance is unmistakable. $f(25)$ values following mild calcination were at least three times greater than the corresponding values following severe calcination. The difference in $\mathrm{f}(150)$ is somewhat less, but still easily noticeable. Recall that the effect of increased calcination temperature and atmosphere had a relatively small impact on SBC 3 performance (see Figure 6 in, Green et al. 2002a)

Trona T-50 was also adversely affected by the more severe calcination conditions as shown in Figure 3. Fractional conversions, $\mathrm{f}(25)$ and $\mathrm{f}(150)$ are plotted versus cycle number for two tests, one test using calcination conditions of $200^{\circ} \mathrm{C}$ in $\mathrm{CO}_{2}$ completed this quarter, and an earlier test using standard calcination conditions. With the exception of the single $\mathrm{f}(25)$ data point corresponding to cycle 3 with calcination in $\mathrm{He}$ at $120^{\circ} \mathrm{C}$, the results are similar to those of Figure 2 for Trona T-200. The reason for the large decrease associated with this single point is unknown. Mild calcination results in a large increase in $\mathrm{f}(25)$ and a smaller, but still noticeable increase in $f(150)$. Further comparison of results from Figures 2 and 3 shows that the values of both $f(25)$ and $f(150)$ are somewhat larger for T-200 than for T-50, i. e., T-200 is more reactive than T-50.

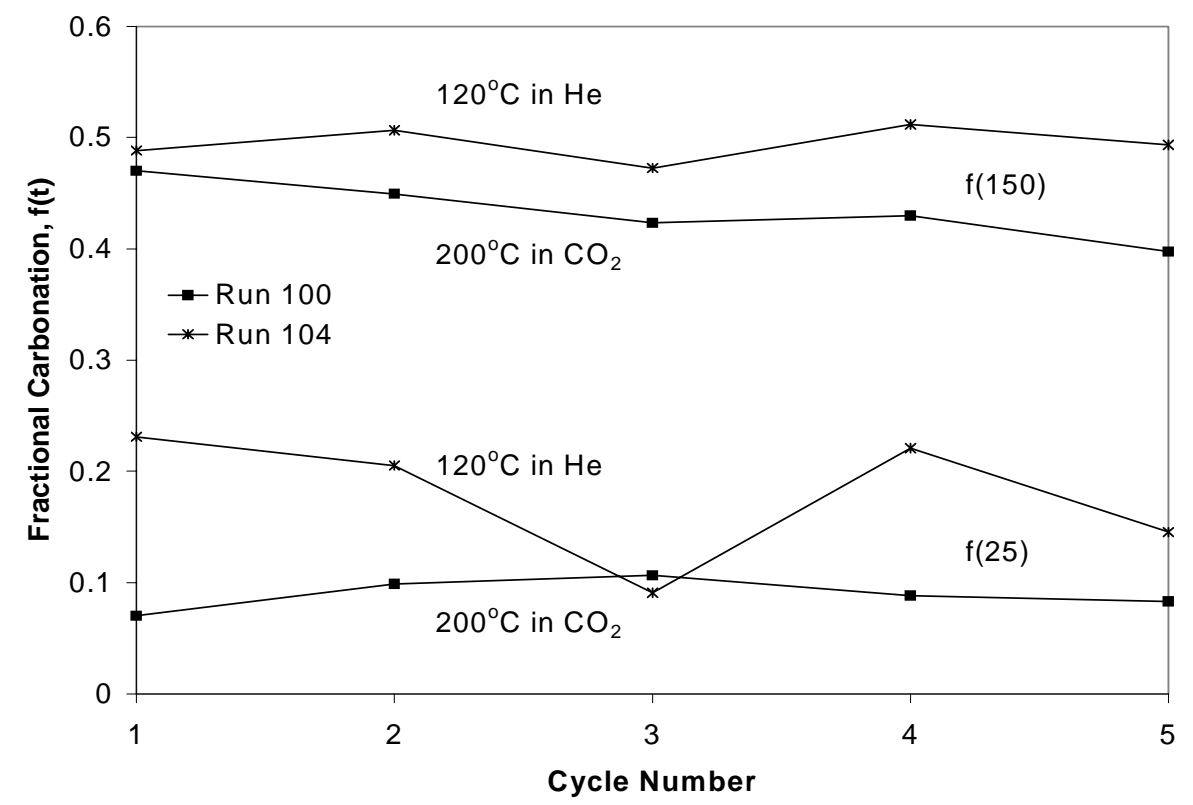

Figure 3. Comparison of $f(25)$ and $f(150)$ using trona T-50 with calcination in $\mathrm{He}$ at $120^{\circ} \mathrm{C}$ and $\mathrm{CO}_{2}$ at $200^{\circ} \mathrm{C}$.

Having proven that performance of Trona T-200 and T-50 are adversely affected by severe calcination conditions, the next two tests examined intermediate calcination conditions of $160^{\circ} \mathrm{C}$ in $\mathrm{He}$ and $140^{\circ} \mathrm{C}$ in $\mathrm{CO}_{2}$, both using T-200. Figures 4 and 5, respectively, show $\mathrm{f}(25)$ and $\mathrm{f}(150)$ as a function of cycle number for each of the four calcination conditions. The test using $140^{\circ} \mathrm{C}$ in $\mathrm{CO}_{2}$ was terminated after three cycles because of reactor problems. 


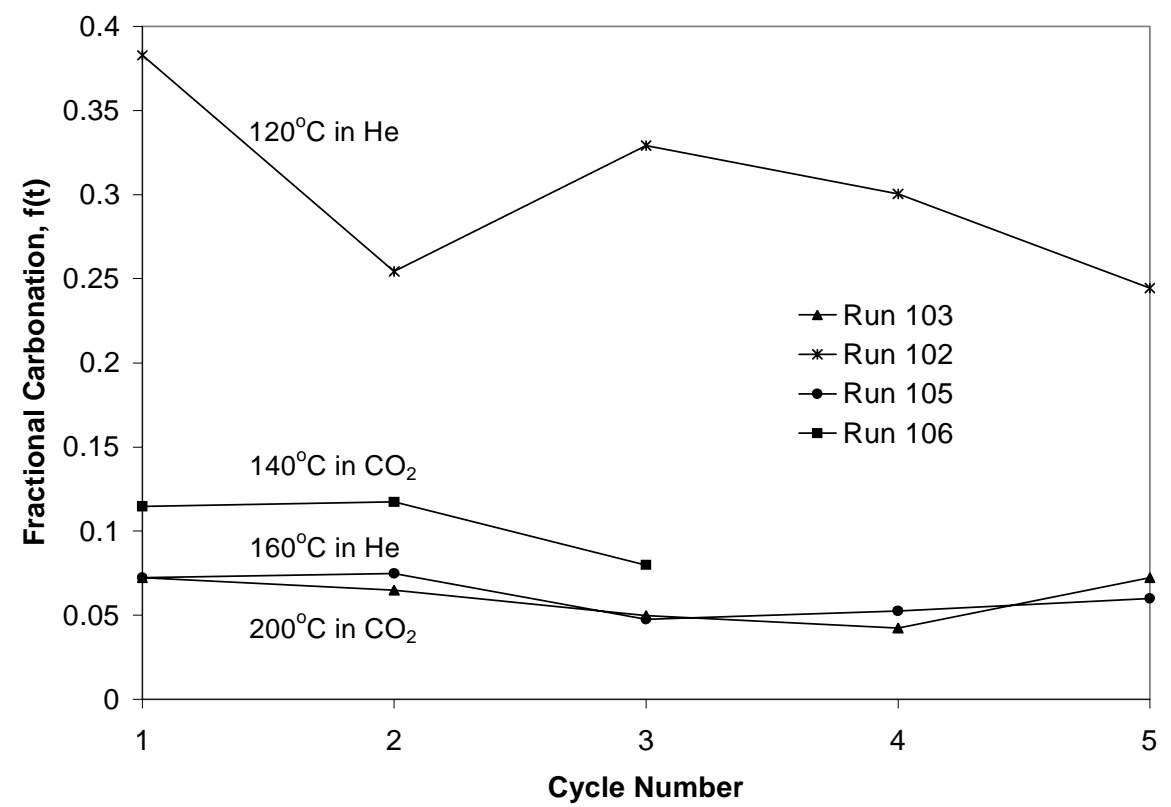

Figure 4. Comparison of $f(25)$ values for trona $T-200$ as a function of calcination temperature and atmosphere.

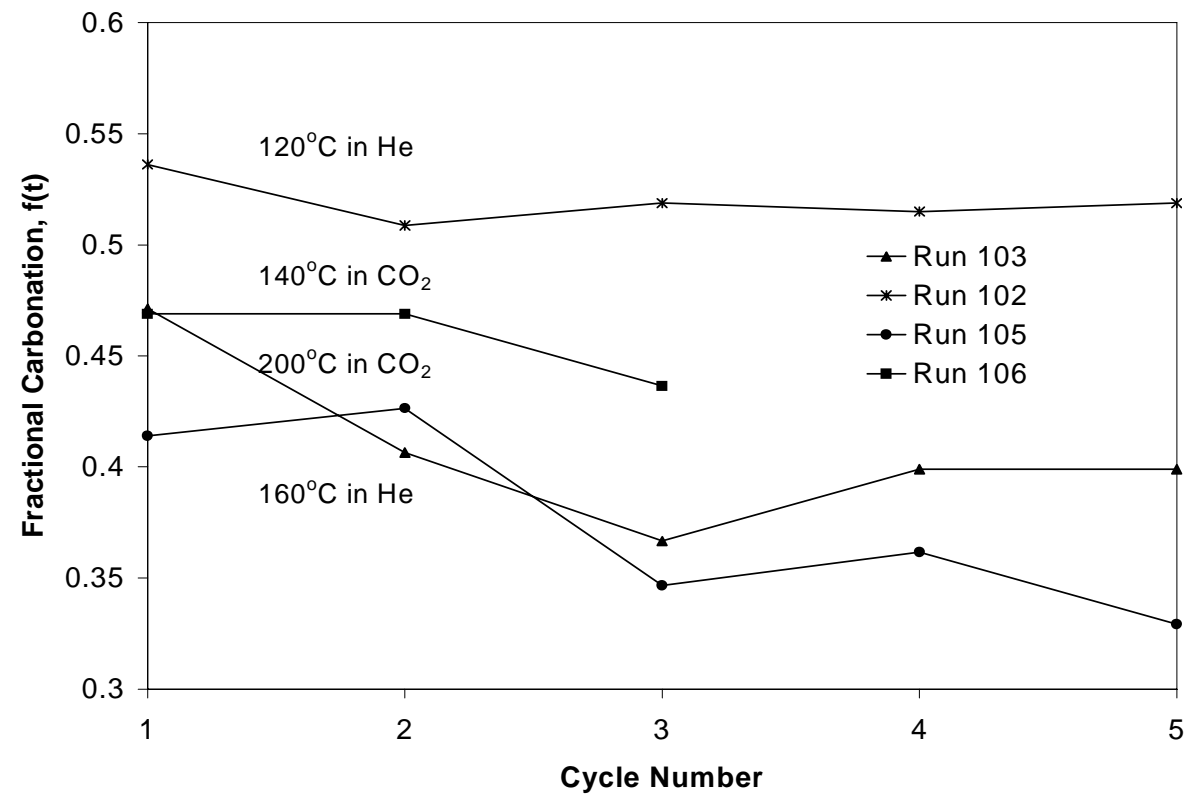

Figure 5. Comparison of $f(150)$ values for trona T-200 as a function of calcination temperature and atmosphere. 
These figures suggest that even moderate increases in the severity of calcination conditions causes a significant decrease in both reactivity and capacity of trona, but with the data presently available it is not clear if the decrease is associated with temperature, atmosphere, or both.

\subsection{Thermogravimetric Testing at RTI}

Thermogravimetric testing this quarter focused on investigation of different types of potassium carbonate sorbents. Extra fine potassium carbonate (Armand Products) and technical grade potassium carbonate (EM Science) were tested for carbonation activity at $60^{\circ} \mathrm{C}$. The results are shown in Figure 6. After drying to constant weight the technical grade material gained approximately 22 percent in weight, and approached a weight gain consistent with formation of a salt intermediate in composition between carbonate and bicarbonate forms. From the process design standpoint the rapid initial weight gain of 5 to 10 percent is significant in that full scale gas solid contact for a reaction of this kind would likely take place in a short residence time transport reactor. The extra fine material reacted much more slowly and approached a lower sorption capacity.

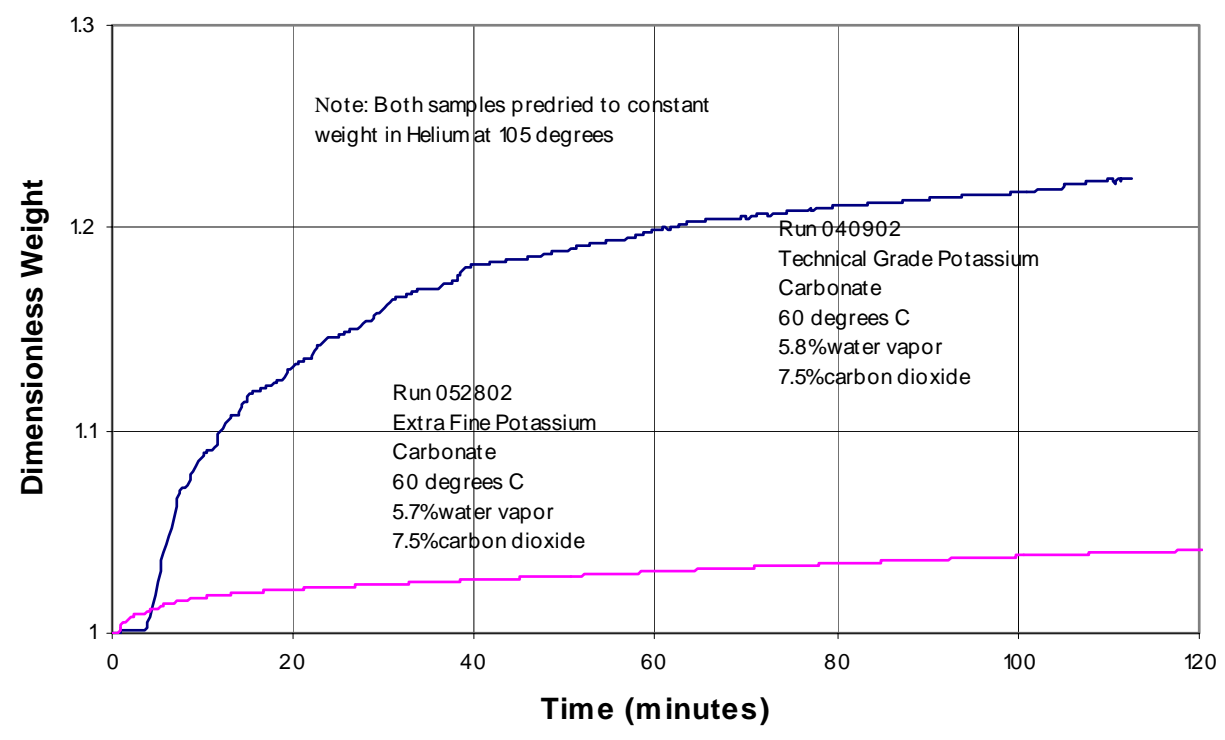
Figure 6. Carbonation of dried commercial grade and extra fine potassium carbonate
samples $\left(60^{\circ} \mathrm{C}\right)$.

Similar testing on the technical grade material was conducted at $70^{\circ} \mathrm{C}$, with results of duplicate tests shown in Figure 7. Reproducibility was not good for these tests with weight gains after two hours of about $1.4 \%$ in one case and $2.4 \%$ in the other. Following a lag that is possibly due to delays in addition of water vapor to the reactant gas, the initial reaction rate was relatively rapid with a $1.0 \%$ weight gain over the course of 5 minutes in run 42402 . 


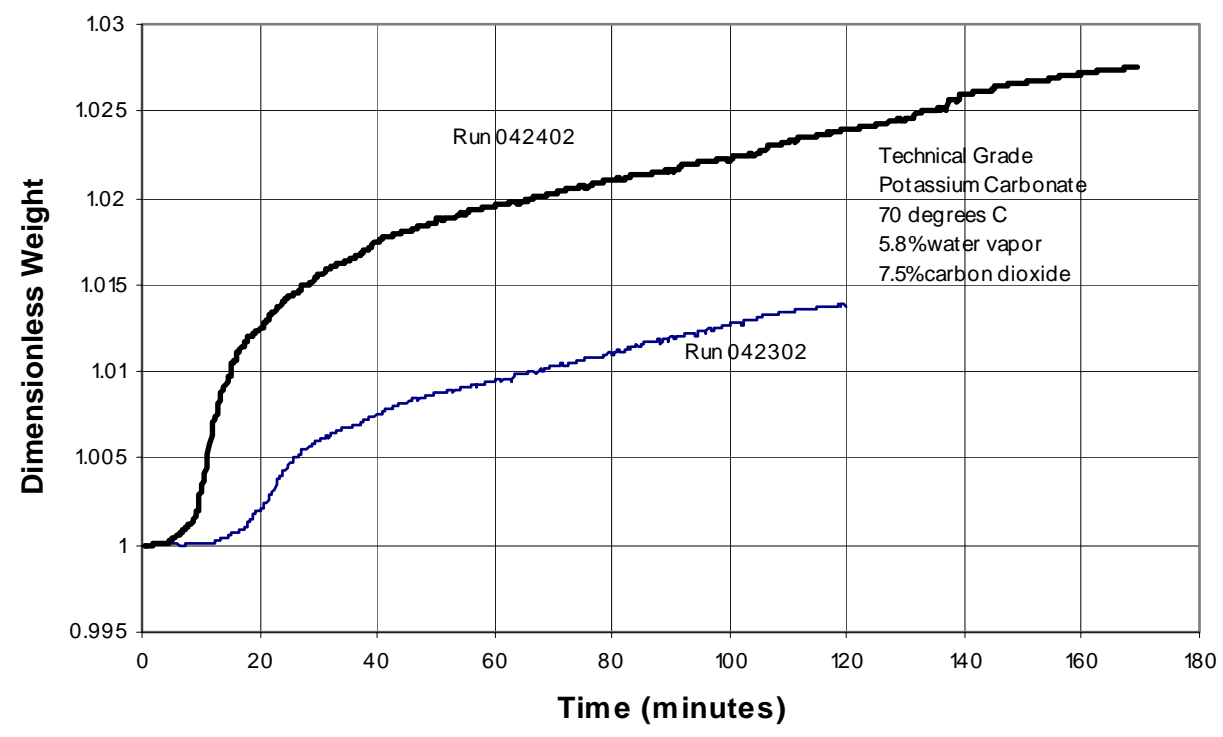

Figure 7. Carbonation of potassium carbonate $\left(70^{\circ} \mathrm{C}\right)$.

A supported potassium carbonate sorbent was prepared by spray drying. This material is more durable than any of the unsupported potassium carbonate or calcined sodium carbonate materials tested to date. Durability, or attrition resistence is an important consideration for process designs involving multicycle processing in transport reactor systems. This material was composed of $40 \%$ potassium carbonate and 60 percent (presumably inert) proprietary support material. Data from duplicate carbonation tests conducted at $60^{\circ} \mathrm{C}$ are shown in Figure 8. In these tests, an extremely rapid weight gain of about $3 \%$ of the sorbent weight was observed. (This is equivalent to $7.5 \%$ of the potassium carbonate present.)

These tests were repeated at $70^{\circ} \mathrm{C}$. Duplicate carbonation tests were conducted on predried material and rapid weight gains of about $2.5 \%$ of the sorbent weight (or $6.3 \%$ of the weight of potassium carbonate were observed. Nearly all of the reaction took place within a few minutes. After about two hours the gas was changed to dry carbon dioxide in one case and dry helium in the other, while maintaining the temperature at $70^{\circ}$. The sorbent lost 40 to 50 percent of the weight gain under these conditions. Calcination was completed at $150^{\circ} \mathrm{C}$. These data are shown in Figure 9.

The $40 \%$ supported potassium carbonate sorbent was also subjected to a three-cycle isothermal carbonation/calcination test at $70^{\circ} \mathrm{C}$. The dried sample was initially reacted with a mixture of $5.7 \%$ water vapor and $7.5 \%$ carbon dioxide and rapidly gained about $2.7 \%$ of sorbent weight $(6.8 \%$ of potassium carbonate weight). When the sweep gas was switched to dry helium at $70^{\circ} \mathrm{C}$ the sample gave up about half of its initial weight gain. This was repeated for two additional cycles with similar results. Under isothermal conditions the sorbent had a working capacity of approximately 3 to $3.5 \%$ of the mass of potassium carbonate. 


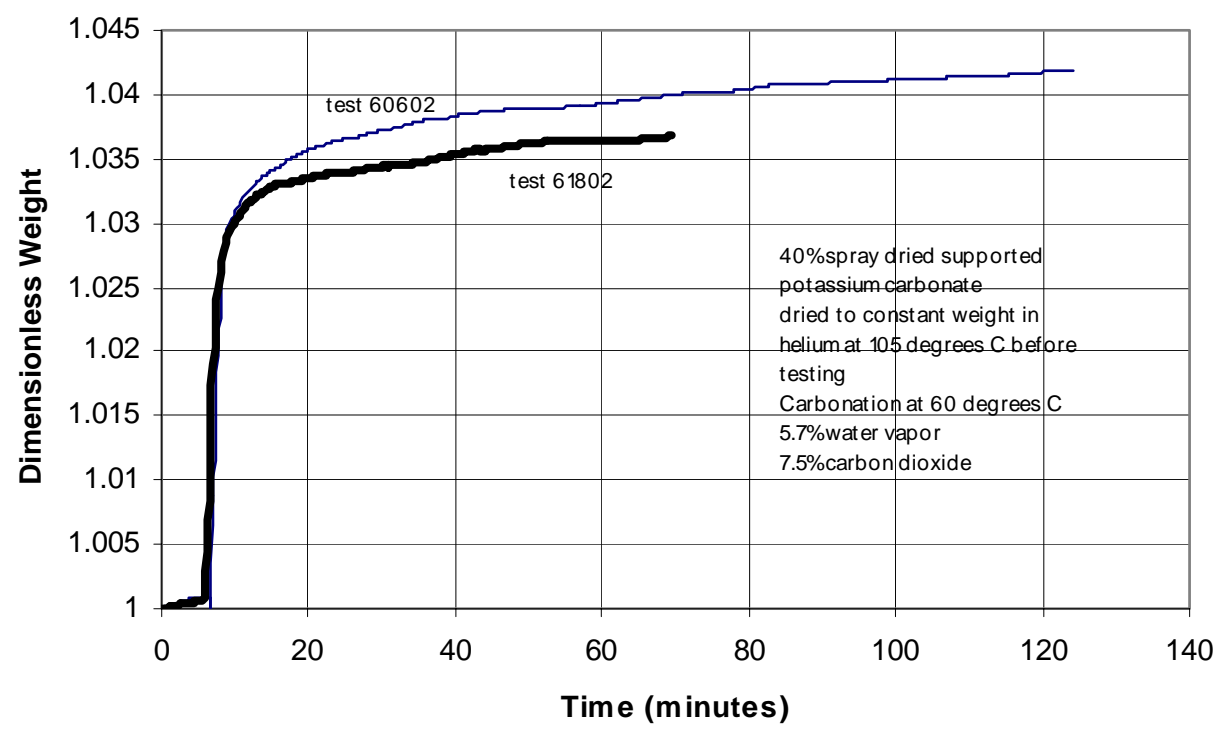

Figure 8. Duplicate carbonation tests of $40 \%$ supported potassium carbonate.

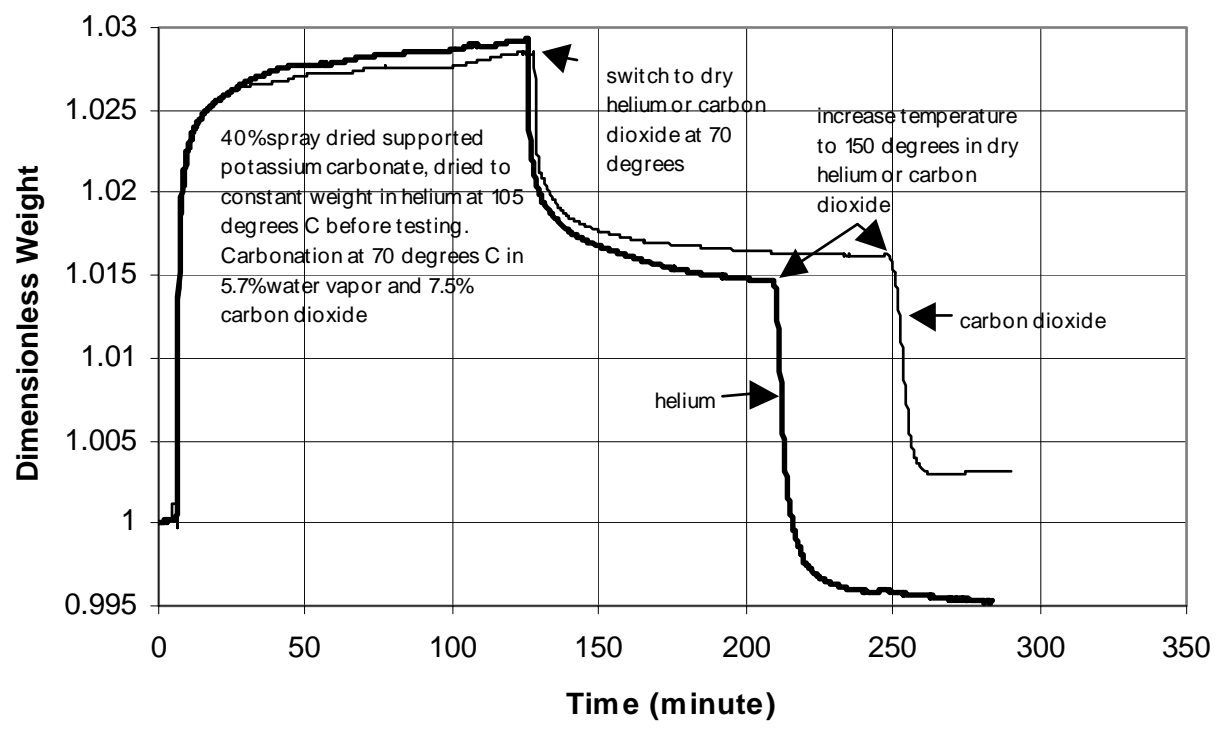

Figure 9. Carbonation of $40 \%$ supported potassium carbonate at $70^{\circ} \mathrm{C}$ followed by calcination in helium and carbon dioxide. 
These data are shown in Figure 10. At present, no practical way to take advantage of this concentration swing is apparent, however the rapid weight gain is significant even if, as is likely, a thermal swing is necessary to recover the carbon dioxide.

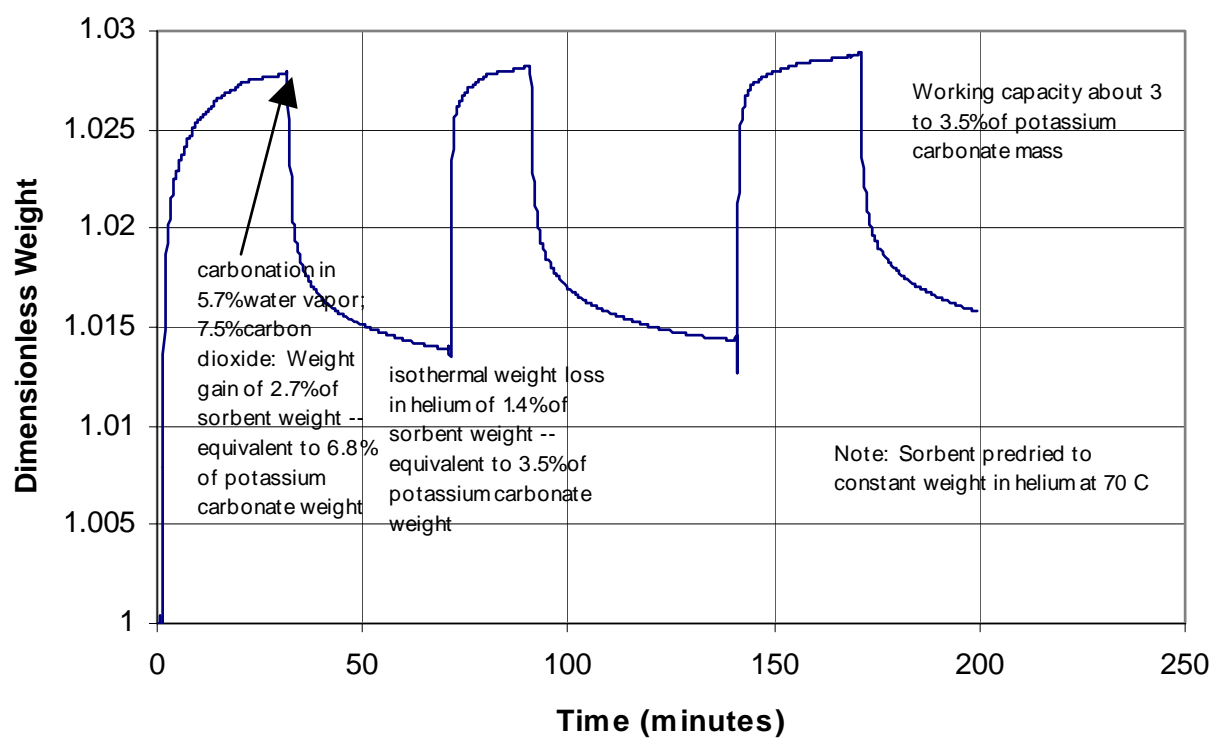

Figure 10. Cyclic carbonation/calcination of supported (40\%) potassium carbonate -isothermal of $70^{\circ} \mathrm{C}$.

\subsection{Fluidized Bed Testing at RTI}

Two 5-cycle fluidized bed reactor tests were conducted this quarter. The first test was conducted with T-50 trona. The reactor was loaded with $406 \mathrm{~g}$ of material, and the material was not removed between cycles. This was equivalent to an initial bed height of 6 inches, resulting in a bed height to diameter ratio of 3 . This mass of trona, after calcination, has a carbon dioxide capacity of $37 \mathrm{~g}$. All calcinations were carried out in nitrogen at $150^{\circ} \mathrm{C}$.

Carbonation reactions were conducted in a simulated flue gas of 4.7 to $6.5 \%$ carbon dioxide and approximately $6.9 \%$ water vapor. Carbonation test temperatures varied within the fluidized bed through the course of the cycles, peaking at approximately $75^{\circ} \mathrm{C}$. The carbonation cycles were stopped after approximately three hours duration even though most of the stoichiometric capacity of the bed was unused, because the initial rates were of greatest interest. Carbon dioxide removal, and the associated fluidized bed temperature profiles are shown in Figures 11 through 20. The temperature at the "bottom", "middle" and "top" of the bed were measured at $1 ", 3 "$ and 5" above the flow distributor. A summary of these data is given in Table 2.

The results are relatively consistent from cycle to cycle with no indication that the activity of the sorbent declined over the course of the five cycles. Variations in temperature are unavoidable with strongly exothermic reactions in the present well-insulated reactor system. The initial removal rates of 15 to 30 percent, as shown in the data for the first 15 to 30 minutes of the run may be more significant than the overall sorbent capacity usage over the three hour duration. 


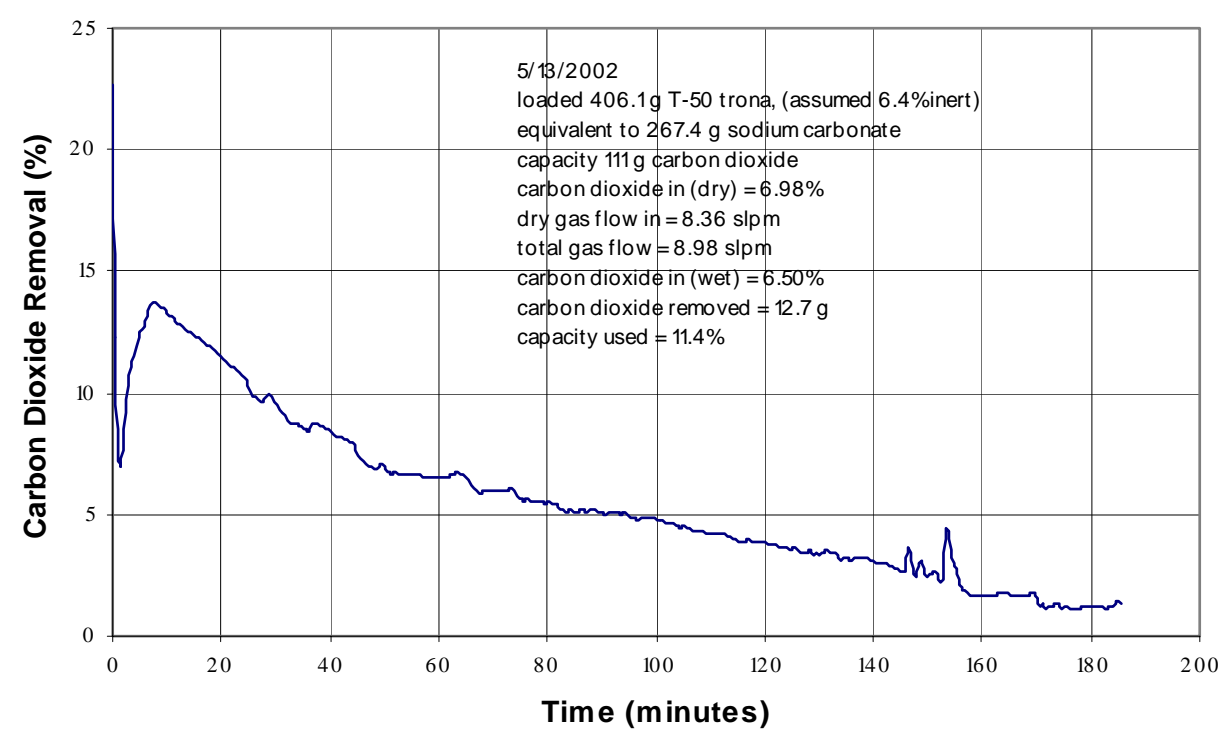

Figure 11. Carbon dioxide removal with trona Cycle 1 -- 5/13/2002.

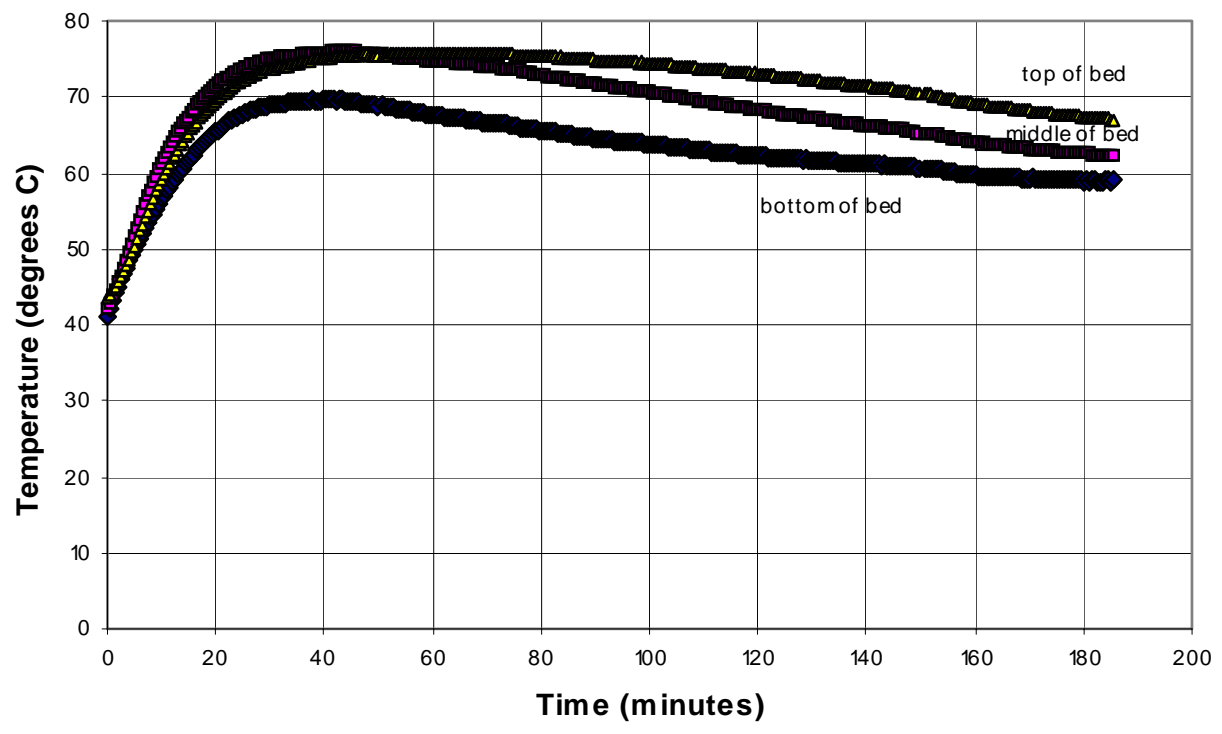

Figure 12. Temperature profile--carbonation Cycle 1 -- 5/13/2002. 


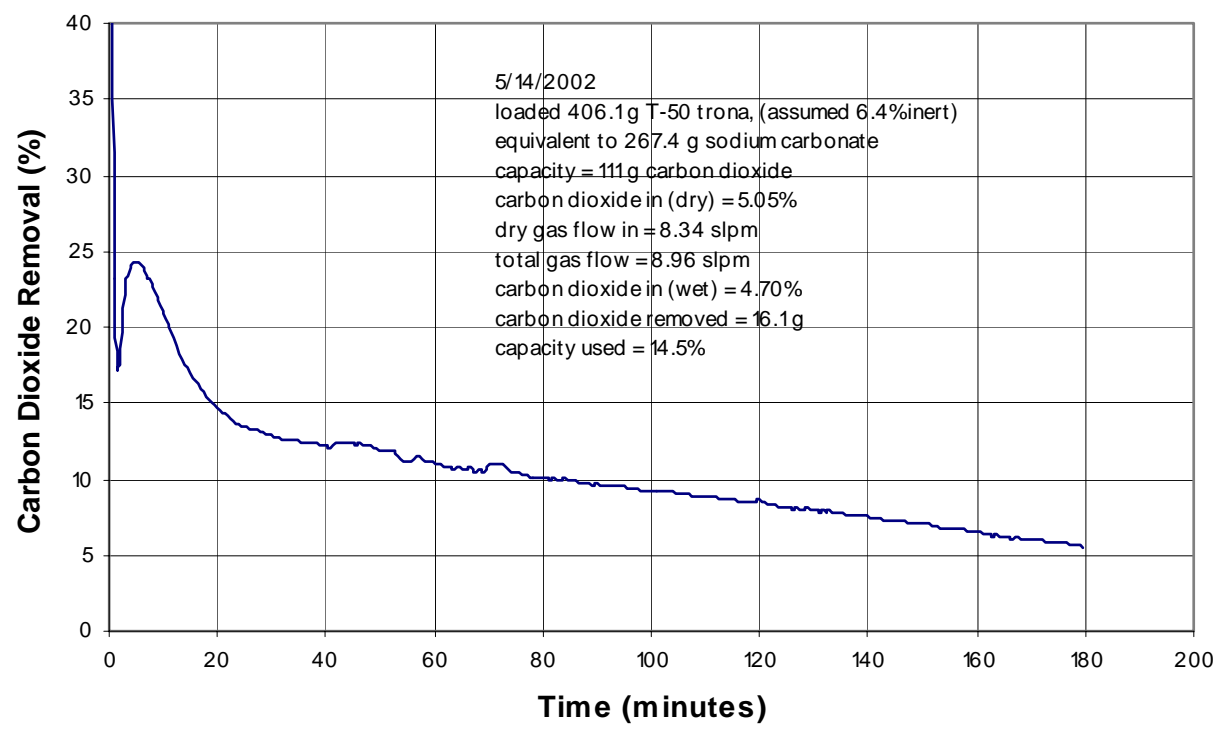

Figure 13. Carbon dioxide removal with trona-Cycle 2-5/14/2002.

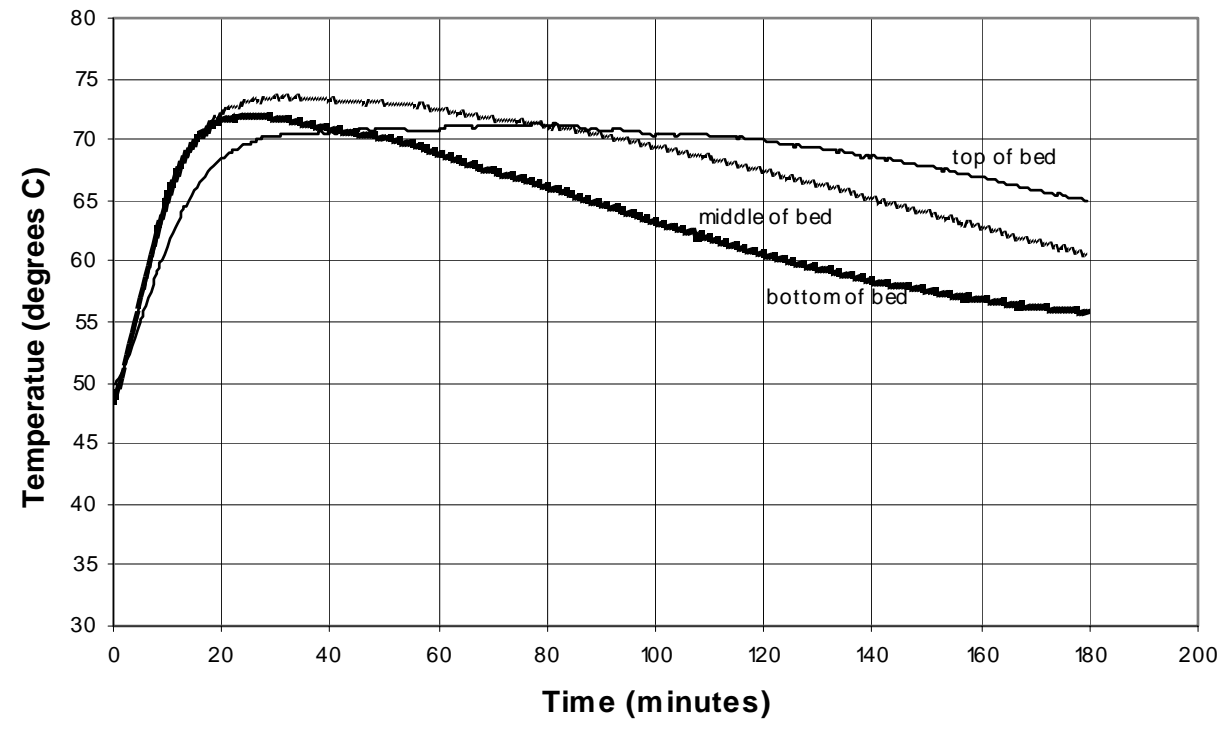

Figure 14. Temperature profile-carbonation Cycle 2-5/14/2002. 


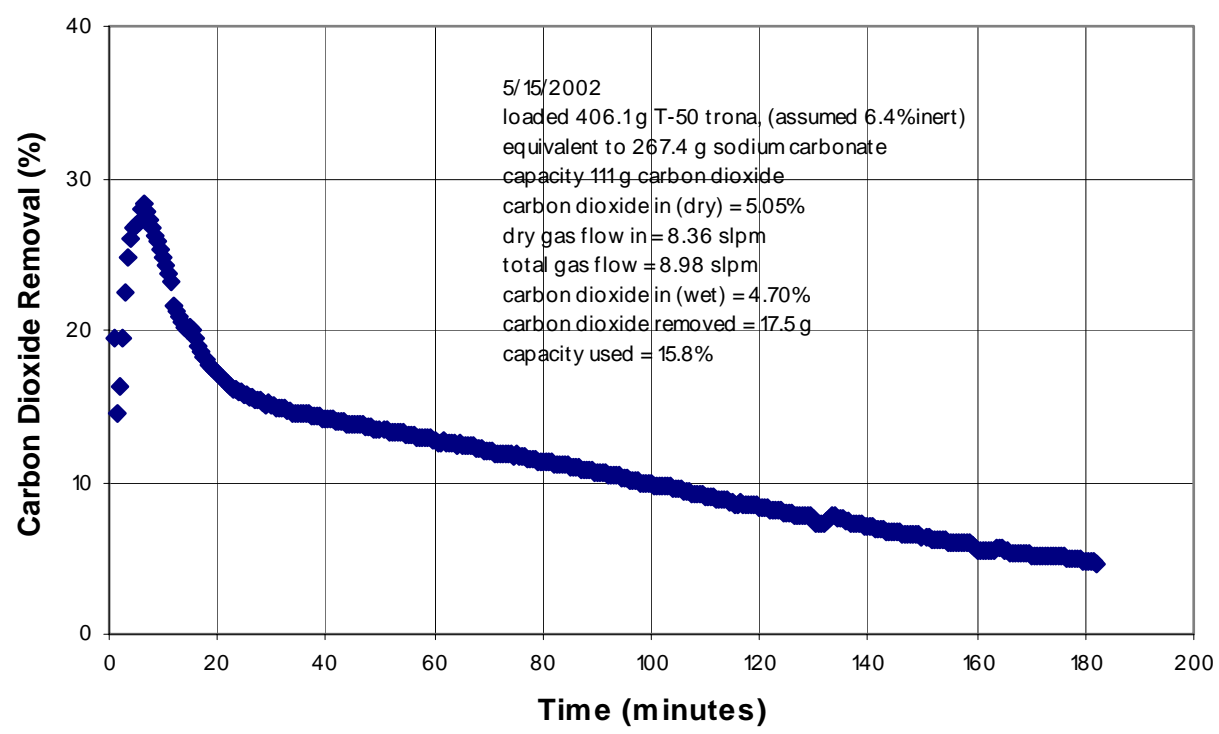

Figure 15. Carbon dioxide removal with trona- Cycle 3-5/15/2002.

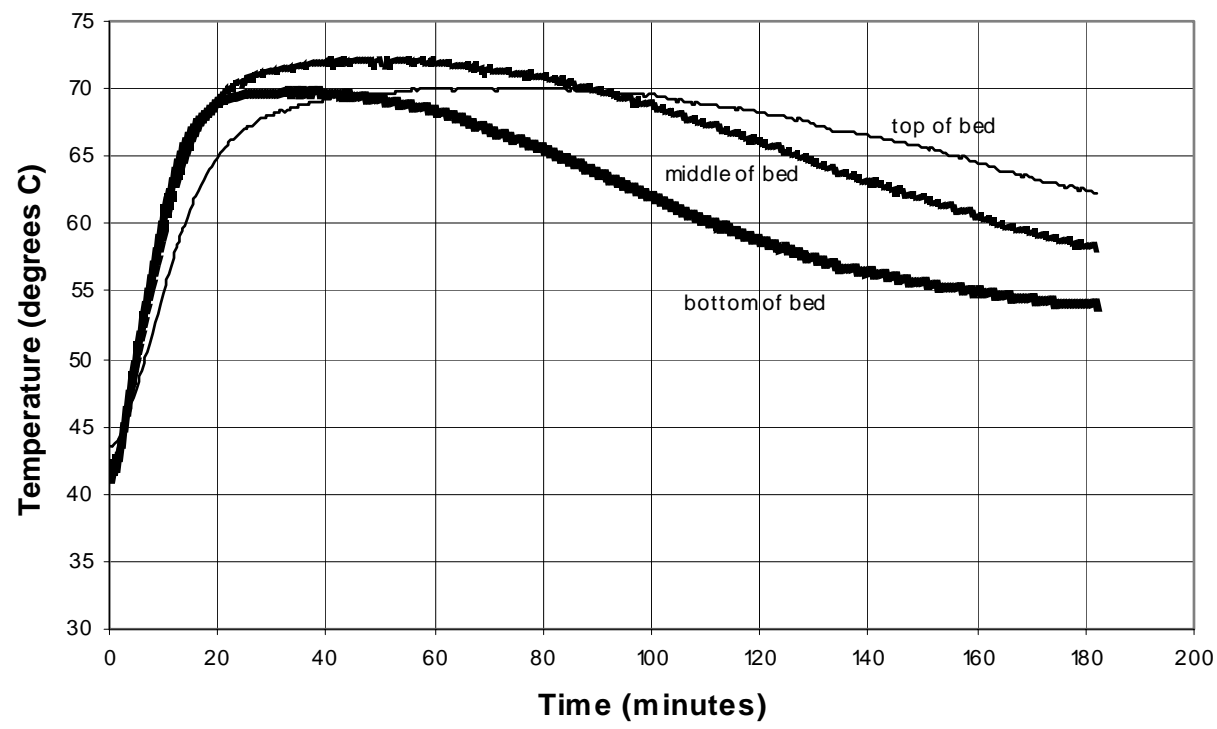

Figure 16. Temperature profile-carbonation Cycle 3-5/15/2002. 


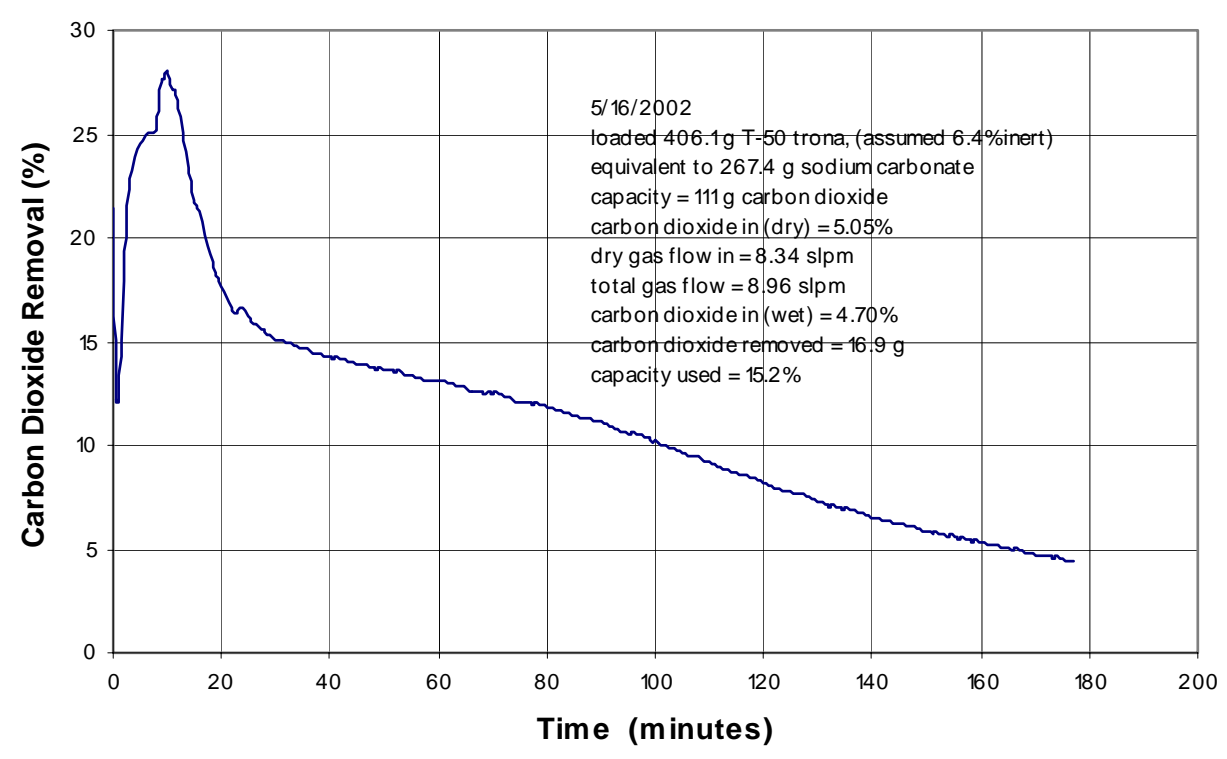

Figure 17. Carbon dioxide removal with trona- Cycle 4-5/16/2002.

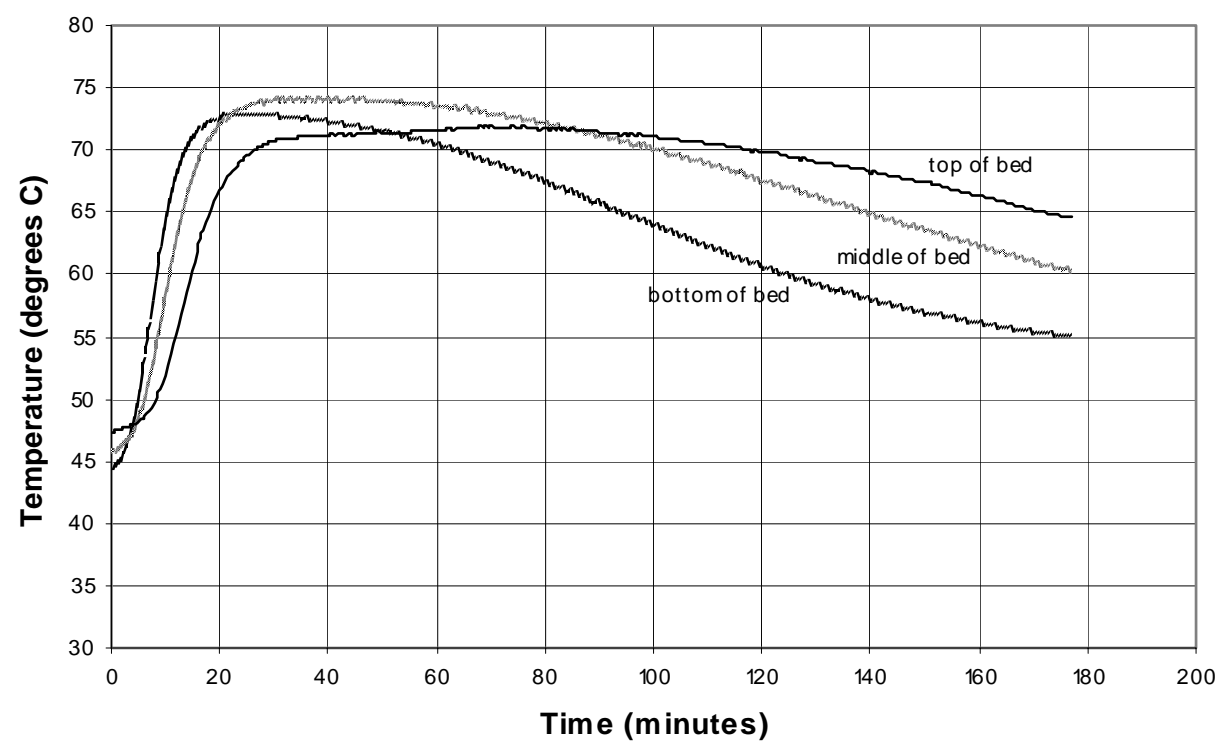

Figure 18. Temperature profile-carbonation Cycle 4-5/16/2002. 


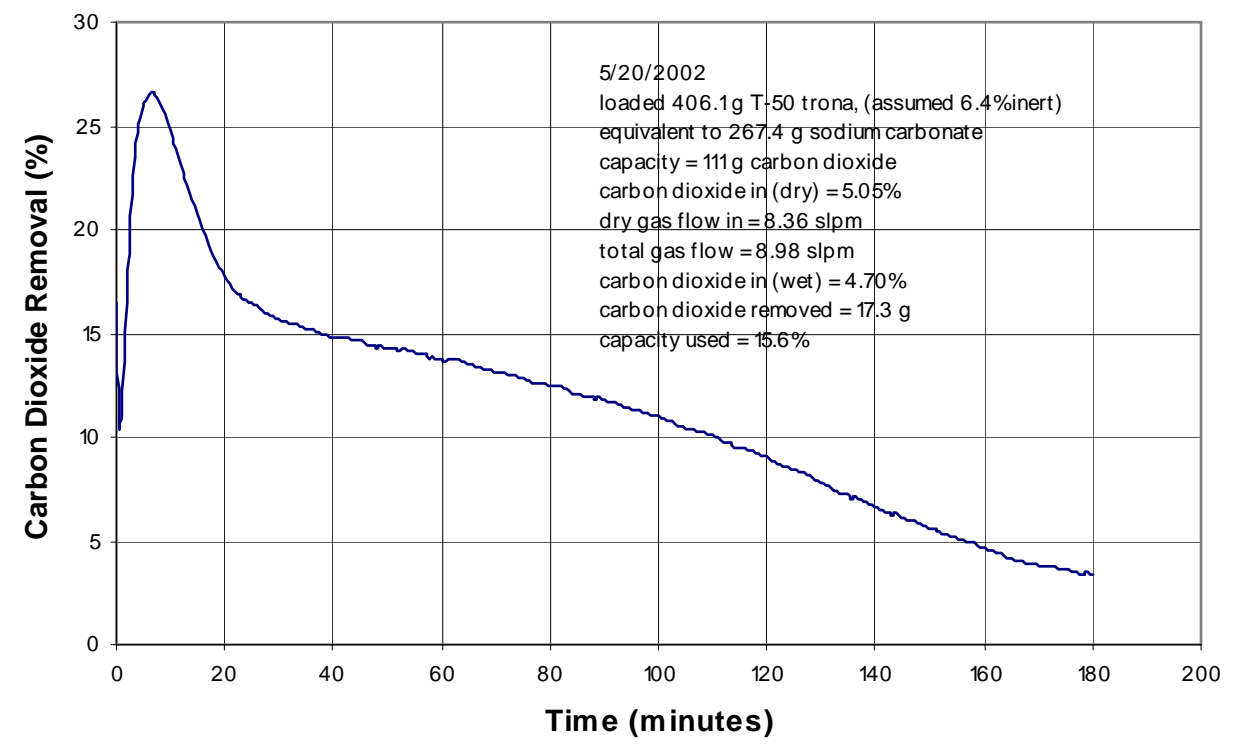

Figure 19. Carbon dioxide removal with trona- Cycle 5-5/20/2002.

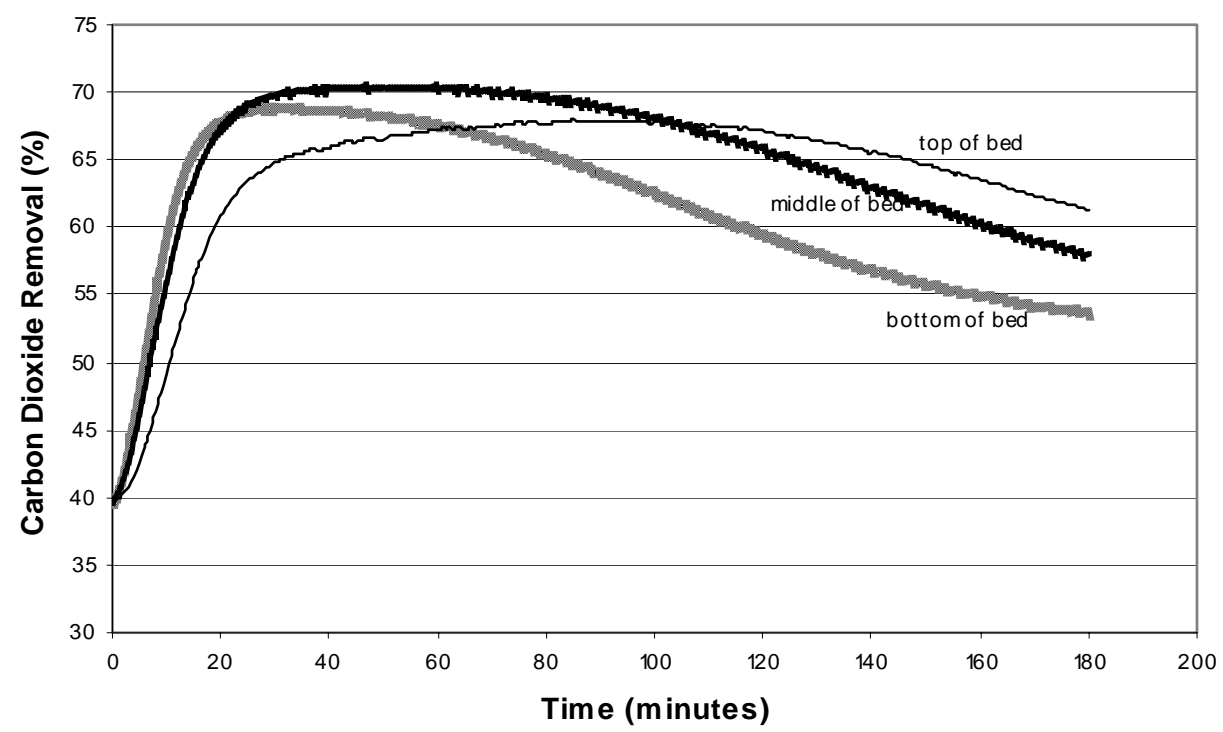

Figure 20. Temperature profile-carbonation Cycle 5-5/20/2002. 
Table 2. Carbon Dioxide Removal in 5-cycle Fluidized Bed Test Using Trona T-50 as Sorbent Precursor.

\begin{tabular}{l|c|c|c|c|c}
\hline \hline Cycle & \multicolumn{1}{|c|}{$\mathbf{1}$} & \multicolumn{1}{c|}{$\mathbf{2}$} & \multicolumn{1}{c|}{$\mathbf{3}$} & \multicolumn{1}{c}{$\mathbf{4}$} & \multicolumn{1}{c}{$\mathbf{5}$} \\
\hline Total Gas Flow (slpm) & 8.98 & 8.96 & 8.98 & 8.96 & 8.98 \\
\hline $\mathrm{CO}_{2}$ in (\%) & 6.98 & 4.70 & 4.70 & 4.70 & 4.70 \\
\hline $\mathrm{H}_{2} \mathrm{O}$ in (\%) & 6.90 & 6.90 & 6.90 & 6.91 & 6.90 \\
\hline $\mathrm{CO}_{2}$ removed (g) & 12.7 & 16.1 & 17.5 & 16.9 & 17.3 \\
\hline Capacity used (\%) & 11.4 & 14.5 & 15.8 & 15.2 & 15.6 \\
\hline \hline
\end{tabular}

A second 5 -cycle fluidized bed test was conducted using a spray-dried $40 \%$ potassium carbonate on alumina support. This material was tested because of its superior attrition resistance to granular potassium carbonate, and because the support provides a heat sink for the energy released by the carbonation reaction. Experimental conditions were similar to the trona tests. The reactor was loaded with $379 \mathrm{~g}$ of sorbent, and the material was not removed between cycles. This was equivalent to an initial bed height of 5.5 inches. The potassium carbonate content of this sorbent has a carbon dioxide capacity of $48.2 \mathrm{~g}$ (assuming conversion to bicarbonate). All calcinations were carried out in nitrogen at $150^{\circ} \mathrm{C}$. Carbonation reactions were conducted in a simulated flue gas of $6.28 \%$ carbon dioxide and approximately $6.2 \%$ water vapor. Carbonation test temperatures varied within the fluidized bed through the course of each cycle, peaking at approximately $105^{\circ} \mathrm{C}$. The carbonation cycles were stopped after 3 to 3.5 hours duration even though most of the stoichiometric capacity of the bed was unused, because the initial rates were of greatest interest. Carbon dioxide removal, and the associated fluidized bed temperature profiles are shown in Figures 21 through 30 . The temperature at the "bottom", "middle" and "top" of the bed were measured as in the trona tests. A summary of these data is given in Table 3 .

\subsection{Properties of Sorbent Materials}

\subsubsection{Attrition Characteristics of $\mathbf{4 0 \%}$ Supported Sorbent Materials}

Samples of the $40 \%$ supported potassium carbonate material were subjected to air jet attrition testing (ASTM D 5757 -95) at RTI. The material was tested before and after fluidized bed reactor testing. The sample of used sorbent was collected after five carbonation cycles but before the fifth calcination. The jet cup attrition indices of the fresh material and the used material were 0.65 and 1.1 respectively. Based on these data, the $40 \%$ supported potassium carbonate material appears to have sufficient attrition resistence for use in a transport reactor.

\subsubsection{Surface Area and Porosity Characteristics of $40 \%$ Supported Sorbent Material}

The properties of the $40 \%$ supported potassium carbonate material were determined prior to fluidized bed reactor testing and are given in Table 4. 


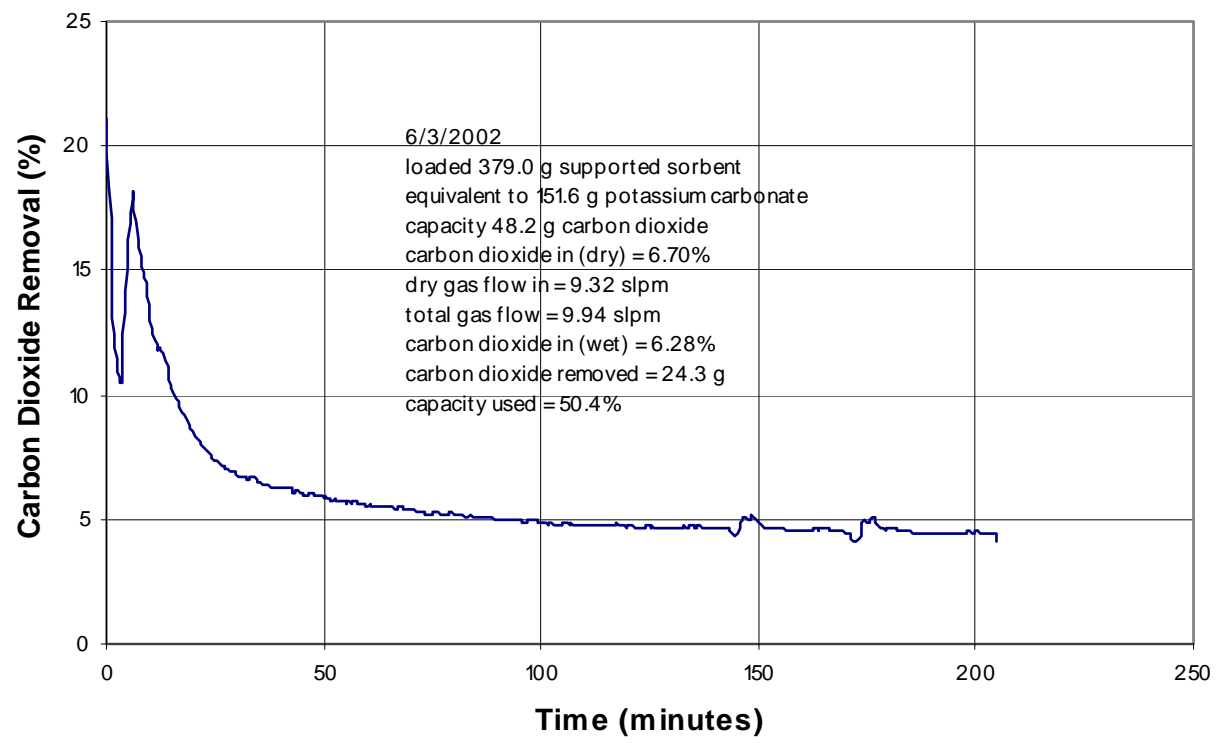

Figure 21. Fluidized bed carbonation of 40\% supported potassium carbonate--Cycle 1.

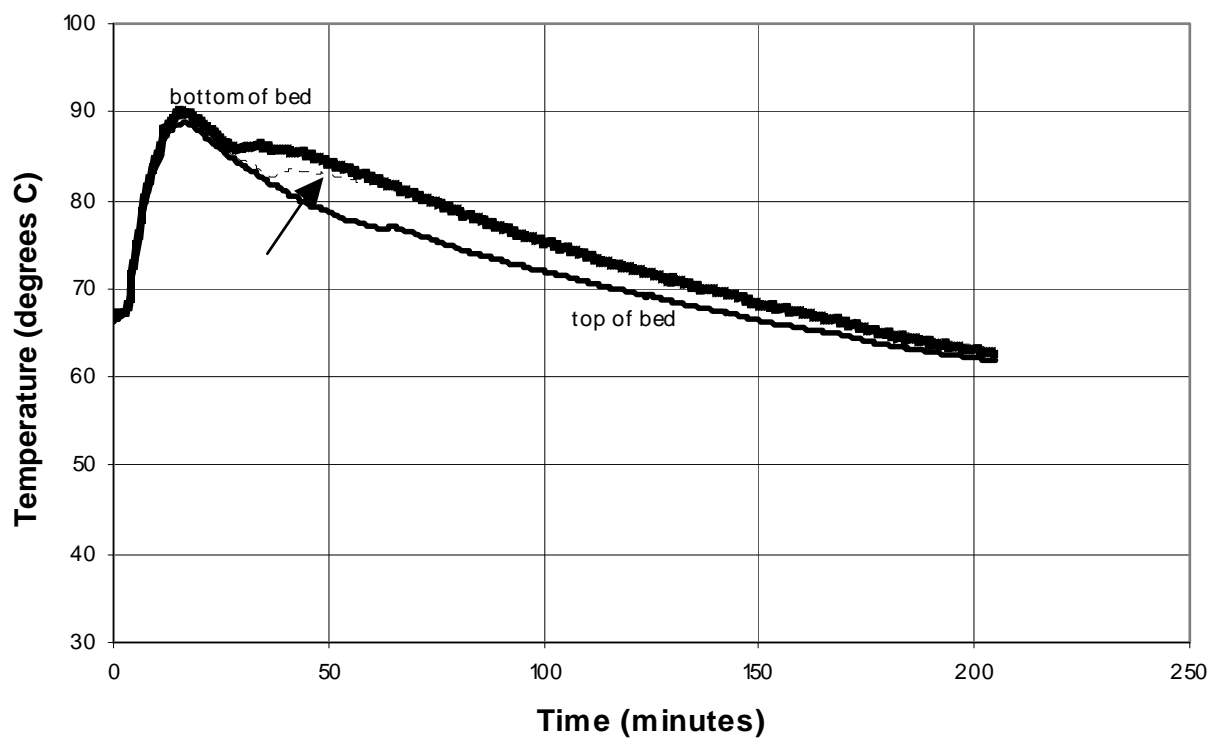

Figure 22. Temperature profile -- $40 \%$ supported potassium carbonate--Cycle 1. 


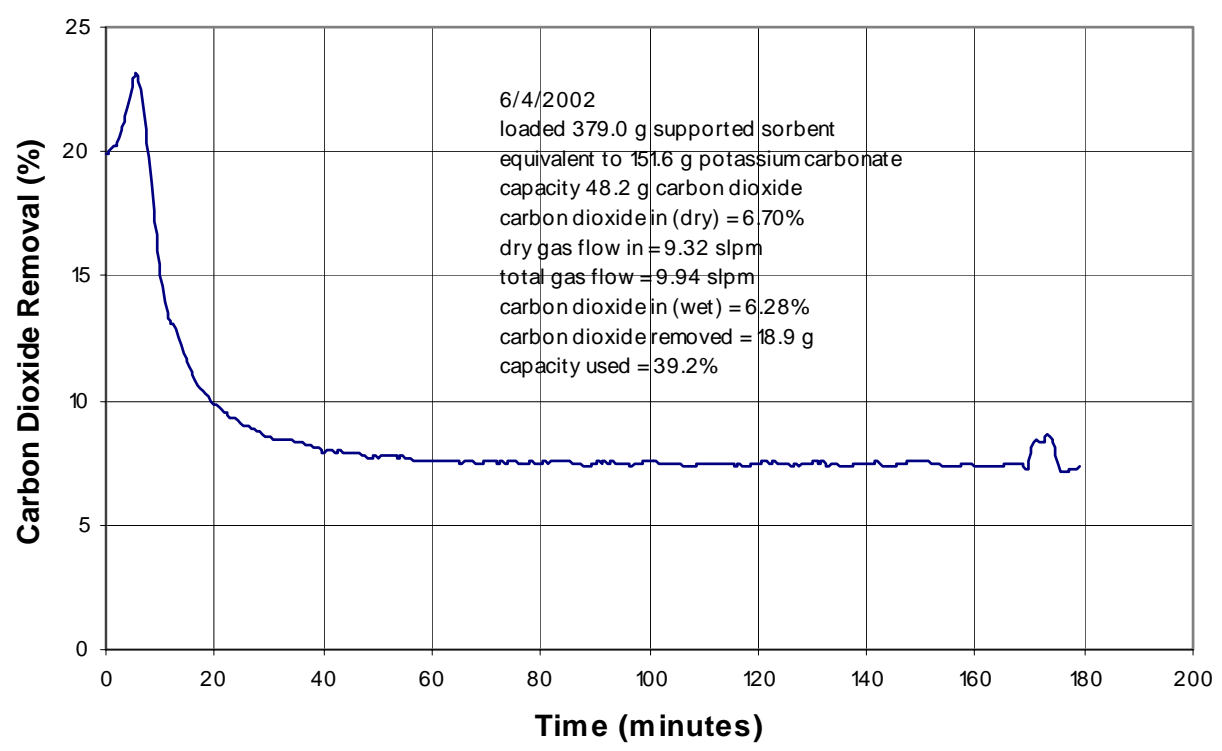

Figure 23. Fluidized bed carbonation of $40 \%$ supported potassium carbonate--Cycle 2.

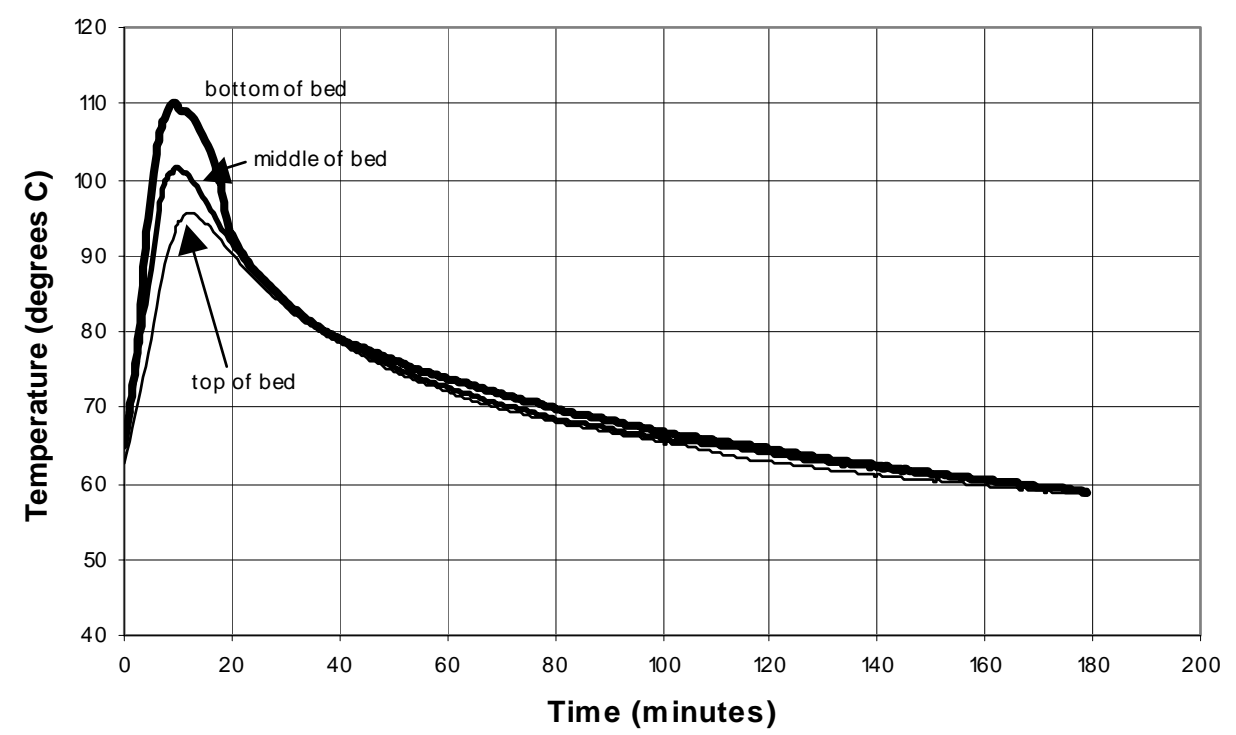

Figure 24. Temperature profile-40\% supported potassium carbonate-Cycle2. 


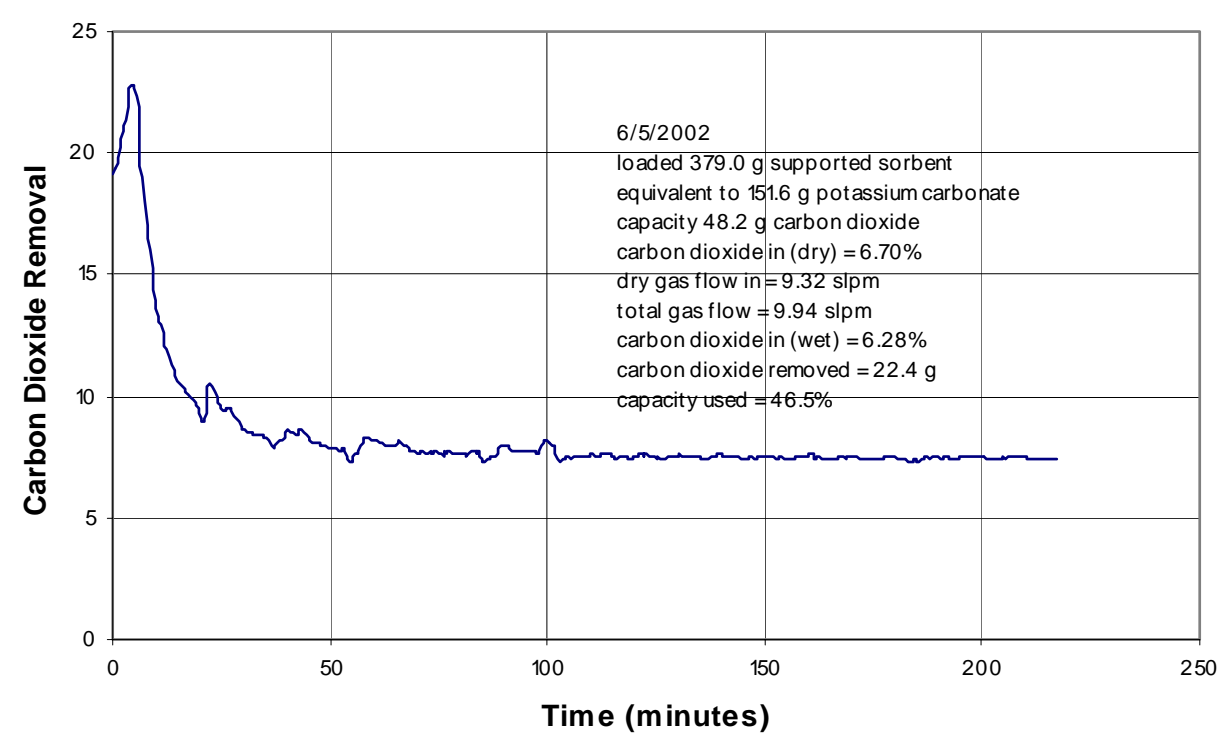

Figure 25. Fluidized bed carbonation of $40 \%$ supported potassium carbonate-Cycle 3 .

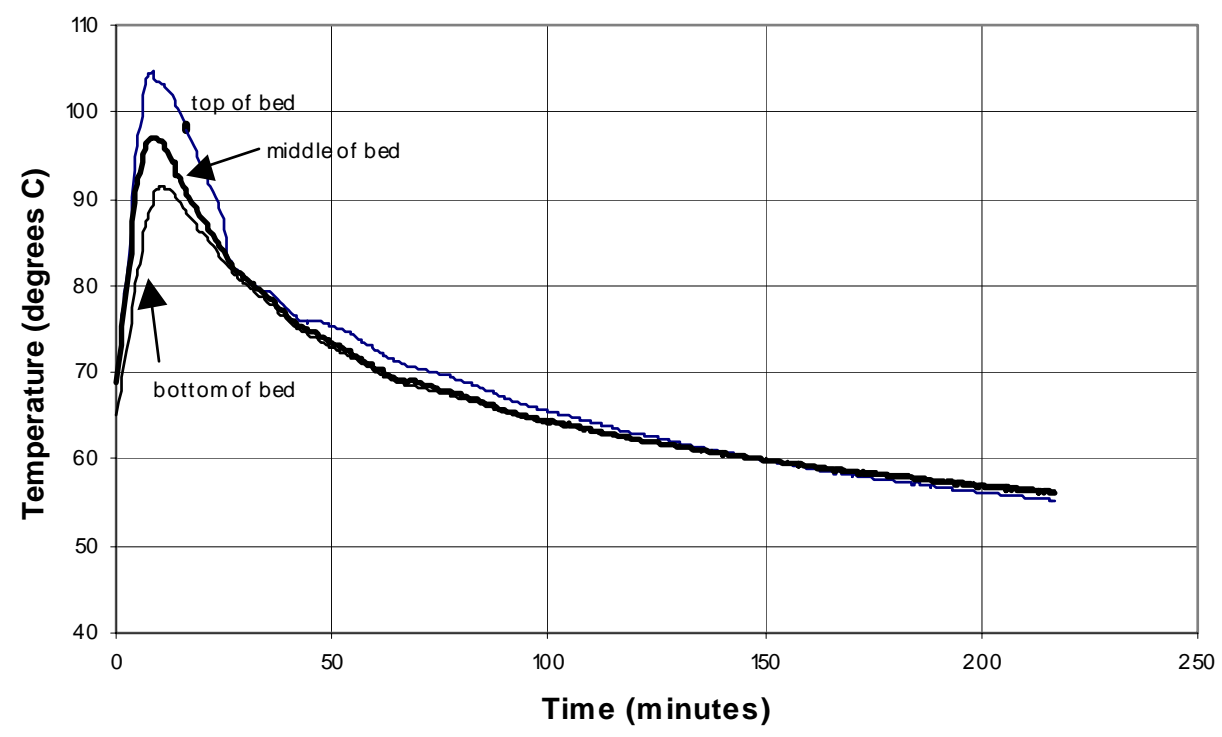

Figure 26. Temperature profile-40\% supported potassium carbonate-Cycle 3. 


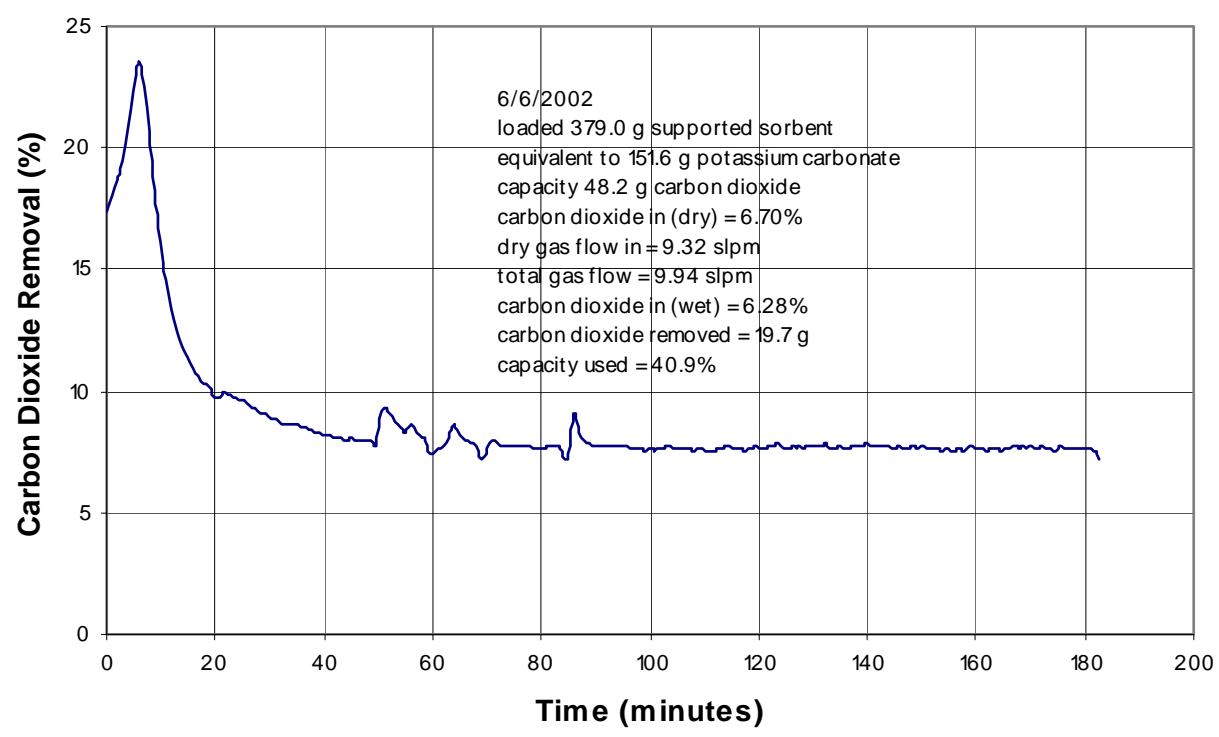

Figure 27. Fluidized bed carbonation of $40 \%$ supported potassium carbonate-Cycle 4 .

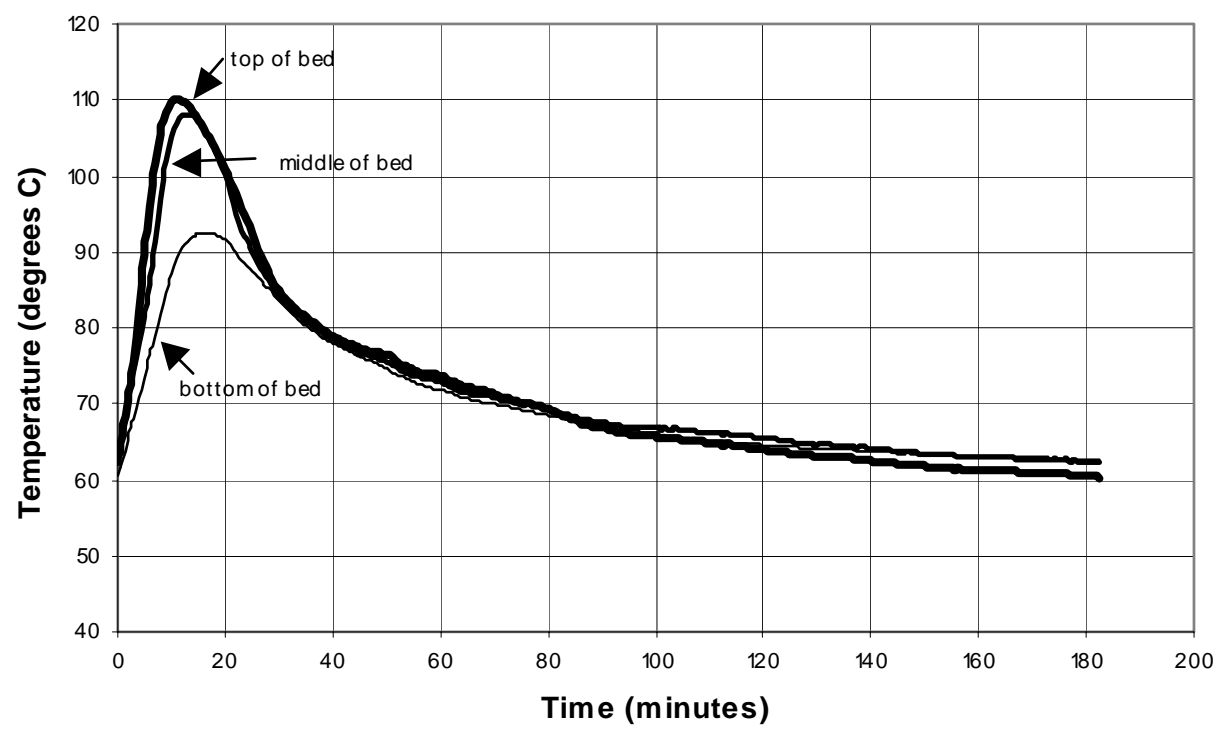

Figure 28. Temperature profile-40\% supported potassium carbonate-Cycle 4. 


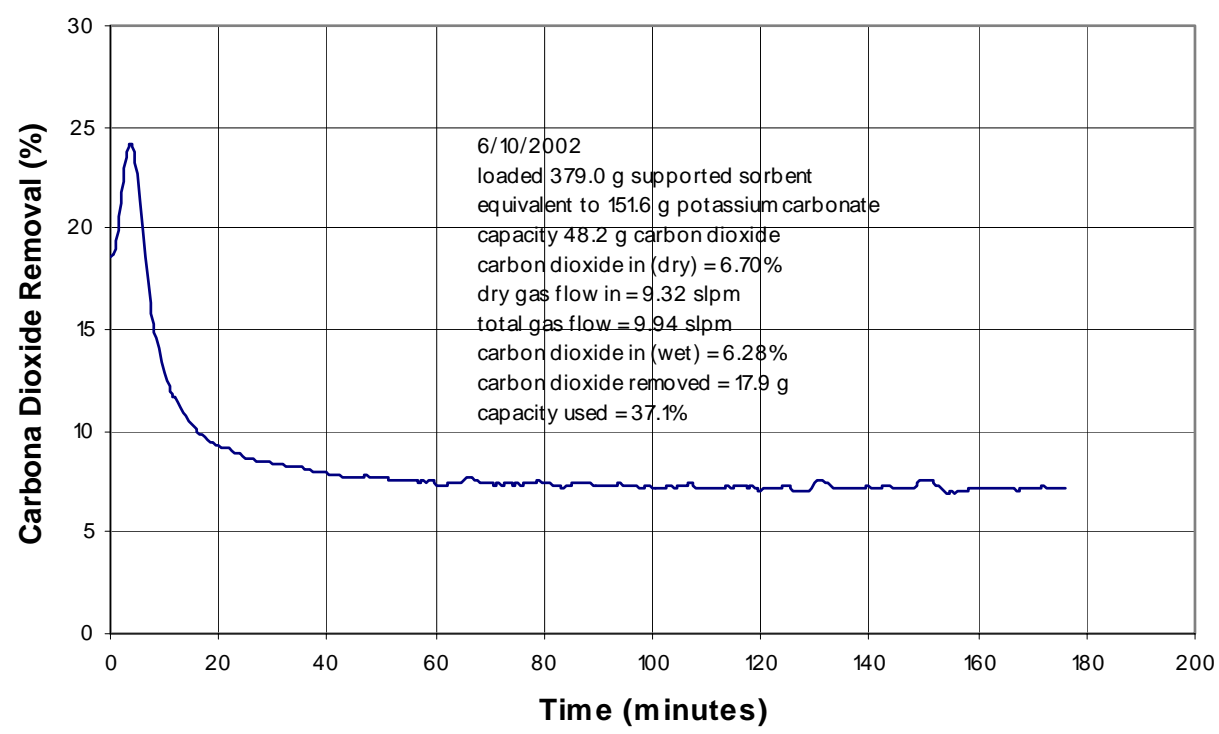

Figure 29. Fluidized bed carbonation of $40 \%$ supported potassium carbonate-Cycle 5 .

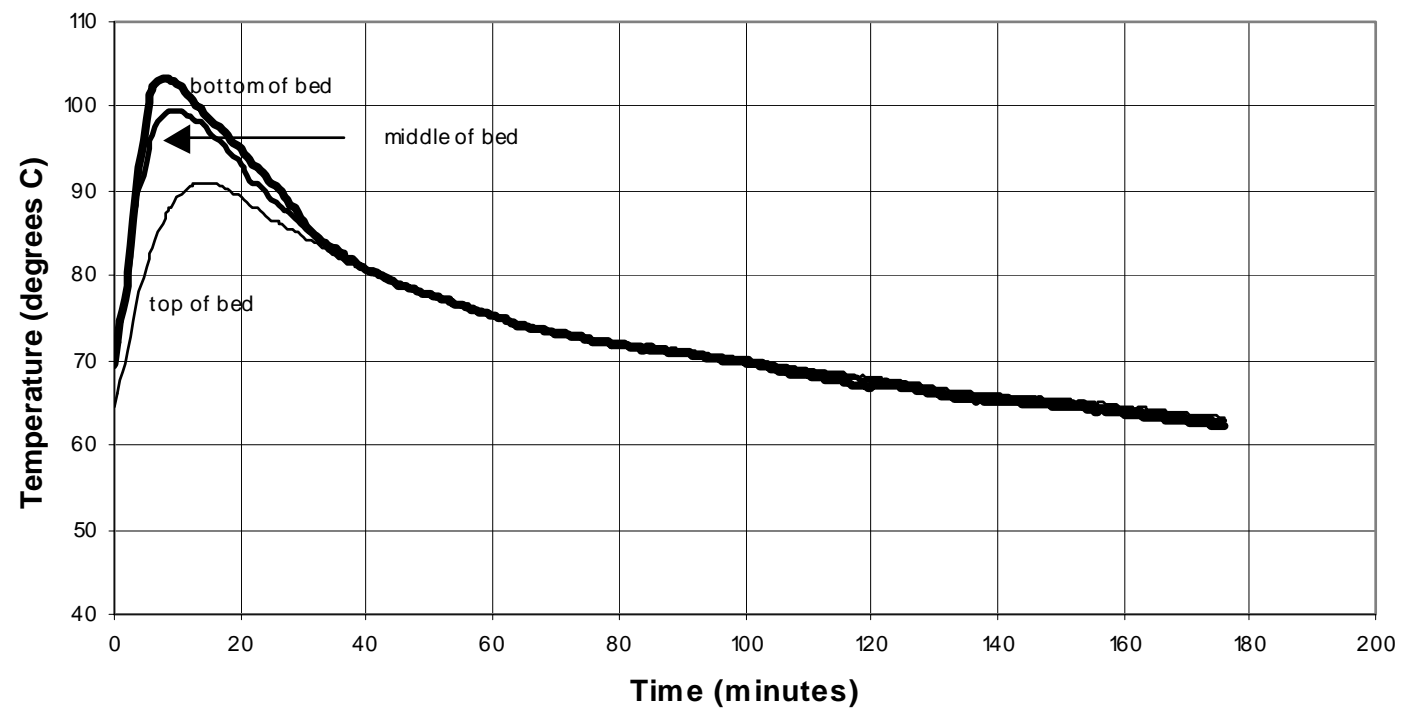

Figure 30. Temperature profile-40\% supported potassium carbonate-Cycle 5. 
Table 3. Carbon Dioxide Removal in 5-cycle Fluidized Bed Test Using Spray Dried Supported Potassium Carbonate as Sorbent Precursor.

\begin{tabular}{l|r|r|r|r|c}
\hline \hline Cycle & \multicolumn{1}{|c|}{} & \multicolumn{1}{c|}{$\mathbf{2}$} & \multicolumn{1}{c|}{$\mathbf{3}$} & \multicolumn{1}{c}{} & $\mathbf{5}$ \\
\hline Total Gas Flow (slpm) & 9.94 & 9.94 & 9.94 & 9.94 & 9.94 \\
\hline $\mathrm{CO}_{2}$ in (\%) & 6.28 & 6.28 & 6.28 & 6.28 & 6.28 \\
\hline $\mathrm{H}_{2} \mathrm{O}$ in (\%) & 6.24 & 6.24 & 6.24 & 6.24 & 6.24 \\
\hline $\mathrm{CO}_{2}$ removed (g) & 24.3 & 18.9 & 22.4 & 19.7 & 17.9 \\
\hline Capacity used (\%) & 50.4 & 39.2 & 46.5 & 40.9 & 37.1 \\
\hline \hline
\end{tabular}

Table 4. Properties of $40 \%$ Supported Potassium Carbonate

\begin{tabular}{|c|c|}
\hline BET Surface Area & $4.48\left(\mathrm{~m}^{2} / \mathrm{g}\right)$ \\
\hline \multicolumn{2}{|l|}{ Mercury Porosimetry Data } \\
\hline Total Intrusion Volume & $0.3084 \mathrm{ml} / \mathrm{g}$ \\
\hline Total Pore Volume & $19.693 \mathrm{~m}^{2} / \mathrm{g}$ \\
\hline Median Pore Diameter (volume) & $4670 \AA$ \\
\hline Median Pore Diameter (area) & $79 \AA$ \\
\hline Average Pore Diameter & $276 \AA$ \\
\hline Bulk Density & $1.4652 \mathrm{~g} / \mathrm{ml}$ \\
\hline Skeletal Density & 2.6731 \\
\hline Porosity & $45.1861 \%$ \\
\hline
\end{tabular}

BET surface area measurements were also conducted on the fines generated during production of the sorbent following calcination. These data are given in Table 5.

Table 5. BET Surface Areas of Fines from $\mathbf{4 0} \%$ Supported Material

\begin{tabular}{l|l}
\multicolumn{1}{c|}{ Process Conditions } & \multicolumn{1}{c}{ BET Surface Area $\left(\mathrm{m}^{2} / \mathbf{g}\right)$} \\
\hline Calcined at $400^{\circ} \mathrm{C}$ & 13.87 \\
\hline Calcined at $500^{\circ} \mathrm{C}$ & 11.62 \\
\hline \hline
\end{tabular}




\subsubsection{Physical Properties of 10\% Supported Potassium Carbonate}

The properties of the $10 \%$ supported potassium carbonate materials scheduled for fluidized bed reactor testing during the next quarter are given in Table 6.

Table 6. Properties of $10 \%$ Supported Potassium Carbonate

\begin{tabular}{|c|c|}
\hline BET Surface Area & $92.94 \mathrm{~m}^{2} / \mathrm{g}$ \\
\hline Compact Bulk Density & $0.66 \mathrm{~g} / \mathrm{ml}$ \\
\hline \multicolumn{2}{|l|}{ Mercury Porosimetry Data } \\
\hline Total Intrusion Volume & $0.4609 \mathrm{ml} / \mathrm{g}$ \\
\hline Total Pore Volume & $66.807 \mathrm{~m}^{2} / \mathrm{g}$ \\
\hline Median Pore Diameter (volume) & $1170 \AA$ \\
\hline Median Pore Diamere (area) & $69 \AA$ \\
\hline Average Pore Diameter & $276 \AA$ \\
\hline Bulk Density & $1.1624 \mathrm{~g} / \mathrm{ml}$ \\
\hline Skeletal Density & 2.2039 \\
\hline Porosity & $53.5777 \%$ \\
\hline \multicolumn{2}{|l|}{ Particle Size Distribution } \\
\hline$+150 \mu$ & $15.42 \%$ \\
\hline$-150+125 \mu$ & $9.45 \%$ \\
\hline$-125+106 \mu$ & $23.88 \%$ \\
\hline$-106+90 \mu$ & $10.95 \%$ \\
\hline$-90+75 \mu$ & $26.87 \%$ \\
\hline$-75+53 \mu$ & $12.94 \%$ \\
\hline$-53 \mu$ & $0.50 \%$ \\
\hline
\end{tabular}

\subsection{Thermodynamic Analysis}

In the April 2002 Quarterly Report (Green et al., 2002b), equilibrium data for the carbonization of $\mathrm{Na}_{2} \mathrm{CO}_{3}$ to Wegscheider's Salt, derived from the interpretation of LSU's and RTI's TGA carbonization experiments, were compared to established equilibrium data produced by Church and Dwight and the HSC Chemistry program. The carbonization of $\mathrm{Na}_{2} \mathrm{CO}_{3}$ to Wegscheider's 
Salt is given by the reverse of the following reaction

$$
\frac{2}{3} \mathrm{Na}_{2} \mathrm{CO}_{3} \cdot 3 \mathrm{NaHCO}_{3} \rightarrow \frac{5}{3} \mathrm{Na}_{2} \mathrm{CO}_{3}+\mathrm{CO}_{2}+\mathrm{H}_{2} \mathrm{O}
$$

Reaction 1

The equilibrium constant, $\mathrm{K}_{1}$, for Reaction 1 is given by

$$
\mathrm{K}_{1}=\mathrm{P}_{\mathrm{CO}_{2}} \mathrm{P}_{\mathrm{H}_{2} \mathrm{O}}
$$

where $\mathrm{P}_{\mathrm{CO} 2}$ and $\mathrm{P}_{\mathrm{H} 2 \mathrm{O}}$ are the partial pressures of $\mathrm{CO}_{2}$ and $\mathrm{H}_{2} \mathrm{O}$, reacting gas, atm.

As mentioned above, equilibrium data for Reaction 1 were derived from two distinctly different TGA experiments: one set was carried out at various temperatures but at a constant given temperature throughout the length of an individual experiment; and the other set was carried out at a variety of heating rates. The derivation of the equilibrium data has been described previously by Green et al., 2002 and the derived equilibrium data are summarized below in Table 7.

\section{TABLE 7. Equilibrium Constants and Temperatures Determined from TGA} Experiments for Reaction 1.

\begin{tabular}{c|c|l}
\hline Equilibrium Constant $\mathrm{K}_{1}, \mathrm{~atm}^{2}$ & Equilibrium Temperature, $\mathrm{T}_{\text {eq }}, \mathrm{K}$ & TGA Experiment type \\
\hline $1.28 \times 10^{-2}$ & 355.6 & Constant temperature \\
\hline $4.42 \times 10^{-3}$ & 348.7 & Constant heating rate \\
\hline \hline
\end{tabular}

As shown in Figure 18 of Green, et al. 2002b, the derived equilibrium data listed in Table 7 are very close to the equilibrium data predicted by the HSC Chemistry; however, as pointed out in that report, the HSC Chemistry predicts disturbing violations of Le Chatelier's principle for the $\mathrm{Na}_{2} \mathrm{CO}_{3}-$ Wegscheider - $\mathrm{NaHCO}_{3}$ system. For a given equilibrium temperature the equilibrium constant predicted by the data of Church and Dwight is a factor of eight smaller than the equilibrium constant derived from the TGA carbonization data. Based on these observations concerning the equilibrium data of Church and Dwight, and HSC Chemistry, the data shown in Table 7 were correlated in the form

$$
K_{1}=2.445 \times 10^{18} e^{-16614 / T_{\text {eq }}}
$$

Equation 6 was derived using the enthalpy of reaction, for Reaction $1, \Delta \mathrm{H}_{\mathrm{rxn} 1}$, given by the thermodynamic data of Vanderzee (1982), or

$$
\Delta \mathrm{H}_{\mathrm{rxn1}}=33,012 \mathrm{cal} / \mathrm{gmol} \mathrm{CO}_{2}
$$

at $\mathrm{T}=352 \mathrm{~K}$.

Actually the enthalpies of reaction from the three sources of thermodynamic data used, that is, Church and Dwight, HSC Chemistry and Vanderzee, were practically the same. The 
preexponential constant in Equation 6 was calculated by minimizing the following function with respect to $A$

$$
\mathrm{S}=\sum_{\mathrm{i}=1}^{2}\left(\mathrm{~K}_{1 \mathrm{i}}-\mathrm{A} \mathrm{e}^{-16614 / \mathrm{T}_{\mathrm{i}}}\right)^{2}
$$

where $\mathrm{K}_{1 \mathrm{i}}$ is the $\mathrm{i}^{\text {th }}$ experimentally measured equilibrium constant for

Reaction 1 shown in Table 7, atm²,

$\mathrm{T}_{\mathrm{i}}$ is the $\mathrm{i}^{\text {th }}$ experimentally measured equilibrium temperature shown in Table $7, \mathrm{~K}$,

and $\quad A$ is the preexponential constant, $\mathrm{atm}^{2}$.

In the past two quarters, $\mathrm{RTI}$ has directed considerable attention toward examining $\mathrm{K}_{2} \mathrm{CO}_{3}$ as a potential dry adsorbent of $\mathrm{CO}_{2}$ from flue gas. Based on TGA carbonization and calcination data, which has not been entirely consistent and reproducible, $\mathrm{K}_{2} \mathrm{CO}_{3}$ appears to rapidly react with $\mathrm{CO}_{2}$ and $\mathrm{H}_{2} \mathrm{O}$ to form either a potassium analog of the sodium-based Wegscheider's Salt or potassium bicarbonate. Since the Wegscheider's Salt analog has not yet been found in the literature, no thermodynamic data are available with which to do analyses of processes involving such a salt. For the time being, RTI's analyses of potassium carbonate based processes will be focused on the formation of potassium bicarbonate from the carbonization of the carbonate.

The reaction of carbon dioxide and water vapor with potassium carbonate to form potassium bicarbonate is given by the reverse of the following reaction

$$
2 \mathrm{KHCO}_{3} \rightleftharpoons \mathrm{K}_{2} \mathrm{CO}_{3}+\mathrm{CO}_{2}+\mathrm{H}_{2} \mathrm{O}(\mathrm{g})
$$

The equilibrium constant for Reaction $2, \mathrm{~K}_{2}$, is given by

$$
\mathrm{K}_{2}=\mathrm{P}_{\mathrm{CO}_{2}} \mathrm{P}_{\mathrm{H}_{2} \mathrm{O}}
$$

Using enthalpy, Gibbs free energy and heat capacity data, the equilibrium constant can be computed as

$$
\text { en } K_{2}=-26.97-13887 / T+10.589 \ell n T-1.0967 \times 10^{-2} \mathrm{~T}-1.7311 \times 10^{5} / \mathrm{T}^{2}
$$

Over a temperature range of 300 to $400 \mathrm{~K}$, Equation 10 can be approximated by

$$
\ell \mathrm{nK}_{1}=39.381-17237 / \mathrm{T}
$$

In this temperature range the heat of reaction for Reaction 2 is approximately 


$$
\Delta \mathrm{H}_{\mathrm{Rxn2}} \approx 17237 * 1.987=34250 \frac{\mathrm{cal}}{\mathrm{gmol} \mathrm{CO}_{2}}
$$

In using either sodium or potassium carbonates to absorb carbon dioxide from flue gas, an idea of the approximate temperature at which the carbonizer might operate can be obtained using Equations 6 and 11, respectively. For a flue gas containing approximately $16 \% \mathrm{H}_{2} \mathrm{O}$ and $8 \%$ $\mathrm{CO}_{2}$ at 1 atm pressure, Equation 6 predicts that the reaction of $\mathrm{CO}_{2}$ with sodium carbonate would need to be carried out at temperatures less than $83^{\circ} \mathrm{C}$, and, for potassium carbonate, Equation 11 predicts operating temperatures less than $121^{\circ} \mathrm{C}$ would be required. Thus, the potassium carbonate based processes have the potential to operate at higher temperatures than the sodium carbonate based $\mathrm{CO}_{2}$ removal process. Whether this fact makes one process superior to the other has not been fully evaluated.

The temperature at which processes using sodium or potassium based sorbents can operate will be considerably lower than those predicted by Equation 6 or 11, respectively, for the following reasons:

1. The concentration of $\mathrm{CO}_{2}$ and $\mathrm{H}_{2} \mathrm{O}$ will decrease with extent of adsorption of $\mathrm{CO}_{2}$ and $\mathrm{H}_{2} \mathrm{O}$ from the flue gas; thus by Equation 6 or 11 the maximum temperature at which the carbonation reaction will proceed will decrease. At the same time the carbonation reaction is releasing large quantities of heat causing the gas/solid temperatures to rise unless measures are taken to remove heat in the carbonation reactor by processes such as evaporation of injected liquid water. Hence, the temperature of the gas and solids entering the carbonizer must be considerably lower than the equilibrium temperature predicted by Equation 6 or 11 based on the entering gas composition.

2. Based on TGA experiments the carbonization rate will be proportional to the difference between the equilibrium temperature calculated by Equation 6 (or Equation 11 for $\mathrm{K}_{2} \mathrm{CO}_{3}$ ) based on bulk gas concentrations and the bulk gas temperature. While the carbonization reactor for a commercial-scale process will not be a TGA reactor, it is reasonable to assume that the reaction rate in large scale reactor such as a fast fluidized bed would also be roughly proportional to the difference in equilibrium temperature and the bulk gas/solid temperature. Therefore, in order to get reasonable carbonization rates the entering gas/solid temperature will need to be considerably less than the entering equilibrium temperature.

In the past three quarterly reports RTI has reported a number of carbonation experiments carried out in the 2" fluidized bed reactor. Comparison of the maximum temperature achieved in these experiments with the equilibrium temperature computed from the inlet gas composition yields some interesting results.

Typically, in the fluidized bed experiments, the reactor is loaded with either sodium bicarbonate or potassium carbonate. The solid sorbent is heated to a fairly high temperature as described in the quarterly reports. In the case of sodium bicarbonate sorbent, the material is calcined to carbonate. The bed is cooled under a flow of gas to roughly $60^{\circ} \mathrm{C}$. After introduction of $\mathrm{CO}_{2}$ and $\mathrm{H}_{2} \mathrm{O}$ in the simulated flue gas to the bed, the bed self-heats rapidly to a maximum temperature as shown, for example, in Figure 30 of the present report. It will be shown below that the maximum observed temperature approaches the equilibrium temperature calculated 
based on the inlet gas composition and usually does not exceed this temperature. The initial rapid increase in the measured temperature is due to the heat released by the carbonization reaction. As the bed/gas temperature approaches the equilibrium temperature the reaction rate will slow due to the fact that the reaction rate is roughly proportional to the difference between the equilibrium temperature and the gas temperature. In addition, the carbonization rate will decrease as the carbonate is exhausted from bed solids. As the reaction slows the amount of heat carried out of the reactor by heating gas will exceed the rate of generation of heat by reaction and the bed/gas temperature will decrease from the maximum observed temperature. Table 8 shows a comparison of maximum observed temperature in the fluidized bed and the equilibrium temperature calculated based the inlet gas composition using either Equation 6 for sodium carbonate case or Equation 11 for the potassium case.

Table 8 shows that in most of the fluidized bed experiments, the maximum observed temperature parallels the equilibrium temperature calculated based on the inlet gas partial pressures of carbon dioxide and water vapor.

\subsection{Thermodynamic Consideration for $\mathrm{CO}_{2}$ Removal Process Design}

The expressions for the chemical equilibrium constants given by Equations 6 and 11 for the carbonation of sodium carbonate to Wegscheider's Salt and potassium carbonate to potassium bicarbonate, respectively, can be used to give valuable information concerning the design of a dry $\mathrm{CO}_{2}$ removal system. In the sections below, examples will be considered which use a flue gas composition containing $8 \%$ carbon dioxide and $16 \%$ water vapor. Extension of the results to other compositions will be apparent.

The carbonizer will be considered to be a fast fluidized bed in which flue gas and solids flow concurrently. This system should minimize pressure drop and equipment diameters in comparison to fixed bed or bubbling fluidized reactors.

In the discussion above it was found that for a flue gas containing $8 \% \mathrm{CO}_{2}$ and $16 \% \mathrm{H}_{2} \mathrm{O}(\mathrm{v})$ using a sodium carbonate sorbent, the maximum temperature at which carbonation would take place is $83^{\circ} \mathrm{C}$. Assuming that $\mathrm{CO}_{2}$ and $\mathrm{H}_{2} \mathrm{O}$ are removed from the flue gas, the maximum allowable temperature is given by the solution of the following equation:

$$
\frac{(16-x)(8-x)}{(100-2 x)^{2}}=K_{1}
$$

where $\mathrm{x}$ is the moles of $\mathrm{CO}_{2}$ removed from 100 moles of flue gas.

The derivation of Equation 15 is explained in Table 9. A calculation basis of 100 moles of flue gas containing $16 \% \mathrm{H}_{2} \mathrm{O}$ and $8 \% \mathrm{CO}_{2}$ is assumed. Then $\mathrm{x}$ moles of $\mathrm{CO}_{2}$ are assumed to be removed from the flue gas. Lastly, as shown in Table 9, the equilibrium constant at this new composition is computed. 
Table 8. Comparison of Equilibrium Temperature Calculated Based on Inlet Gas Composition and Maximum Observed Fluidized Bed Temperature.

Material: Calcined SBC \#3 October 2001 Quarterly Report

\begin{tabular}{c|c|c|c|c|c}
\hline Cycle & 1 & 2 & 3 & 4 & 5 \\
\hline Max temp, ${ }^{\circ} \mathrm{C}$ & 84 & 85 & 70 & 62 & 49 \\
\hline Equilibrium $\mathrm{Temp}^{\circ}{ }^{\circ} \mathrm{C}$ & 88 & 90 & 87 & 82 & 80 \\
\hline
\end{tabular}

Material: Calcined Trona T-50 January 2002 Quarterly Report

\begin{tabular}{c|c|c|c|c|c}
\hline Cycle & 1 & 2 & NA & NA & NA \\
\hline Max temp, ${ }^{\circ} \mathrm{C}$ & 88 & 73 & NA & NA & NA \\
\hline Equilibrium Temp, ${ }^{\circ} \mathrm{C}$ & 86 & 81 & NA & NA & NA \\
\hline
\end{tabular}

Material: $\mathrm{K}_{2} \mathrm{CO}_{3}$ April 2002 Quarterly Report

\begin{tabular}{c|c|c|c|c|c}
\hline Cycle & NA & NA & NA & NA & NA \\
\hline Max temp, ${ }^{\circ} \mathrm{C}$ & 115 & NA & NA & NA & NA \\
\hline Equilibrium Temp, ${ }^{\circ} \mathrm{C}$ & 120 & NA & NA & NA & NA \\
\hline
\end{tabular}

Material: Supported $\mathrm{K}_{2} \mathrm{CO}_{3}\left(40 \% \mathrm{~K}_{2} \mathrm{CO}_{3}\right)$ Present Report

\begin{tabular}{c|c|c|c|c|c}
\hline Cycle & 1 & 2 & 3 & 4 & 5 \\
\hline Max temp, ${ }^{\circ} \mathrm{C}$ & 90 & 110 & 104 & 110 & 103 \\
\hline Equilibrium Temp, ${ }^{\circ} \mathrm{C}$ & 120 & 120 & 120 & 120 & 120 \\
\hline \hline
\end{tabular}

Suppose $50 \%$ of the $\mathrm{CO}_{2}$ is removed from the flue gas or $\mathrm{x}=4$. Then by Equation 13 , the equilibrium constant, $\mathrm{K}_{1}$, will equal $5.671 \times 10^{-3} \mathrm{~atm}^{2}$. Using Equation 6 the maximum allowable temperature below which the carbonation reaction will proceed is $76.7^{\circ} \mathrm{C}$. Figure 31

summarizes the results of these calculations for various $\mathrm{CO}_{2}$ removals. Figure 31 shows two sets of results: one for $\mathrm{CO}_{2}$ removal via sodium carbonate-based sorbent computed using Equation 13; and the other for potassium carbonate based sorbents. The results for the potassium based sorbent were calculated using Equation 13 with the equilibrium constant for Reaction $1, \mathrm{~K}_{1}$, being replaced by the equilibrium constant for Reaction 2. The two curves in Figure 31 define the region of temperature and $\mathrm{CO}_{2}$ removal in which operation of the sodium and potassium carbonate processes are possible. For example, the region above the curve marked " $\mathrm{Na}_{2} \mathrm{CO}_{3}$ " is the region in which the removal of $\mathrm{CO}_{2}$ will not proceed using $\mathrm{Na}_{2} \mathrm{CO}_{3}$ based sorbent. 
Table 9. Calculation of the equilibrium constant for the carbonizer after the absorption of $x$ moles of $\mathrm{CO}_{2}$ per 100 moles of flue gas

\begin{tabular}{l|l|l}
\hline \hline Component & Initial Moles & Equilibrium Moles \\
\hline $\mathrm{CO}_{2}$ & 8 & $8-x$ \\
\hline $\mathrm{H}_{2} \mathrm{O}$ & 16 & $16-x$ \\
\hline Inert & 76 & 76 \\
\hline Total Moles & 100 & $100-2 \mathrm{x}$ \\
\hline
\end{tabular}

$$
K=P_{\mathrm{CO}_{2}} P_{\mathrm{H}_{2} \mathrm{O}}=\frac{(8-x)(16-x)}{(100-2 x)^{2}}
$$

Total Pressure $\approx 1 \mathrm{~atm}$

As can be seen from Figure 31, the potassium carbonate based sorbent gives a wider range of practical operating temperatures than the sodium based sorbent.

Another factor that affects the performance of the carbonizer is the operating line that describes the temperature of gas/sorbent as a function of $\mathrm{CO}_{2}$ removal from the flue gas. The following discussion is based on a fast fluidized bed carbonizer with a flue gas velocity of roughly 4.9 $\mathrm{m} / \mathrm{sec}(15 \mathrm{ft} / \mathrm{sec})$ and a bed density is $0.032 \mathrm{~g} / \mathrm{cm}^{3}\left(21 \mathrm{~b} / \mathrm{ft}^{3}\right)$. The bed density of $0.032 \mathrm{~g} / \mathrm{cm}^{3}$ is approaching the upper limit used in fast fluidized beds; however, this density will help insure that the carbonization kinetics, based on a unit volume of bed, will be as rapid as possible. Under the above assumptions, for every $100 \mathrm{kgmol}$ of flue gas treated in carbonizer, $79,130 \mathrm{~kg}$ of sorbent will be fed to the carbonizer. Assuming constant heat capacities of the solid phase and a solid heat capacity of $0.25 \mathrm{cal} / \mathrm{gmol} \mathrm{K}$, ignoring the sensible heat of the gas with respect to that of the solid sorbent, and neglecting the increase in solid mass flow rate due to incorporation of $\mathrm{CO}_{2}$ and $\mathrm{H}_{2} \mathrm{O}$ into the sorbent gives the following heat balance operating lines for the carbonizer:

$$
\begin{array}{r}
\text { For } \mathrm{Na}_{2} \mathrm{CO}_{3} \text { based sorbent } \\
\Delta \mathrm{T}=1.67 \mathrm{x} \\
\frac{\text { For } \mathrm{K}_{2} \mathrm{CO}_{3} \text { based sorbent }}{\Delta \mathrm{T}=1.73 \mathrm{x}}
\end{array}
$$

where $\Delta \mathrm{T}$ is the increase in solid/gas temperature relative to the inlet temperature, ${ }^{\circ} \mathrm{C}$ $\mathrm{X}$ is $\mathrm{gmol} \mathrm{CO}_{2}$ removed from flue gas per $100 \mathrm{gmol}$ of flue gas treated 


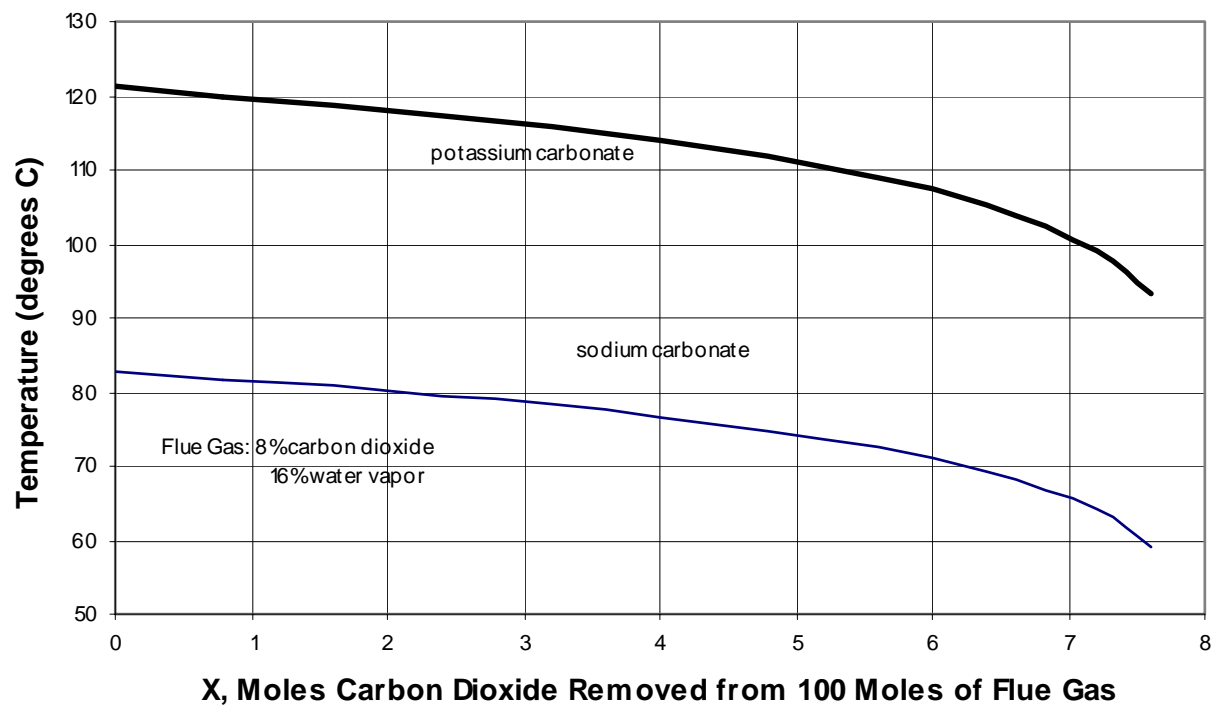

Figure 31. Equilibrium temperatures for the carbonizer at various levels of $\mathrm{CO}_{2}$ adsorption.

In the derivation of the heat balances, Equation 14 and 15 above, the enthalpies of reaction were assumed to be constant with respect to temperature and equal to these given by Equation 7 and 12, respectively. Graphing the heat balance operating line, such as that given by Equation 14 for the sodium carbonate-based sorbent, along with the corresponding equilibrium curve shown in Figure 31, can yield interesting operational characteristics for the carbonizer. Such a graph is shown in Figure 32. In Figure 32 the heat balance line has been graphed assuming the inlet temperature of the carbonizer is $60^{\circ} \mathrm{C}$. Recalling that in the region above the equilibrium curve the carbonization reaction stops, it can be seen from Figure 32 that the maximum possible removal of $\mathrm{CO}_{2}$ is roughly

$$
\frac{6.2}{8.0} \times 100=77.5 \%
$$

and that the outlet temperature of the carbonizer will approach $70^{\circ} \mathrm{C}$. Higher removals of $\mathrm{CO}_{2}$ can be obtained by lowering the inlet temperature, removing heat from the carbonizer and/or vaporizing liquid water droplets inject into the carbonizer. These steps will have the effect of shifting the operating line downward. Water injection will also shift the equilibrium curve upward. Both of these shifts should yield higher $\mathrm{CO}_{2}$ removals as can be visualized in Figure 32. In addition, these shifts might yield faster carbonization kinetics based on the hypothesis that, like the carbonization rate in the TGA, the rate in the fast fluidized bed reactor will be roughly proportional to the temperature difference between the operating line and the equilibrium curve. 


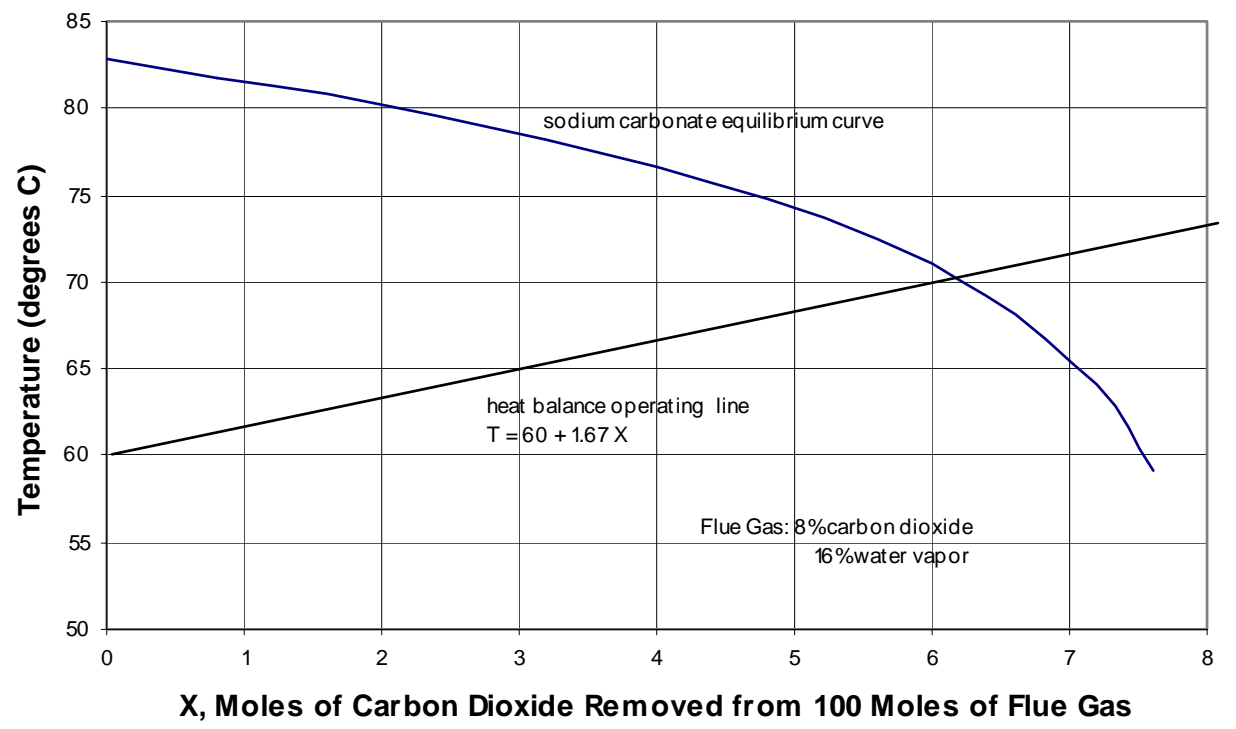

\section{Figure 32. Graphical determination of outlet temperature and $\mathrm{CO}_{2}$ removed in the carbonizer.}

Under the assumptions made above about the operation of the fast fluidized bed carbonizer, primarily that the solid loading is roughly $0.032 \mathrm{~g} / \mathrm{cm}^{3}\left(2 \mathrm{lb} / \mathrm{ft}^{3}\right)$, the mass flow rate of solids through the carbonizer will be roughly 30 times the mass flow rate of the flue gas. Since the $\mathrm{CO}_{2}$ concentration in the inlet flue gas is roughly $8 \%$ (and if it is possible to get around the equilibrium limitations on the extent of $\mathrm{CO}_{2}$ reaction), removal of $100 \%$ of the $\mathrm{CO}_{2}$ from the flue gas would approximately give a $13.4^{\circ} \mathrm{C}$ temperature rise as computed by Equation 14 . Most of the heat released by carbonization could be stored as sensible heat of the solid sorbent without unduly restricting $\mathrm{CO}_{2}$ removal efficiency; although removals approaching 90 to $100 \%$ would not be possible due to equilibrium restraints. At lesser solid loading, greater temperature rises would occur for a given $\mathrm{CO}_{2}$ removal efficiency. To keep equilibrium restrictions from becoming efficiency-limiting, cooling of the carbonizer would be required. This could take the form of external cooling which is probably not practical in large scale, large diameter equipment.

Another alternative might be to vaporize atomized water injected into the carbonizer. Heat removed from the carbonizer by water vaporization or external cooling or by some other means will need to be balanced by roughly an equivalent magnitude of heat addition to the regenerator. Due to the large endothermic enthalpy of reaction for the regeneration of the loaded sorbent and the sheer mass of the $\mathrm{CO}_{2}$ that is desirable to be removed from the flue gas, the heat input requirement of the regenerator will be quite significant in comparison to the total heat input to the power plant at high $\mathrm{CO}_{2}$ removal efficiencies.

Another factor that can influence the operating temperatures in the carbonizers and the need for cooling is the degree to which the solids in the carbonizer are recirculated. 
First, consider $\mathrm{C} \mathrm{CO}_{2}$ removal process wherein the heat released in the $\mathrm{CO}_{2}$ adsorption is stored as sensible heat of the flowing solid which increases in temperature from inlet to the carbonizer outlet. No water will be vaporized to provide cooling. In the regenerator, the heat required by the endothermic regeneration of the sorbent will be supplied primarily by the sensible heat stored in the warm sorbent flowing from the carbonizer. Upon passage through the regenerator the sorbent cools and then is recycled back to the carbonizer. A simplified flow sheet of such conceptual $\mathrm{CO}_{2}$ removal process is shown in Figure 33.

As can be seen in Figure 33, flue gas is contacted with regenerated sorbent in the carbonizer. As carbon dioxide and water in the flue gas react with the sorbent, the sorbent is heated as has been described in detail above. The sorbent and treated flue gas are separated in a cyclone. The warm sorbent loaded with $\mathrm{CO}_{2}$ and $\mathrm{H}_{2} \mathrm{O}$ is passed to the regenerator where it is contacted with a $\mathrm{CO}_{2}$-rich sweep gas. In the regenerator, carbon dioxide and water are released from the solid into the $\mathrm{CO}_{2}$-rich sweep gas while the solid is cooled due to the endothermicity of the regeneration reaction. Following the regeneration riser, the regenerated sorbent and sweep gas are separated in a cyclone. The cool, regenerated sorbent is then recycled to the bottom of the carbonizer riser.

The sweep gas leaving the regeneration cyclone is cooled to condense some of the water that is picked up by the regenerator sweep gas and is used as a method to control the level of water vapor in the sweep gas that is recycled to the bottom of the regenerator riser. A purge stream is then removed from the sweep gas loop. This stream contains carbon dioxide and water and is suitable for further processing and eventual sequestration.

Although a great deal of research work on the project has gone into developing and understanding the carbonization aspects, the regeneration step may be more complex and intriguing than carbonization.

In the paragraphs below the regeneration step will be looked at in more detail, and the question of whether the heat requirements for the carbonization and regeneration steps can be supplied by the sensible heat of the circulating sorbent will be addressed.

To simplify the analysis of the regeneration step, it will be assumed that the inlet molar flow rate of the flue gas and regenerator sweep gas are equal. Based on the assumptions made for the carbonizer, as discussed above, the equality of the flue gas and sweep gas is not unreasonable in that a high loading of solids in the sweep gas will be obtained with a bed density of 0.032 $\mathrm{g} / \mathrm{cm}^{3}\left(2 \mathrm{lb} / \mathrm{ft}^{3}\right)$ and the sweep gas flow will not be excessive in comparison to the flue gas flow. One way to reduce the solid loading in the regenerator would be to have a circulating fast fluidized bed system for the carbonizer and take only a small bleed stream of the circulating cabonizer solids for regeneration; however such a set up would require the use of cooling in the carbonizer and a major source of heat other than the sensible heat of the solids in the regenerator. For the present discussion it will be assumed that the carbonizer/regenerator configuration is as shown in Figure 33.

The analysis of the regeneration process is very similar to that of the carbonization process. One of the major assumptions made in the analysis of the carbonization step was that the flue gas contained $8 \% \mathrm{CO}_{2}$ and the calculation basis was assumed to be 100 moles of the flue gas. 


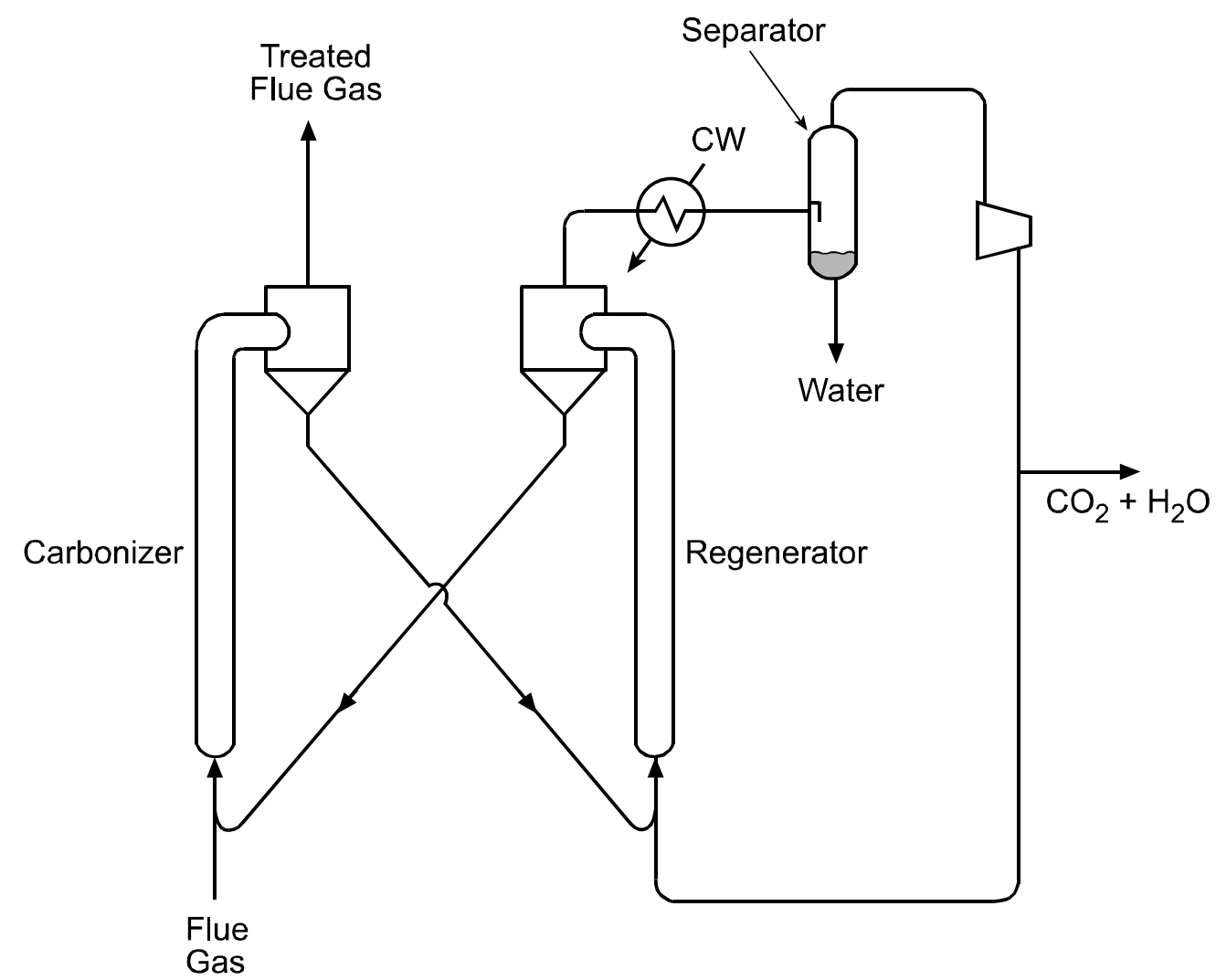

Figure 33. Dry sorbent $\mathrm{CO}_{2}$ removal process utilizing sorbent as heat carrier.

The analysis of the regenerator, the calculation basis will also be assumed to be 100 moles of sweep gas flowing to the inlet of the regenerator riser and that a maximum of 8 moles of $\mathrm{CO}_{2}$ can be transferred from the sorbent to the sweep gas.

The equilibrium equations, which limit the extent of possible regeneration of the sorbent, are based on Reaction 1 for sodium carbonate-based sorbent and Reaction 2 for potassium carbonate. Using a development similar to that used for the carbonizer, the following equilibrium relations for the regeneration process have been developed:

\section{For $\mathrm{CO}_{2} / \underline{\mathrm{H}}_{2} \mathrm{O}$ Sweep Gas}

$$
\mathrm{K}_{\mathrm{i}}=\mathrm{P}_{\mathrm{CO}_{2}} \mathrm{P}_{\mathrm{H}_{2} \mathrm{O}}=\frac{\left(100\left(1-\mathrm{y}_{\mathrm{H}_{2} \mathrm{O}}\right)+Z\right)\left(100 \mathrm{y}_{\mathrm{H}_{2} \mathrm{O}}+\mathrm{Z}\right)}{(100+2 \mathrm{Z})^{2}}
$$

where $\quad y_{\mathrm{H}_{2} \mathrm{O}}$ is the mole fraction water vapor in the sweep gas $\mathrm{Z}$ is the moles $\mathrm{CO}_{2}$ transfer from the sorbent to the sweep gas per 100 moles of inlet sweep gas 
For Insert Sweep Gas

$$
\mathrm{K}_{\mathrm{i}}=\mathrm{P}_{\mathrm{CO}_{2}} \mathrm{P}_{\mathrm{H}_{2} \mathrm{O}}=\frac{\mathrm{Z}^{2}}{(100+2 \mathrm{Z})^{2}}
$$

In Equations 17 and 18, the subscript "i" of the equilibrium constants refers to sodium carbonate based sorbent for $\mathrm{i}=1$ and potassium carbonate based sorbent for $\mathrm{i}=2$. The development of these equations is summarized in Table 10.

Table 10. Development of equilibrium curves for the regenerator.

\begin{tabular}{l|l|l}
\hline \hline $\mathrm{CO}_{2} / \mathrm{H}_{2} \mathrm{O}$ Sweep Gas & Initial Moles & Equilibrium Moles \\
\hline Component & $100\left(1-\mathrm{y}_{\mathrm{H}_{2} \mathrm{O}}\right)$ & $100\left(1-\mathrm{y}_{\mathrm{H}_{2} \mathrm{O}}\right)+\mathrm{Z}$ \\
\hline $\mathrm{CO}_{2}$ & $100 \mathrm{y}_{\mathrm{H}_{2} \mathrm{O}}$ & $100 \mathrm{y}_{\mathrm{H}_{2} \mathrm{O}}+\mathrm{Z}$ \\
\hline $\mathrm{H}_{2} \mathrm{O}$ & 0 & 0 \\
\hline Inert & 0 & $100+2 \mathrm{Z}$ \\
\hline Total Moles & 100 & \\
\hline
\end{tabular}

$$
K=P_{\mathrm{CO}_{2}} P_{\mathrm{H}_{2} \mathrm{O}}=\frac{\left(100\left(1-\mathrm{y}_{\mathrm{H}_{2} \mathrm{O}}\right)+Z\right)\left(100 \mathrm{y}_{\mathrm{H}_{2} \mathrm{O}}+Z\right)}{(100+2 Z)^{2}}
$$

\begin{tabular}{|c|c|c|}
\hline Component & Initial Moles & Equilibrium Moles \\
\hline $\mathrm{CO}_{2}$ & 0 & $Z$ \\
\hline $\mathrm{H}_{2} \mathrm{O}$ & 0 & Z \\
\hline Inert & 100 & 100 \\
\hline Total Moles & 100 & $100+2 Z$ \\
\hline
\end{tabular}

$$
\mathrm{K}=\mathrm{P}_{\mathrm{CO}_{2}} \mathrm{P}_{\mathrm{H}_{2} \mathrm{O}}=\frac{\mathrm{Z}^{2}}{(100+2 \mathrm{Z})^{2}}
$$

Equations 17 and 18 have been applied to regeneration in the special cases of the inlet sweep gas containing no steam, only carbon dioxide and the case of using an inert sweep gas. These cases are not of interest from a practical standpoint but give some insight into TGA regeneration experiments. The results of these cases are summarized in Figure 34. 


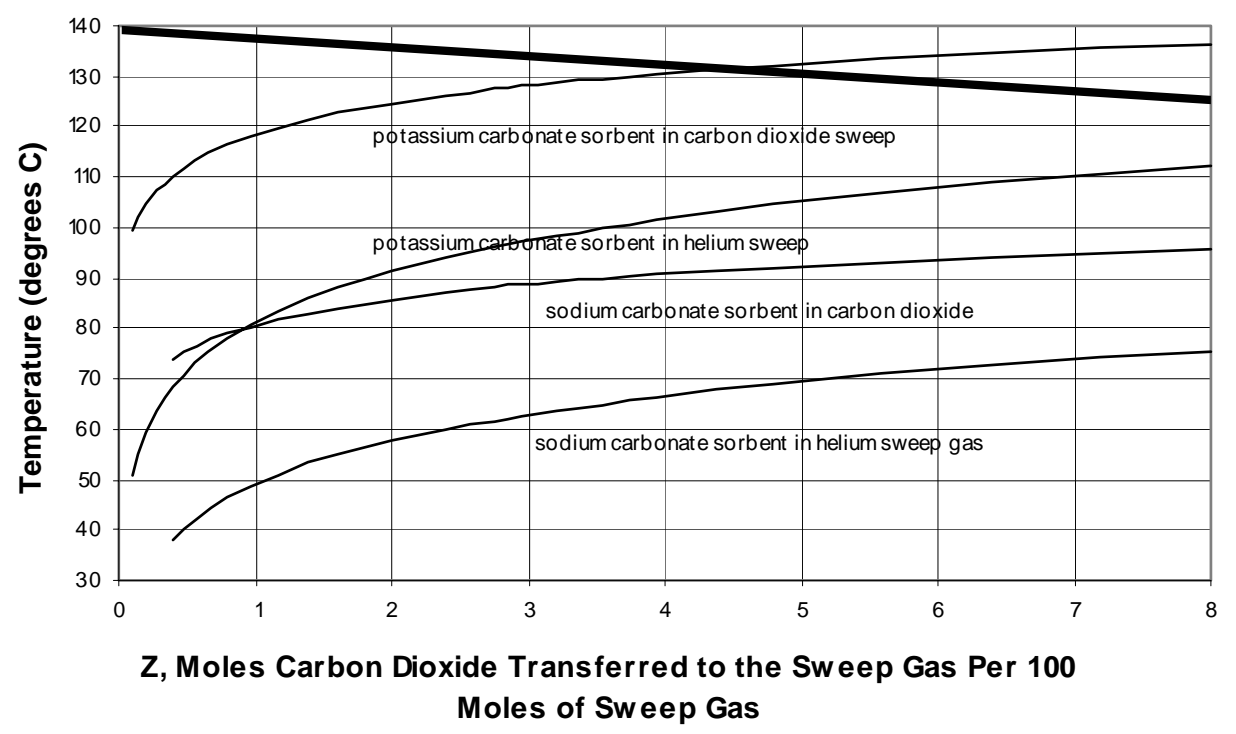

Figure 34. Equilibrium curves for the moles $\mathrm{CO}_{2}$ transferred to the sweep gas per 100 moles of inlet sweep gas.

In Figure 34 the areas above the equilibrium curves for the four different cases shown represent the conditions of temperature and $\mathrm{CO}_{2}$ transfer in which regeneration can occur for the respective cases. Figure 34 shows that regeneration of sodium carbonate sorbents can be accomplished at substantially lower temperatures, roughly $40^{\circ} \mathrm{C}$ lower, than potassium carbonate sorbents. Also as shown in Figure 34, inert sweep gas such as helium can lower regeneration temperature over using pure $\mathrm{CO}_{2}$ as a sweep gas. This fact is important in the interpretation of experiments which show rapid regeneration in helium but may not be as rapid in $\mathrm{CO}_{2}$ sweep gas. Figure 34 shows that the smaller the amount of $\mathrm{CO}_{2}$ accumulated in the sweep gas, the lower the permissible regeneration temperature. In TGA regeneration experiments, large amounts of sweep gas are passed over the sample pan; and therefore the amount of $\mathrm{CO}_{2}$ that accumulates in the sweep gas over the sample will be very small, approaching zero percent. At these low accumulations the minimum regeneration temperatures drop rapidly. Thus, such experiments could yield misleading information about the rate and temperature at which regeneration can take place in the presence of a real sweep gas which will contain large quantities of accumulated $\mathrm{CO}_{2}$ and water vapor.

As in the case of carbonization; simple heat balance operating lines can be derived for the fast fluidized bed regenerator. In the example as shown in Figure 33 and explained in the text, the regeneration is set up as a mirror of the carbonization process. Thus the heat balance operating lines for the regeneration are

$$
\text { For } \mathrm{Na}_{2} \mathrm{CO}_{3} \text { based sorbent }
$$

$$
\Delta \mathrm{T}=-1.67 \mathrm{Z}
$$


For $\mathrm{K}_{2} \mathrm{CO}_{3}$ based sorbent

$\Delta T=-1.73 Z$

Equation (20) has been graphed on Figure 34 for a inlet temperature to the regenerator of $140^{\circ} \mathrm{C}$. The point at which the heat balance operating line crosses the equilibrium curve, regeneration cannot proceed. As shown in Figure 34 for potassium carbonate sorbent, the regeneration will be possible until 4.7 moles of $\mathrm{CO}_{2}$ per 100 moles of inlet $\mathrm{CO}_{2}$ sweep gas are accumulated. For this case the outlet temperature of the Regenerator will be $132^{\circ} \mathrm{C}$. This is an unfortunate circumstance because the outlet temperature of the regenerator is the inlet temperature (ignoring sensible heat of the flue gas and sweep gas) of the carbonizer.

Referring to Figure 31, it can be seen that for the $\mathrm{K}_{2} \mathrm{CO}_{3}$ sorbent and the flue gas containing $8 \%$ $\mathrm{CO}_{2}$ and $16 \% \mathrm{H}_{2} \mathrm{O}$, the maximum possible inlet temperature of the carbonizer is $121^{\circ} \mathrm{C}$, not $132^{\circ} \mathrm{C}$. Therefore, for the process shown Figure 33, it is not possible to capture $\mathrm{CO}_{2}$ in the carbonizer assuming the inlet to the regenerator is at $140^{\circ} \mathrm{C}$. Solving simultaneously Equations $13,14,17$ and 19 , which, with $\mathrm{y}_{\mathrm{H} 2 \mathrm{O}}$ set to zero, describe the carbonizer operating with $\mathrm{Na}_{2} \mathrm{CO}_{3}$ based sorbent and the regenerator operating with pure $\mathrm{CO}_{2}$ in the inlet sweep gas, and requiring that the inlet temperature of carbonizer equals the outlet temperature of the regenerator, yields a solution that implies that it is theoretically possible to use the sensible heat of the solid as both a heat sink in the carbonization and as heat source in the regeneration of the sorbent.

The solution of the above listed equations for $\mathrm{Na}_{2} \mathrm{CO}_{3}$-based sorbent with the regenerator inlet sweep gas being pure $\mathrm{CO}_{2}$ is given in Table 11. Also listed in this table are results obtained for solving the appropriate equations listed in the text for the case of $\mathrm{K}_{2} \mathrm{CO}_{3}$-based sorbent. As can be seen from Table 11, it is theoretically possible to remove only about 10 to $12 \%$ of the $\mathrm{CO}_{2}$ in the flue gas using the sensible heat of the solids. This range of removals is not practical due to the fact that the sorbent/gas temperatures in the carbonizer and regenerator differ from the

Table 11. Possible $\mathrm{CO}_{2}$ Removals Using the Sorbent as a Heat Absorber in the Carbonizer and a Heat Source in the Regenerator.

\begin{tabular}{l|c|c|c}
\hline \hline $\begin{array}{c}\text { Sorbent } \\
\text { Base }\end{array}$ & $\begin{array}{c}\% \mathbf{C O}_{2} \text { Removal } \\
\text { from Flue Gas }\end{array}$ & $\begin{array}{c}\text { Carbonizer } \\
\text { Inlet }\end{array}$ & $\begin{array}{c}\text { Temperature }{ }^{\circ} \mathbf{C} \\
\text { Outlet }\end{array}$ \\
\hline $\mathrm{Na}_{2} \mathrm{CO}_{3}$ & 12.0 & 80.0 & 81.6 \\
\hline $\mathrm{K}_{2} \mathrm{CO}_{3}$ & 10.6 & 119.8 & 121.3 \\
\hline \hline
\end{tabular}

equilibrium temperature by only about $2^{\circ} \mathrm{C}$. This implies that the kinetics of carbonization and regeneration would be impossibly slow. Another potential obstacle is that in actual practice, the sweep gas will contain both water vapor and carbon dioxide.

Examination of Figure 33 shows that the presence of water vapor in the sweep gas arises from the fact that cooling water may be available at $30^{\circ} \mathrm{C}$ minimum which would result in incomplete 
water removal from recycled sweep gas. Using Equation 17 the effects of various levels of water vapor in the inlet sweep gas to the regenerator can be determined. Results of applying this equation to the cases of $\mathrm{Na}_{2} \mathrm{CO}_{3}$-based and $\mathrm{K}_{2} \mathrm{CO}_{3}$-based sorbents are shown in Figures 35 and 36, respectively. In these, it can be seen that increasing the water content in the sweep greatly effects the minimum temperature needed to carry out the regeneration. The minimum temperature increases rapidly in going from 0 to $10 \%$ water vapor in the sweep gas; but the increase in the minimum regeneration temperature only increases about 6 to $9^{\circ} \mathrm{C}$ with increase in water content from 10 to $50 \%$. Examination of Equation 17 shows that the effect of increasing water content of the sweep is symmetric about $50 \%$ water vapor and that the effects of water vapor on minimum temperature are equivalent for $20 \% \mathrm{H}_{2} \mathrm{O}$ and $80 \% \mathrm{H}_{2} \mathrm{O}$, etc. The maximum in the minimum regeneration temperatures occurs at $50 \%$ water vapor in the sweep gas and is equal to about $107^{\circ} \mathrm{C}$ for $\mathrm{Na}_{2} \mathrm{CO}_{3}$-based sorbents and $149^{\circ} \mathrm{C}$ for $\mathrm{K}_{2} \mathrm{CO}_{3}$-based sorbents.

To operate the liquid/vapor separator, shown in Figure 33, to obtain $10 \%$ water vapor in the inlet regenerator sweep gas would require cooling the sweep gas leaving the regenerator from a temperature well over $107^{\circ} \mathrm{C}$ in the case of $\mathrm{Na}_{2} \mathrm{CO}_{3}$, as shown in Figure 35 , to $46^{\circ} \mathrm{C}$. This would require a large investment in heat exchange equipment and a separator and a huge flow of cooling water, plus the sweep gas would in all likelihood need to be reheated. By operating at $50 \%$ water in the sweep gas, the carbonizer would need to be operated at only $7^{\circ} \mathrm{C}$ hotter than for $10 \%$ water vapor case and the cooling exchanger and separator could be eliminated. Reheat of the sweep gas would be needed but the quantity of heat required would be reduced in comparison to the $10 \%$ water vapor case.

It was shown above that for the case where the inlet sweep gas was pure $\mathrm{CO}_{2}$, it was possible to remove 10 to $12 \%$ of the $\mathrm{CO}_{2}$ from the flue gas using the sorbent as a heat carrier. It was also shown that a small fraction of water vapor in the sweep gas could be detrimental to the goal of controlling heat using the sorbent. This water caused the minimum regeneration temperature to rise as shown in Figures 35 and 36. In order to determine at what water content the idea of using the sorbent as sole source of heat supply and heat absorption, Equation 17 can be used. The maximum carbonization temperature of a flue gas containing $16 \% \mathrm{H}_{2} \mathrm{O}$ and $8 \% \mathrm{CO}_{2}$ can be found at the condition where the equilibrium constant, $\mathrm{K}_{\mathrm{i}}$, equals the product of the $\mathrm{CO}_{2}$ and water vapor partial pressures. If the minimum regeneration temperature is equal to or greater than the maximum carbonization temperature then no $\mathrm{CO}_{2}$ will be absorbed from the flue gas. Thus setting $Z$ equal to zero in Equation 17, Equation 17 becomes

$$
\mathrm{K}_{\mathrm{i}}=0.16 \times 0.08=\frac{\left[100\left(1-\mathrm{y}_{\mathrm{H}_{2} \mathrm{O}}\right)\right]\left[100 \mathrm{y}_{\mathrm{H}_{2} \mathrm{O}}\right]}{100^{2}}
$$

Solving Equation 21 gives

$$
\mathrm{y}_{\mathrm{H}_{2} \mathrm{O}}=0.01297
$$




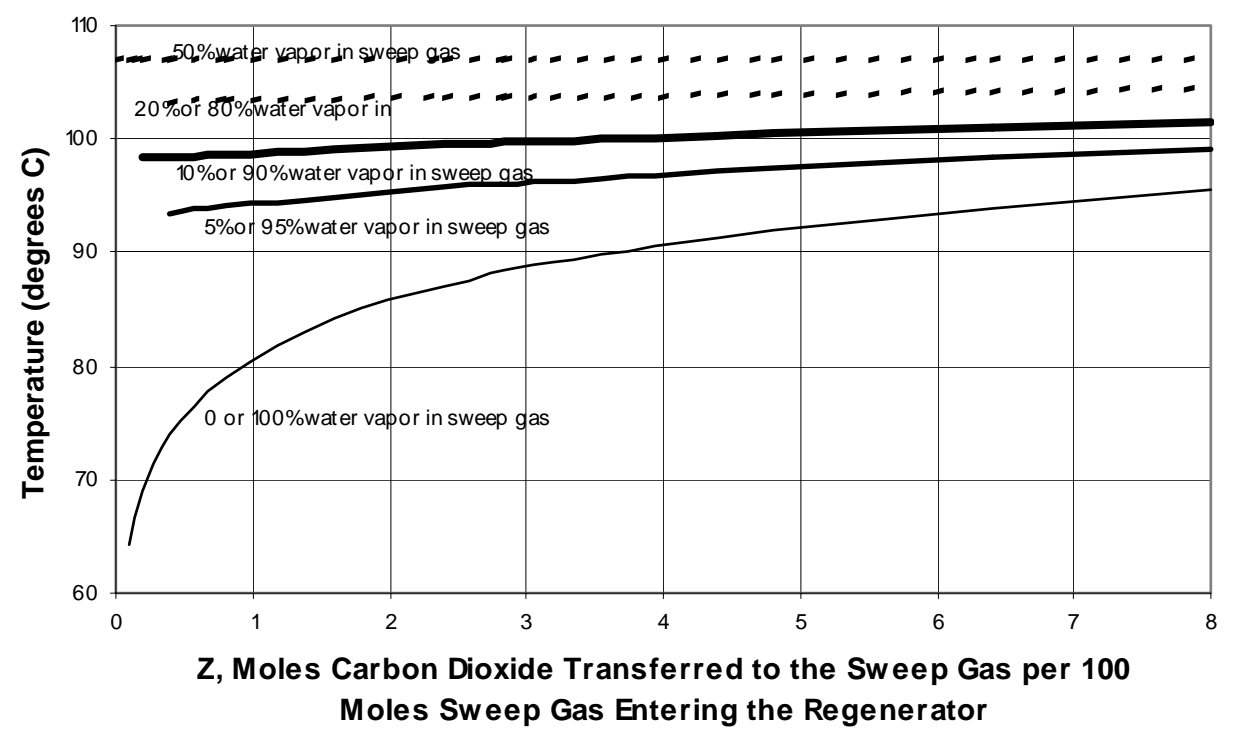

Figure 35. Equilibrium curves for regeneration of sodium carbonate based sorbent.

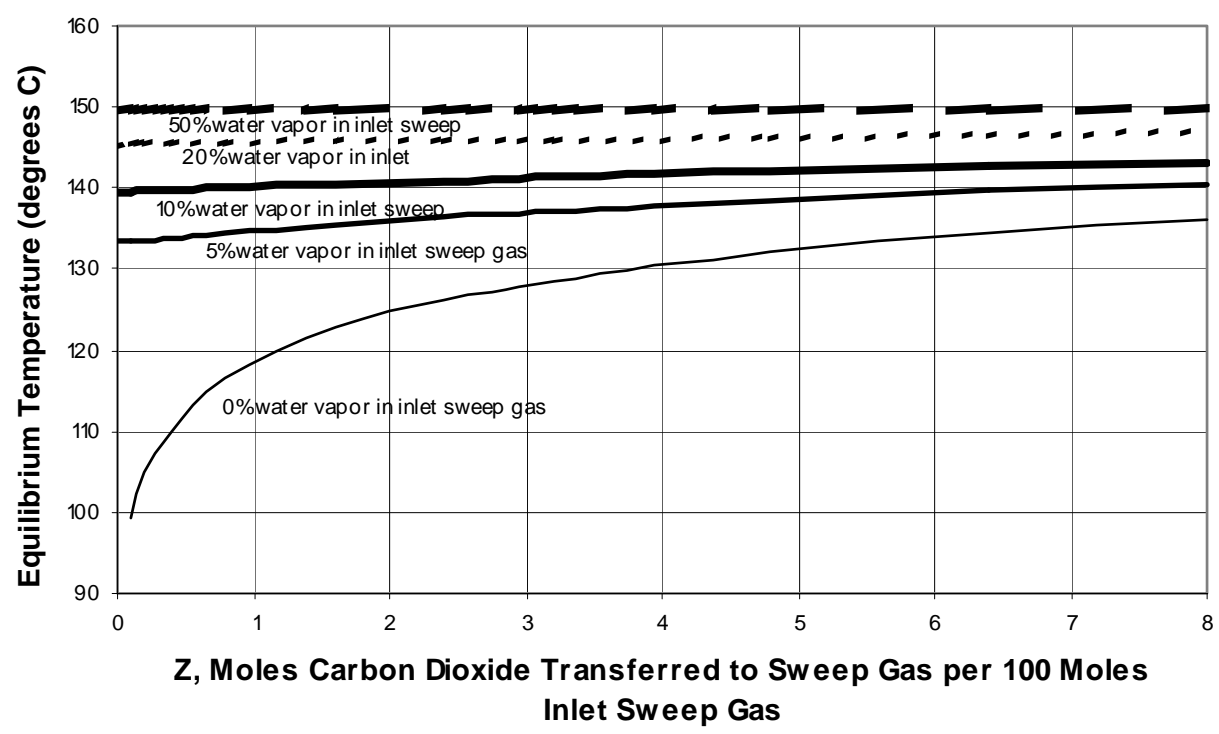

Figure 36. Equilibrium curves for regeneration of potassium carbonate based sorbent. 
Thus for water contents of the inlet regenerator sweep gas of less than 1.297 mole percent, using the sorbent as a sole heat carrier and heat absorber is theoretically possible. On the practical side, in order to obtain $1.297 \% \mathrm{H}_{2} \mathrm{O}$ in the sweep gas the liquid/vapor separator shown in Figure 33 would need to be operated at $11^{\circ} \mathrm{C}$, an impractically low temperature.

Based on the discussion above, it would appear that the sorbent cannot be used as the sole transporter of heat, and more than likely, the carbonizer will need to be cooled by water injection and the regenerator sweep gas will need to be heated by a source of heat external to the $\mathrm{CO}_{2}$ removal system. Also it appears that condensing water out of the regenerator sweep gas has no practical advantage over not cooling and condensing except to perhaps lower the regeneration temperature by roughly $10^{\circ} \mathrm{C}$. Elimination of the water condensation step should greatly reduce capital costs.

\subsection{Properties of Sorbent Materials Removed from Fixed Bed Reactor}

Samples obtained from the LSU fixed bed reactor system were analyzed by Church and Dwight to determine BET surface areas, and subjected to X-ray diffraction and scanning electron microscopy. Sample descriptions and results are shown in Table 12.

Table 12. Surface Areas and X-ray Diffraction Analyses of Samples from Fixed Bed Reactor System

\begin{tabular}{l|l|c|l}
\hline \hline Sample & \multicolumn{1}{|c|}{ Description } & $\begin{array}{c}\text { BET Surface } \\
\text { Area }\end{array}$ & X-ray Diffraction Analysis \\
\hline 6 & $\begin{array}{l}\mathrm{SBC} \# 3 \text {, calcined in nitrogen; } \\
\text { carbonated in 8\% } \mathrm{CO}_{2}, 16 \% \\
\mathrm{H}_{2} \mathrm{O} \text {, balance nitrogen; calcined } \\
\text { in nitrogen }\end{array}$ & $1.47 \mathrm{~m}^{2} / \mathrm{g}$ & $\begin{array}{l}\text { Primarily sodium carbonate } \\
\text { with a small amount of sodium } \\
\text { carbonate monohydrate }\end{array}$ \\
\hline 8 & $\begin{array}{l}\text { SBC \#3, calcined in nitrogen; } \\
\text { carbonated in 8\% } \mathrm{CO}_{2}, 16 \% \\
\mathrm{H}_{2} \mathrm{O} \text {, balance nitrogen }\end{array}$ & $0.738 \mathrm{~m}^{2} / \mathrm{g}$ & $\begin{array}{l}\text { Approximately 85\% } \\
\text { Wegscheider's salt; balance } \\
\text { sodium carbonate }\end{array}$ \\
\hline \hline
\end{tabular}

Scanning electron micrographs of sample 6 at 5 different magnifications are shown in Figures 37 through 41 . Scanning electron micrographs of sample 8 at 5 different magnifications are shown in Figures 42 through 46. 


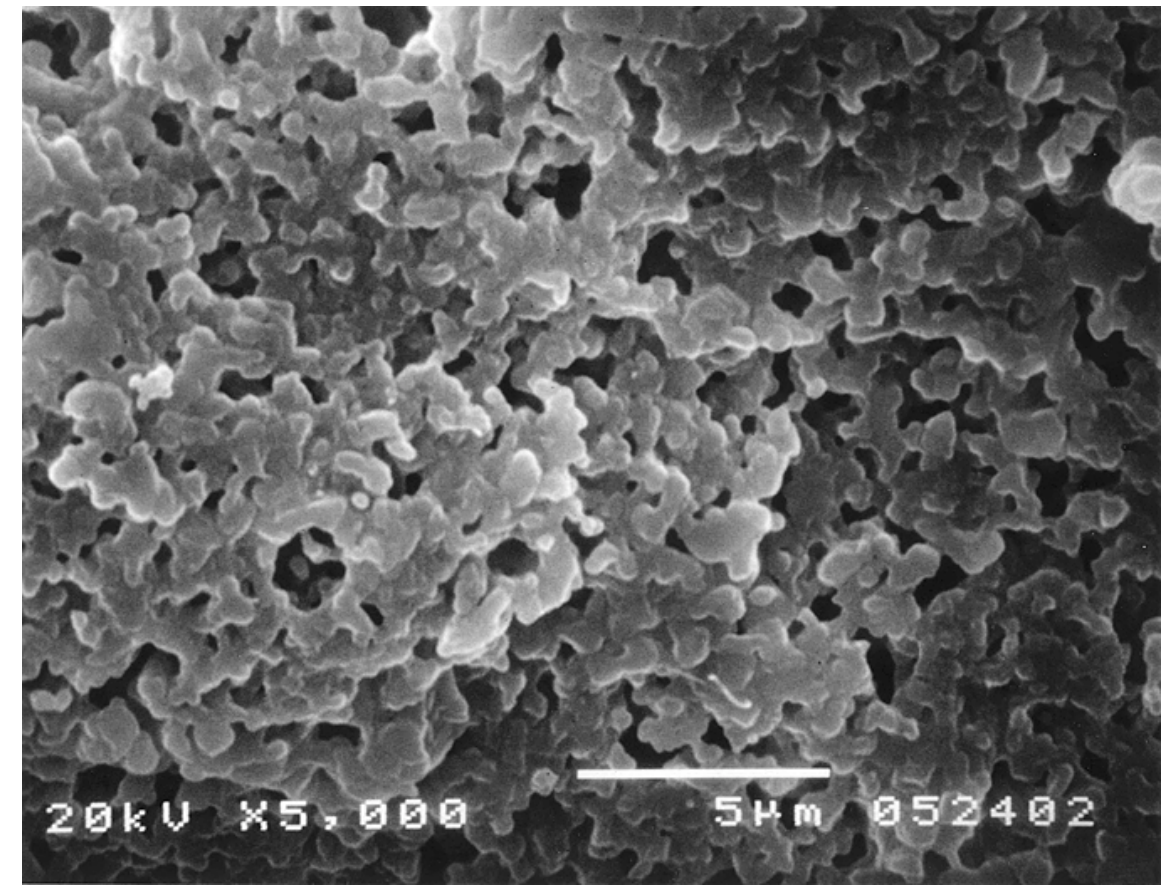

Figure 37. Sample \#6 at $50 \times$ magnification.

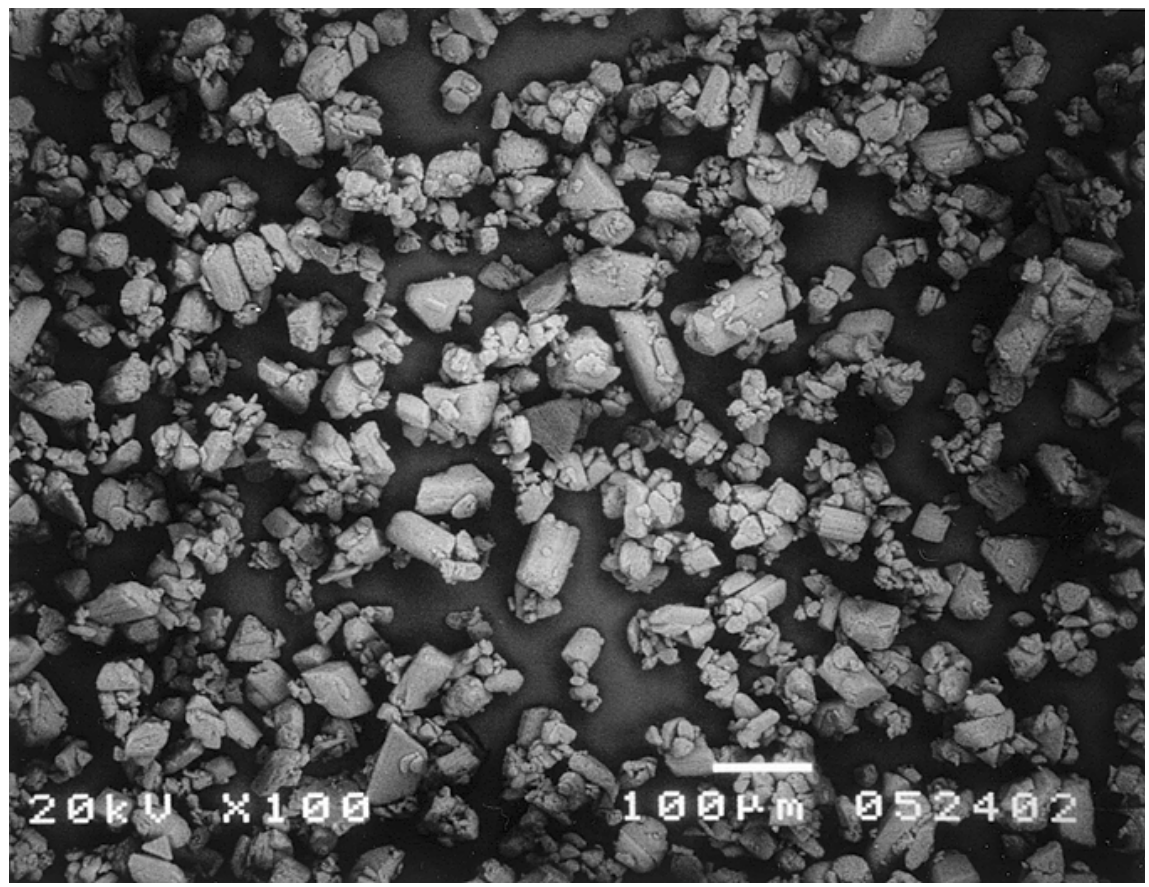

Figure 38. Sample \#6 at $100 \times$ magnification. 


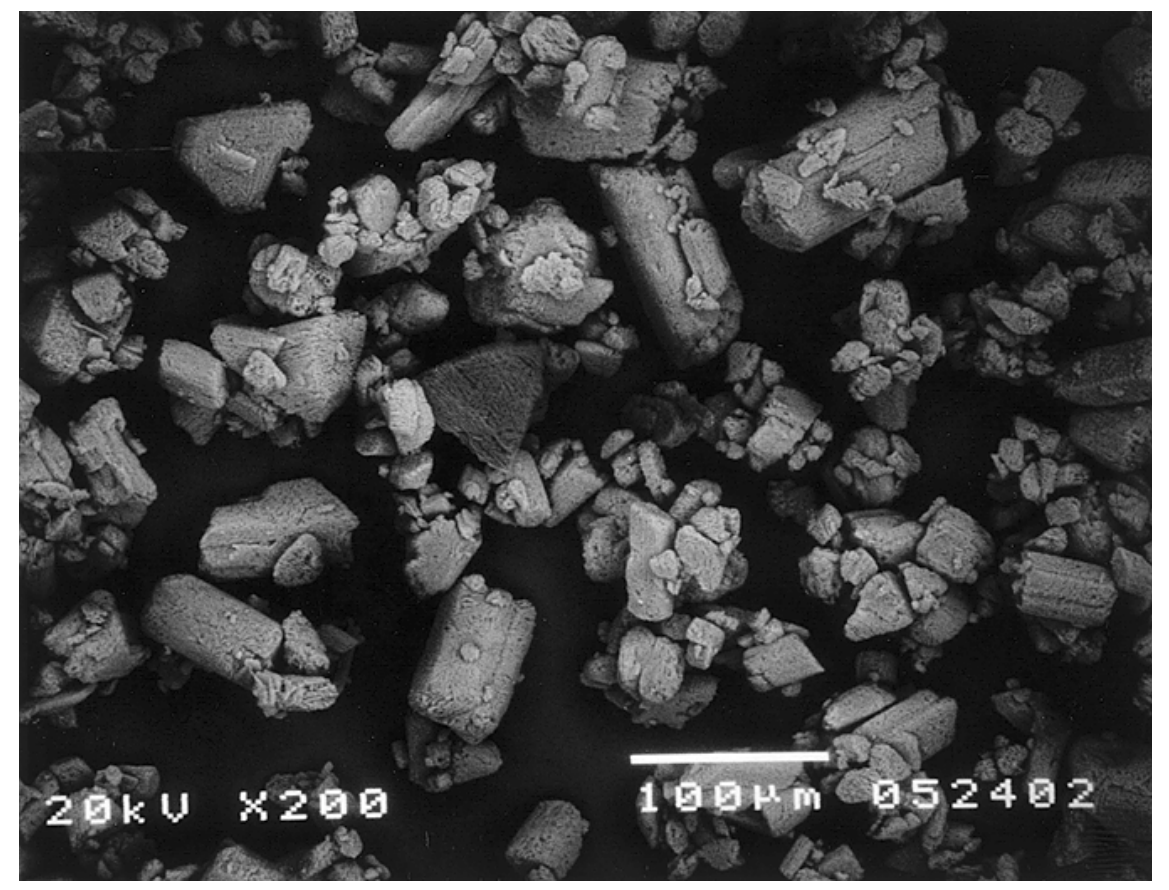

Figure 39. Sample \#6 at $200 \times$ magnification.



Figure 40. Sample \#6 at $500 \times$ magnification 


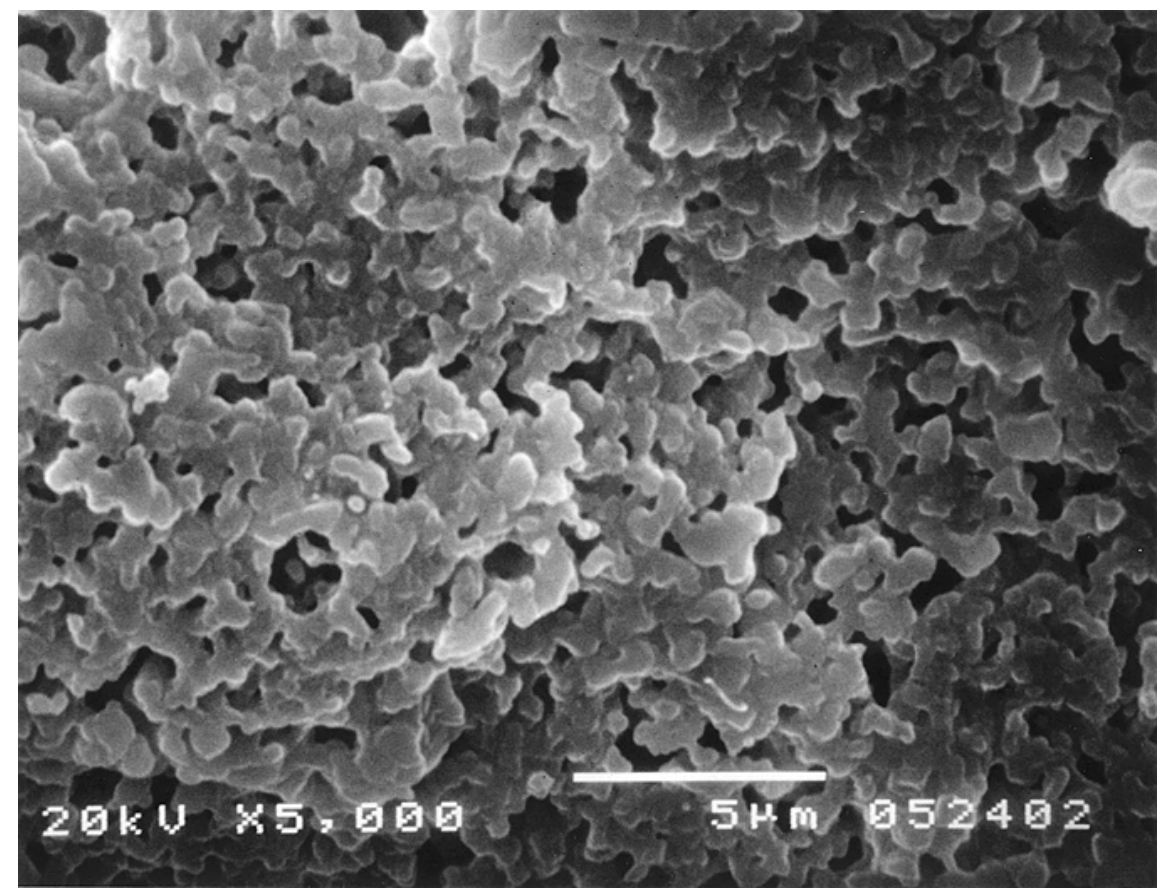

Figure 41. Sample $\# 6$ at 5,000 $\times$ magnification.

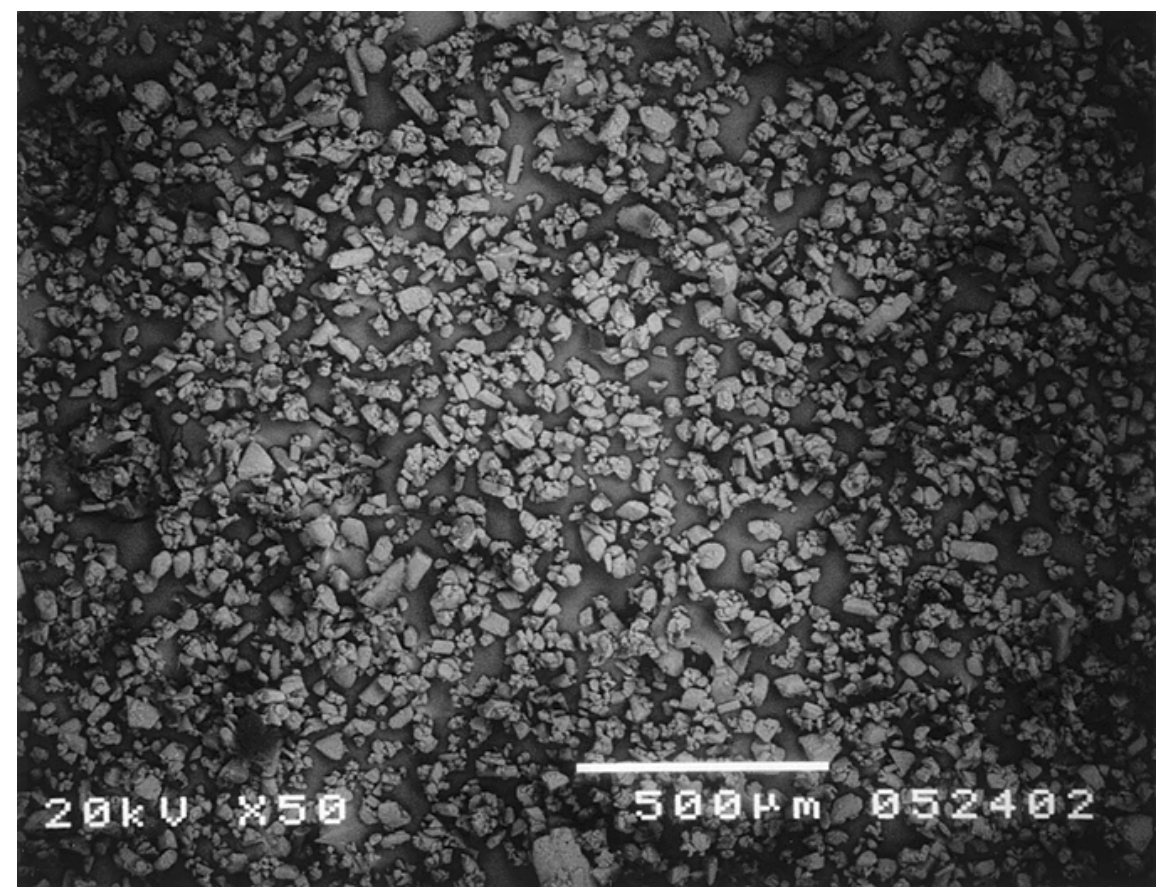

Figure 42. Sample \#8 at $50 \times$ magnification. 


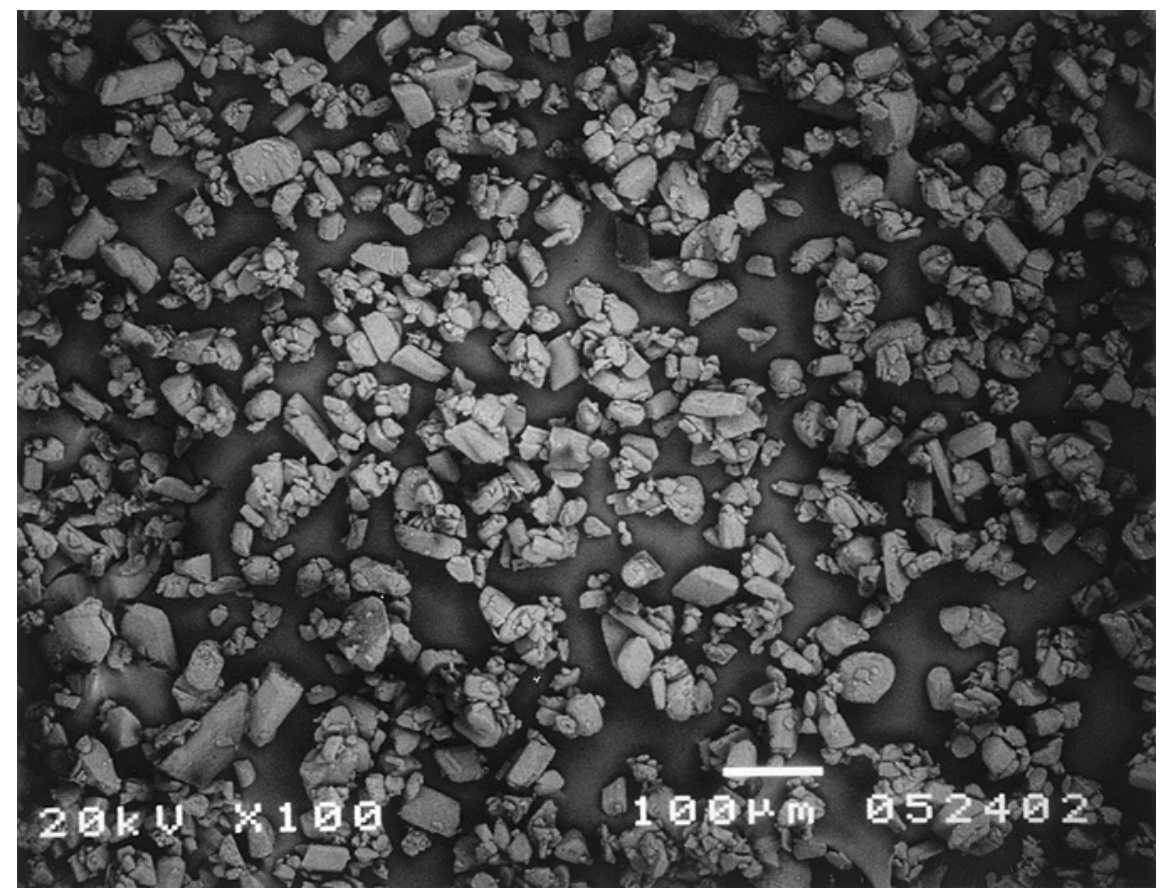

Figure 43. Sample \#8 at $100 \times$ magnification.

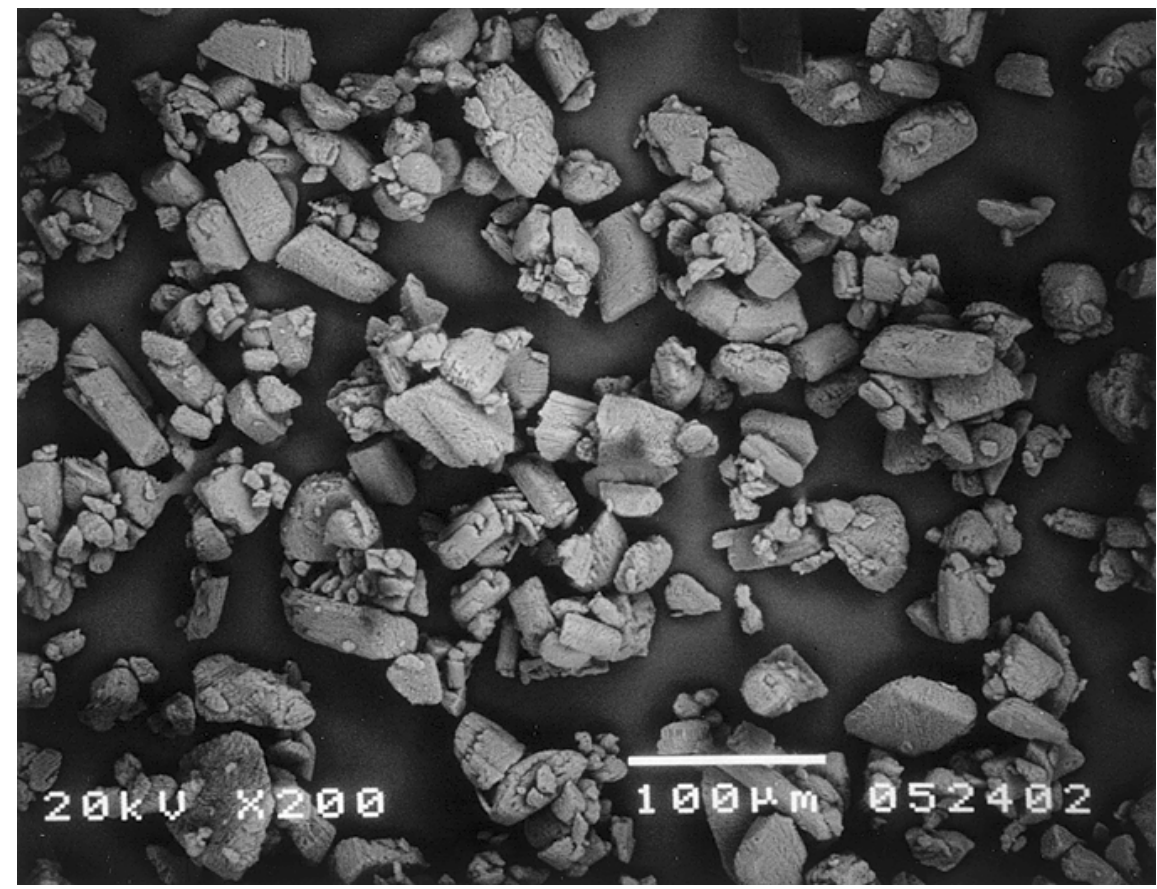

Figure 44. Sample \#8 at $200 \times$ magnification. 


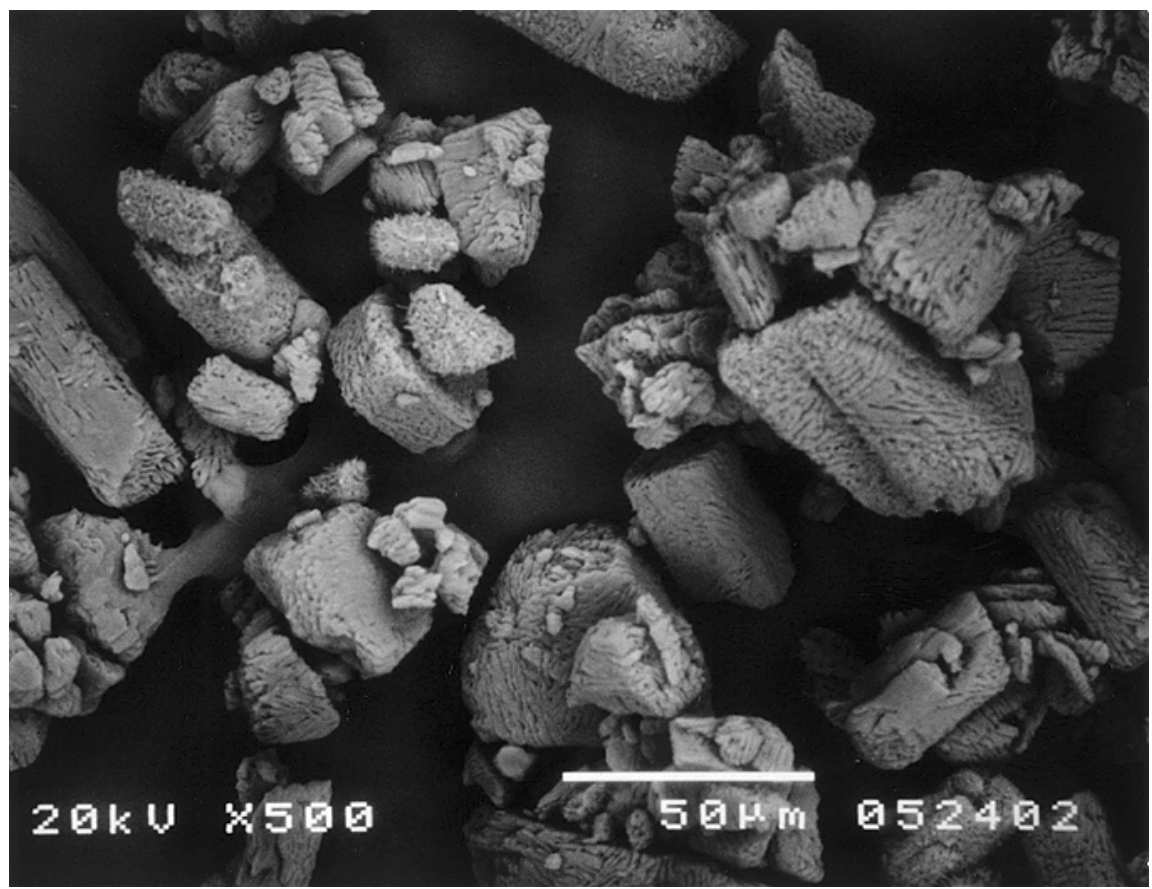

Figure 45. Sample \#8 at $500 \times$ magnification.

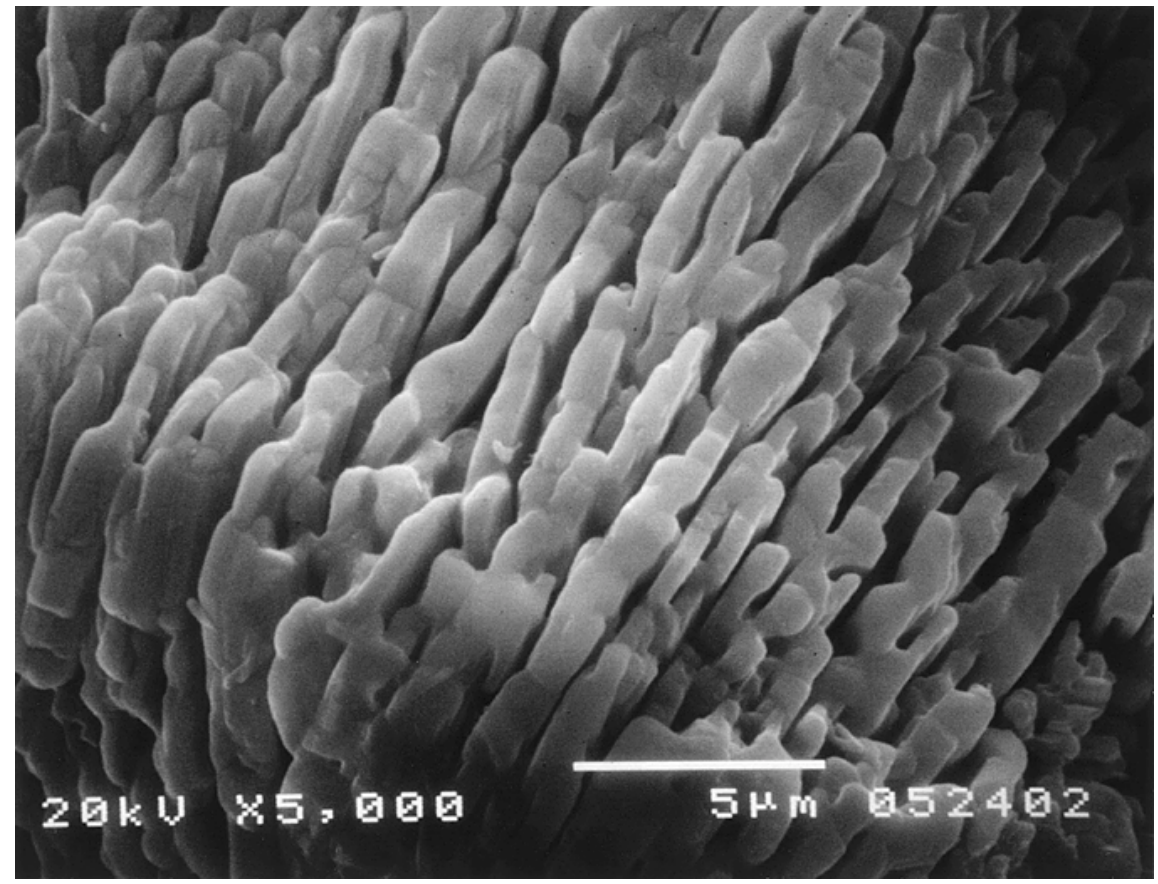

Figure 46. Sample \#8 at 5,000 × magnification. 


\subsection{CONCLUSIONS AND FUTURE WORK}

In cyclic operation with trona as the sorbent precursor, the severity of calcination conditions had a noticeable effect on the carbonation activity of trona during subsequent cycles. Severe calcination conditions were represented by a carbon dioxide atmosphere at $200^{\circ} \mathrm{C}$, while mild conditions were represented by a helium atmosphere at $120^{\circ} \mathrm{C}$. Calcination conditions of intermediate severity had an intermediate effect. This effect was much less pronounced when SBC\#3 is used as the sorbent precursor.

High initial carbonation rates were observed in fluidized bed reactor testing at RTI using trona as a sorbent precursor. Rates declined rapidly over the course of the experiments with capacity utilization (based on sodium carbonate) ranging from 11 to $16 \%$ over 5 cycles. No decline in activity from cycle to cycle was noted with calcination in nitrogen at $150^{\circ} \mathrm{C}$. Initial carbonation rates are of primary importance for short residence time systems such as transport reactors.

An active sorbent material containing $40 \%$ potassium carbonate and $60 \%$ proprietary sorbent material was prepared by spray drying. This material has greater attrition resistance than unsupported potassium carbonate. Potassium carbonate has a higher working temperature range for carbonation than sodium carbonate. The supported material has higher initial reaction rates and higher capacity utilizations than trona. The activity of this material declined over the course of the test with the greatest decline between the first and second cycles. Carbon dioxide removals varied between 18 and 24 percent. A second material with a lower potassium carbonate content was also produced for testing in the next quarter.

X-ray diffraction studies conducted on samples withdrawn from the LSU fixed bed reactor system confirmed that the product of the reaction between sodium carbonate and simulated flue gas was approximately $85 \%$ Wegscheider's salt.

Based on heat transfer analysis of conceptual reactor systems, it appears that the exothermic heat of the carbonation reaction exceeds the amount of heat that can be absorbed by the sorbent particles without extinguishing the reaction. It is likely that the carbonation reactor will require cooling by means of water injection, and the regenerator sweep gas will require external heat addition.

In the coming quarter, LSU will continue to examine the effect of calcination conditions in 5cycle electrobalance tests. The LSU fixed bed reactor system will be modified by replacing the syringe pumps with gas saturators. RTI will conduct fluidized bed testing of a $10 \%$ supported potassium carbonate material and prepare a spray dried supported sodium carbonate material for testing. A project review meeting will be held at DOE/NETL on August 28, 2002.

\subsection{REFERENCES}

ASTM, International, Method D5757-95: Standard Test Method for Determination of Attrition and Abrasion of Powdered Catalysts by Air Jets. 1995 
Green, D.A., Turk, B.S., Gupta, R., and Lopez Ortiz, A., Carbon Dioxide Capture From Flue Gas Using Dry Regenerable Sorbents, Quarterly Technical Progress Report, Research Triangle Institute, January 2001(a).

Green, D.A., Turk, B.S., Gupta, R., Lopez Ortiz, A., Harrison, D.P., and Liang, Y., Carbon Dioxide Capture From Flue Gas Using Dry Regenerable Sorbents, Quarterly Technical Progress Report, Research Triangle Institute, May 2001(b).

Green, D.A., Turk, B.S., Gupta, R., Harrison, D.P., and Liang, Y., Carbon Dioxide Capture From Flue Gas Using Dry Regenerable Sorbents, Quarterly Technical Progress Report, Research Triangle Institute, October 2001(c).

Green, D.A., Turk, B.S., Gupta, R., McMichael, Harrison, D.P., and Liang, Y., Carbon Dioxide Capture From Flue Gas Using Dry Regenerable Sorbents, Quarterly Technical Progress Report, Research Triangle Institute, January 2002(a).

Green, D.A., Turk, B.S., Gupta, R., McMichael, Harrison, D.P., and Liang, Y., Carbon Dioxide Capture From Flue Gas Using Dry Regenerable Sorbents, Quarterly Technical Progress Report, Research Triangle Institute, April 2002(b).

Vanderzee, C. E., Thermodynamic Relations and Equilibria in $\left(\mathrm{Na}_{2} \mathrm{CO}_{3}+\mathrm{NaHCO}_{3}+\mathrm{H}_{2} \mathrm{O}\right)$ : Standard Gibbs Energies of Formation and Other Properties of Sodium Hydrogen Carbonate, Sodium Carbonate Heptahydrate, Sodium Carbonate Decahydrate, Trona: $\left(\mathrm{Na}_{2} \mathrm{CO}_{3} \cdot \mathrm{NaHCO}_{3} \cdot 2 \mathrm{H}_{2} \mathrm{O}\right)$, and Wegscheider's Salt: $\left(\mathrm{Na}_{2} \mathrm{CO}_{3} \cdot 3 \mathrm{NaHCO}_{3}\right)$, J. Chem. Thermodynamics, 14, p. 219-238, 1982. 